NISTIR 8303

\title{
Development and Validation of Small Punch Testing at NIST
}

Enrico Lucon

Jake Benzing Nik Hrabe

This publication is available free of charge from:

https://doi.org/10.6028/NIST.IR.8303

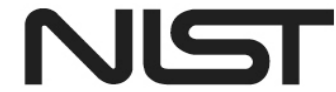

National Institute of Standards and Technology U.S. Department of Commerce 


\title{
Development and Validation of Small Punch Testing at NIST
}

\author{
Enrico Lucon \\ Jake Benzing \\ Nik Hrabe \\ Applied Chemicals and Materials Division \\ Material Measurement Laboratory
}

This publication is available free of charge from:

https://doi.org/10.6028/NIST.IR.8303

April 2020

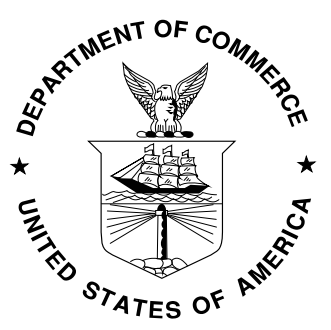

U.S. Department of Commerce Wilbur L. Ross, Jr., Secretary

National Institute of Standards and Technology Walter Copan, NIST Director and Undersecretary of Commerce for Standards and Technology 
Certain commercial entities, equipment, or materials may be identified in this document in order to describe an experimental procedure or concept adequately. Such identification is not intended to imply recommendation or endorsement by the National Institute of Standards and Technology, nor is it intended to imply that the entities, materials, or equipment are necessarily the best available for the purpose.

National Institute of Standards and Technology Interagency or Internal Report 8303 Natl. Inst. Stand. Technol. Interag. Intern. Rep. 8303, 55 pages (April 2020)

This publication is available free of charge from: https://doi.org/10.6028/NIST.IR.8303 


\begin{abstract}
Small Punch (SP) testing is a methodology that uses tiny disks (generally $8 \mathrm{~mm}$ in diameter and $0.5 \mathrm{~mm}$ thick) to estimate mechanical properties of metallic materials, such as tensile properties, fracture toughness, and ductile-to-brittle transition temperature. Empirical correlations are typically used to infer conventional mechanical properties from characteristic forces and displacements obtained from the SP test record. At NIST in Boulder, Colorado, we recently developed experimental and analytical procedures for running SP tests on various materials. We conducted SP tests on three steels with widely different tensile and fracture properties. The NIST setup was successfully qualified by comparing our results on A533B steel to the results obtained in an international round-robin, and also by comparing empirical correlations between SP data and tensile properties to similar relationships published in the literature. We also tested specimens with different surface roughness, to investigate the influence of surface finish on SP test results.
\end{abstract}

\title{
Key words
}

Empirical correlations; international round-robin; Small Punch; surface roughness; tensile properties. 


\section{Table of Contents}

1. Introduction ............................................................................................................................. 1

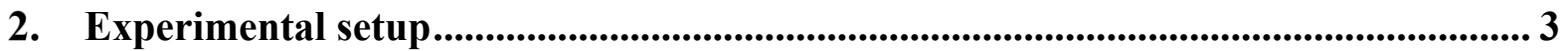

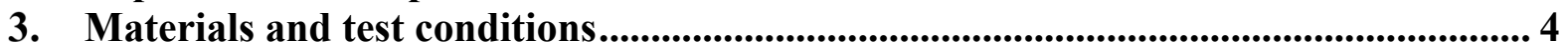

4. Measurements of test system compliance................................................................................ 6

5. Analysis of an individual SP test .................................................................................... 7

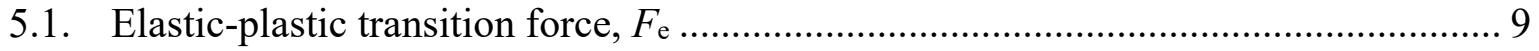

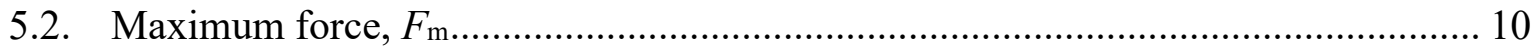

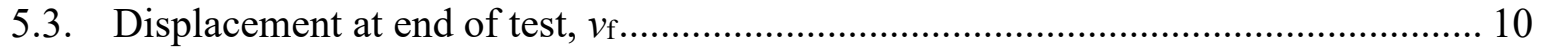

5.4. SP fracture energy, ESP ........................................................................ 10

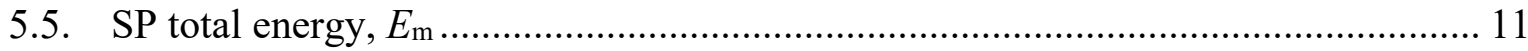

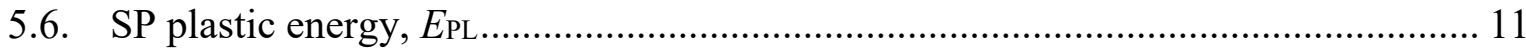

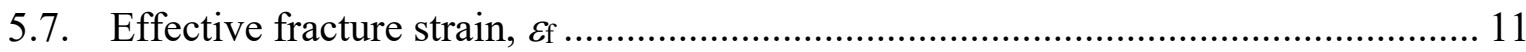

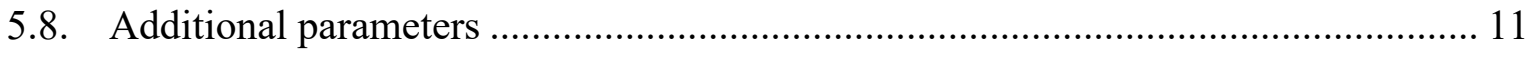

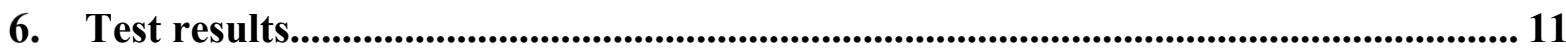

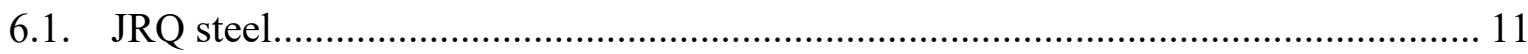

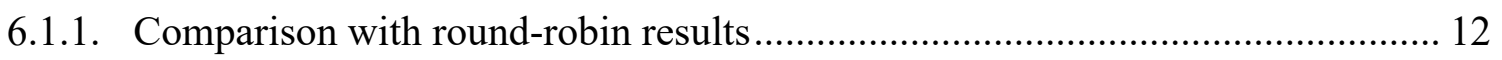

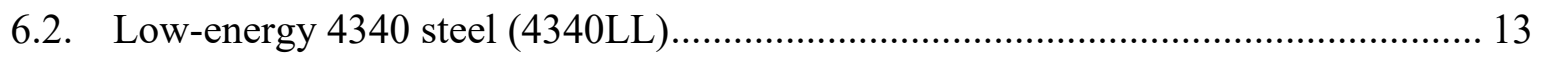

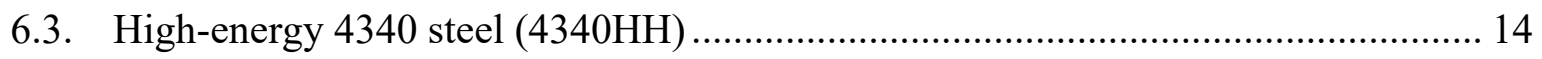

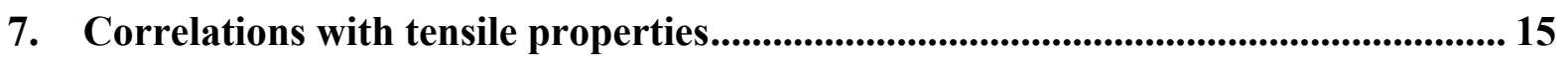

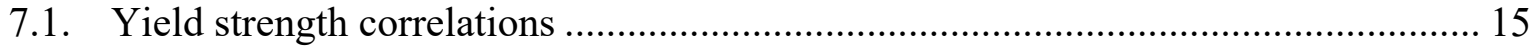

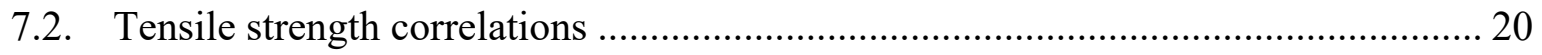

7.3. Total elongation correlations ............................................................................ 24

8. Additional correlations (not previously published) ........................................................ 26

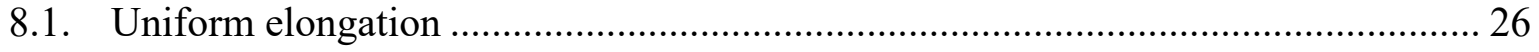

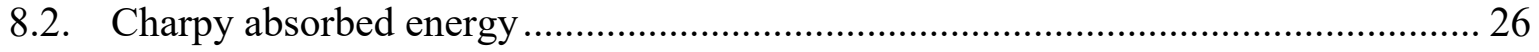

9. Discussion: effect of specimen surface finish .................................................................. 27

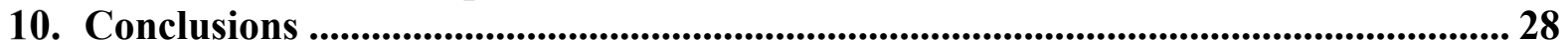

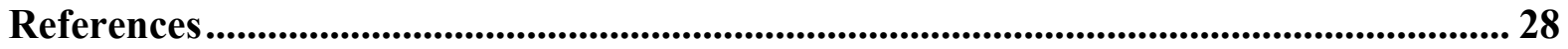

\section{List of Tables}

Table 1 - Chemical composition of the JRQ and 4340 steels (wt \%) ................................... 5

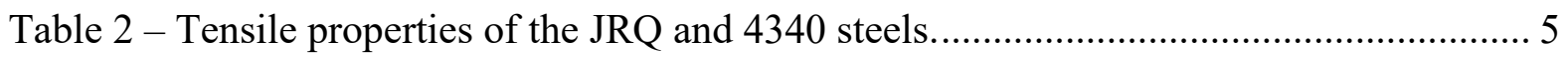

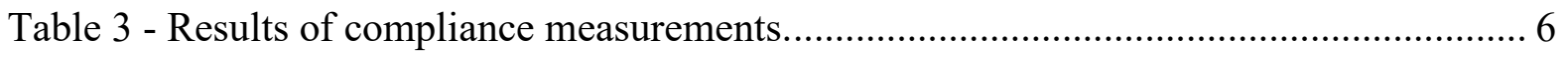

Table 4 - Results of SP tests on JRQ steel (rough specimens). .............................................. 12

Table 5 - Results of SP tests on JRQ steel (polished specimens)......................................... 12

Table 6 - Comparison between round-robin (R-R) and NIST force results for the JRQ steel. 
Table 7 - Results of SP tests on 4340LL steel (rough specimens)..................................... 13

Table 8 - Results of SP tests on 4340LL steel (polished specimens). ................................. 14

Table 9 - Results of SP tests on 4340HH steel (rough specimens)..................................... 14

Table 10 - Results of SP tests on 4340HH steel (polished specimens). .............................. 14

Table 11 - Influence of specimen surface finish on SP test results: results of two-sample

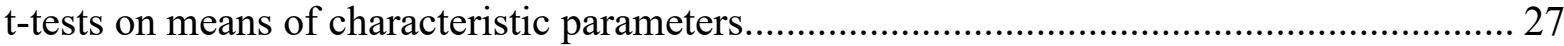

\section{List of Figures}

Figure 1 - Schematic representation of the SP test method.

Figure 2 - Typical form of a SP force-deflection diagram for steel, showing five distinct regions [1].

Figure 3 - SP testing fixture used at NIST, shown disassembled (left) and assembled (right). 3

Figure 4 - SP testing fixture mounted on the test machine with the extensometer for punch displacement measurement.

Figure 5 - Cross-sectional view of SP test setup [14]. The LVDT measuring specimen deflection $(u)$ is indicated as item 5. Punch displacement is indicated as $v$........................... 4

Figure 6 - Dimensions and tolerances of SP specimens [11] .......................................... 5

Figure 7 - Compliance measurements as a function of actuator displacement...................... 7

Figure 8 - Compliance measurements as a function of extensometer displacement. .............. 7

Figure 9 - Force-displacement curves for an SP test on JRQ steel.................................... 8

Figure 10 - Force-displacement curves for an SP test on 4340LL steel. .............................. 8

Figure 11 - Force-displacement curves for an SP test on $4340 \mathrm{HH}$ steel. ............................. 9

Figure 12 - Determination of the elastic-plastic transition force, $F_{\mathrm{e}}$................................. 10

Figure 13 - Comparison between mean force values reported by round-robin participants and

NIST on the JRQ steel. Error bands correspond to \pm twice the standard deviation. ............. 13

Figure 14 - Correlations between yield strength and SP elastic-plastic transition force. The purple dashed line is the linear fit to the rough specimen data, while the pink dash-dotted line

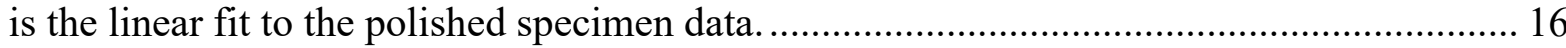

Figure 15 - Comparison between NIST results and the correlation in [24]......................... 18

Figure 16 - Comparison between NIST results and the correlation in [19] ......................... 18

Figure 17 - Comparison between NIST results and the correlation in [19]......................... 19

Figure 18 - Comparison between NIST results and the correlation in [18,20] ................... 19

Figure 19 - Comparison between NIST results and the correlation in [23]........................ 19

Figure 20 - Comparison between NIST results and the correlation in [23] ......................... 20

Figure 21 - Comparison between NIST results and the correlation in [30]......................... 20

Figure 22 - Correlations between tensile strength and SP maximum force, normalized by $h_{02}$. The purple dashed line is the linear fit to the rough specimen data, while the pink dash-dotted line is the linear fit to the polished specimen data. 21

Figure 23 - Correlations between tensile strength and SP maximum force, normalized by $u_{m} h_{0}$. 
Figure 24 - Comparison between NIST results and the correlation in [23]....................... 23

Figure 25 - Comparison between NIST results and the correlation in [25] ........................ 23

Figure 26 - Comparison between NIST results and the correlations in $[23,26]$.................. 23

Figure 27 - Comparison between NIST results and the correlation in [33] ........................ 24

Figure 28 - Comparison between NIST results and the correlations in [19,27] for $\varepsilon$ t.......... 25

Figure 29 - Comparison between NIST results and the correlations in [19,28] for $\varepsilon$ t.......... 25

Figure 30 - Comparison between NIST results and the correlation in [29] for $\varepsilon$ t................. 25

Figure 31 - Correlations between uniform elongation and $u_{m} h_{0}$ obtained at NIST............ 26

Figure 32 - Correlations between Charpy absorbed energy and SP energies for rough and

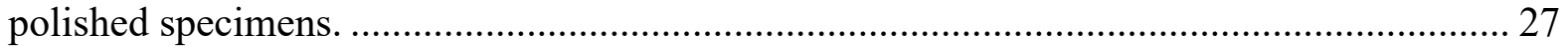

\section{List of Annexes}

Annex 1 - Operational Procedure for Performing Small Punch tests at NIST in Boulder, Colorado

Annex 2 - Spreadsheet-Based Software for the Analysis of a Small Punch Test

Annex 3 - Summary of Correlations between SP Parameters and Tensile Properties (from the literature, 1998-2019, and obtained at NIST) 


\section{Glossary}

ASTM American Society for Testing and Materials

CEN European Committee for Standardization

EDM Electro-Discharge Machining

$D \quad$ In SP testing, specimen diameter (mm)

$\mathrm{d} v / \mathrm{d} t \quad$ In SP testing, punch displacement rate $(\mathrm{mm} / \mathrm{s})$

$E_{\mathrm{m}} \quad$ In SP testing, total energy calculated up to $u_{\mathrm{m}}(\mathrm{J})$

$E_{\mathrm{PL}} \quad$ In SP testing, plastic energy calculated up to $u_{\mathrm{m}}(\mathrm{J})$

$E_{\mathrm{SP}} \quad$ In SP testing, fracture energy calculated up to $u_{\mathrm{f}}(\mathrm{J})$

$\varepsilon_{\mathrm{f}} \quad$ In SP testing, effective fracture strain

$\dot{\varepsilon}_{S P}^{\max } \quad$ In SP testing, estimated maximum strain rate $(1 / \mathrm{s})$

$\varepsilon \mathrm{t} \quad$ In tensile testing, total elongation (\%)

$\varepsilon_{\mathrm{u}} \quad$ In tensile testing, uniform elongation (\%)

$F \quad$ Force $(\mathrm{N})$

$F_{\mathrm{e}} \quad$ In SP testing, elastic-plastic transition force $(\mathrm{N})$

$F_{\text {ept }} \quad$ In SP testing, force at the point of maximum curvature (N)

$F_{\mathrm{e} 1.5} \quad$ In SP testing, force corresponding to the point where the ratio between area under the curve and above the curve equals $1.5(\mathrm{~N})$

$F_{\mathrm{h} 0 / 10, \text { off }}$ In SP testing, force at the intersection between the test record and a line parallel to the slope of the initial linear region with an offset of $0.1 \cdot h_{0}(\mathrm{~N})$

$F_{\text {infl }} \quad$ In SP testing, force at the inflection point of the curve $\left(\mathrm{d}^{2} F / \mathrm{d} u^{2}=0\right)(\mathrm{N})$

$F_{\mathrm{m}} \quad$ In SP testing, maximum force $(\mathrm{N})$

$F_{0.1 \mathrm{~mm}, \text { off }}$ In SP testing, force at the intersection between the test record and a line parallel to the slope of the initial linear region with an offset of $0.1 \mathrm{~mm}(\mathrm{~N})$

$F_{0.1 \mathrm{~mm}} \quad$ In SP testing, force corresponding to a displacement value of $0.1 \mathrm{~mm}(\mathrm{~N})$

$F_{0.48 \mathrm{~mm}} \quad$ In SP testing, force corresponding to a displacement value of $0.48 \mathrm{~mm}(\mathrm{~N})$

$F_{0.5 \mathrm{~mm}} \quad$ In SP testing, force corresponding to a displacement value of $0.5 \mathrm{~mm}(\mathrm{~N})$

$F_{0.645 \mathrm{~mm}}$ In SP testing, force corresponding to a displacement value of $0.645 \mathrm{~mm}(\mathrm{~N})$

$F_{0.65 \mathrm{~mm}}$ In SP testing, force corresponding to a displacement value of $0.65 \mathrm{~mm}(\mathrm{~N})$

$F_{0.9 \mathrm{~mm}} \quad$ In SP testing, force corresponding to a displacement value of $0.9 \mathrm{~mm}(\mathrm{~N})$

$f(v) \quad$ In SP testing, bilinear function used to determine $F_{\text {e }}[10,11]$.

$h_{0} \quad$ In SP testing, initial specimen thickness (mm)

ISO International Standardization Organization

$K \quad$ In SP testing, curvature parameter according to [30]

KV Charpy absorbed energy (J)

$r \quad$ Pearson correlation coefficient

$R a \quad$ Surface roughness $(\mu \mathrm{m})$

$R_{\mathrm{m}} \quad$ In tensile testing, tensile strength (MPa) 
$R_{\mathrm{p} 02} \quad$ In tensile testing, yield strength (MPa)

Slope ini In SP testing, slope of the initial elastic region of the curve $(\mathrm{N} / \mathrm{mm})$

SP Small Punch

tcalc $\quad$ Calculated value of the $t$-test statistic

tcritical Critical value of the $t$-test statistic (if $t_{c a l c}>t_{\text {critical, }}$ means are statistically different)

$u \quad$ Specimen deflection $(\mathrm{mm})$

$v \quad$ Punch displacement $(\mathrm{mm})$

$v_{\mathrm{f}} \quad$ In SP testing, punch displacement corresponding to a $20 \%$ force drop with respect to maximum force ( $\mathrm{mm}$ )

$v_{\mathrm{m}} \quad$ In SP testing, punch displacement at maximum force $(\mathrm{mm})$

$v_{1 p} \quad$ In SP testing, punch displacement at the occurrence of the first significant pop-in $(\mathrm{mm})$. 


\section{Introduction}

In the field of experimental techniques based on sub-size or miniaturized specimens, methodologies based on testing tiny disks represent a method for characterizing the mechanical properties of service-exposed plant components or structures with a minimal amount of material extracted from the component and subjected to destructive testing [1]. Moreover, a significant number of disk specimens can be extracted from machining leftovers or already tested conventional specimens.

The Small Punch (SP) test, also known as the Disk Bend test, was developed in the mid-1980s [2,3] through the use of tiny disks of $3 \mathrm{~mm}$ diameter and $0.25 \mathrm{~mm}$ thickness, centrally loaded by a spherical ball or hemispherical punch, and expanded into a larger lower die. The test system was a module that could be placed between the loading platens of a tensile machine and subsequently loaded [3]. The outcome is a bulge in the disk rather than a shear cut, as in a similar methodology called the Shear Punch test [4]. Although disks of these dimensions are still used for SP testing, nowadays the most popular specimen geometry (which is used in this investigation) is a round disk with a diameter of $8 \mathrm{~mm}$ and a thickness of 0.5 $\mathrm{mm}$, which is the geometry used in this study. The use of square specimens $(10 \mathrm{~mm} \times 10 \mathrm{~mm})$ has also been reported [5].

A schematic representation of the SP test method is shown in Fig. 1.
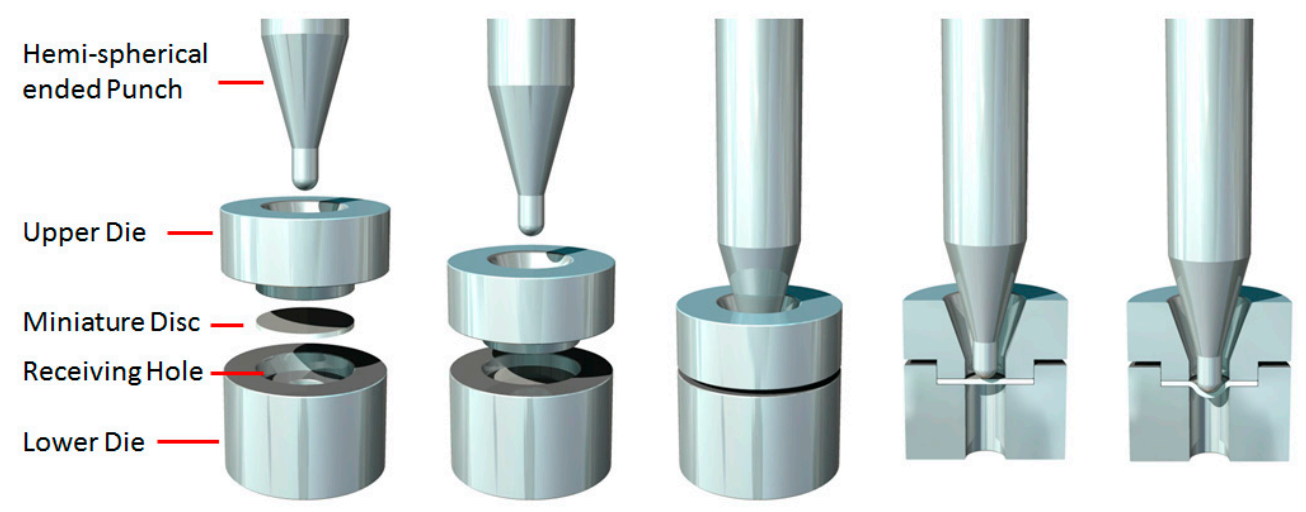

Figure 1 - Schematic representation of the SP test method.

The general form of a SP force/deflection test record for a steel specimen is shown in Fig. 2 [1]. Five distinct regions can be identified:

1. Elastic region,

2. Departure from linearity (elastic-plastic transition),

3. Local bending, transitioning to a membrane stress regime,

4. Membrane stress regime, and

5. Final failure region.

The general form of the test record suggests that yield stress may be associated with the change in slope between regions 1 and 2, while the ultimate tensile stress may be related to the maximum force, and ductility to maximum deflection. Note that, for steels showing low ductility, regions 4 and 5 may be virtually absent or minimized. 


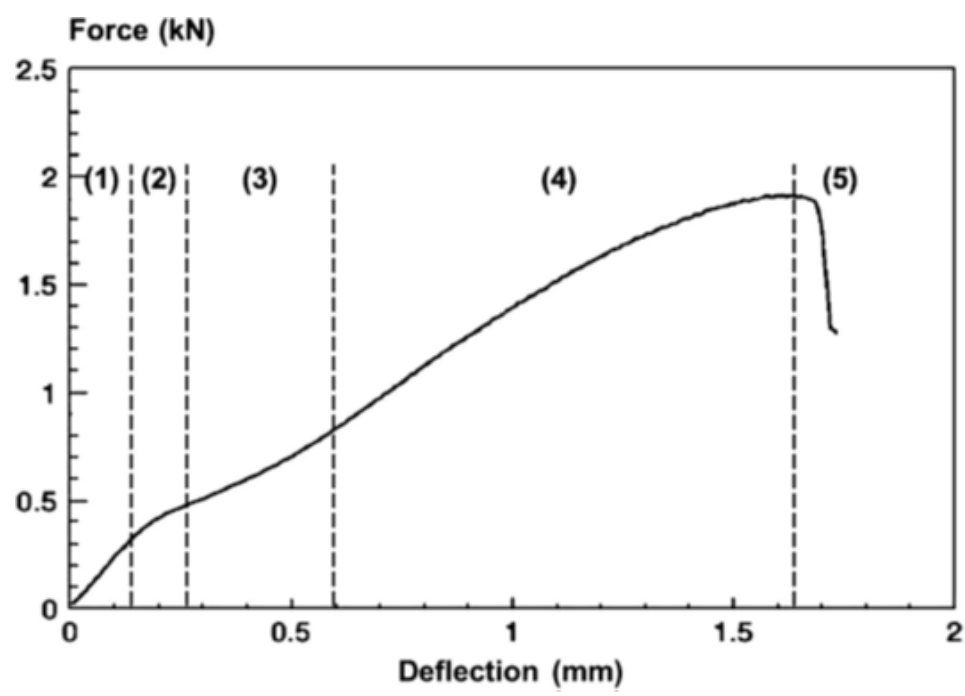

Figure 2 - Typical form of a SP force-deflection diagram for steel, showing five distinct regions [1].

Characteristic values of force, displacement, and energy (calculated by integrating force and displacement) are identified on the test record. These values are generally fed into empirical relations to obtain estimates of specific mechanical parameters (tensile properties, ductile-to-brittle transition temperature, fracture toughness) for the material under investigation. Numerous empirical correlations are available in the literature, and have been developed by comparing characteristic parameters from SP tests with tensile properties, transition temperature data, and fracture toughness values measured by means of conventional tests.

In most cases, correlations appear to be strongly dependent on the material (or the class of material) under investigation, and cannot be expected to be applicable to other materials or material conditions [5].

Note that alternative approaches, of a more analytical nature, have also been proposed. Several authors have matched force-displacement curves from SP tests, up to the point of observed crack initiation, to a database of curves corresponding to a range of stress-strain constitutive behaviors. The model used in this case is a Ramberg-Osgood model with a possible modification to accommodate the discontinuous yield observed in several low-alloy steels [6]. Other analytical methods have also been proposed, involving the use of Neural Networks and Finite Element simulations [7-9].

The approach used in this report for the analysis of SP test results, however, is strictly of a correlative nature.

Even though researchers all over the world have been performing SP tests since the 1980 s, an official test standard issued by an internationally recognized standardization body (ASTM or ISO), is still missing.

The available document that most closely resembles a Test Standard is a European CEN ${ }^{1}$ Workshop Agreement, CWA 15627 (Small Punch Test Method for Metallic Materials), issued in 2007 [10]. At the time of writing, a Draft ASTM Test Method for Small Punch Testing of Metallic Materials [11], modeled after CWA 15627, is being developed inside the ASTM E10.02 Sub-Committee (Behavior and Use of Nuclear Materials).

${ }^{1}$ CEN: Comité Européen de Normalisation (European Committee for Standardization). 


\section{Experimental setup}

The fixture developed at NIST for SP testing, following the recommendations in $[10,11]$, consists of an upper and a lower die, a rod (100 mm long, $2.5 \mathrm{~mm}$ diameter), and a ball $(2.5 \mathrm{~mm}$ diameter). The combination of the rod and ball constitute the punch, which is driven through the specimen, encapsulated between the upper and lower dies. The fixture is shown in Figure 3 in both disassembled (left) and assembled (right) form.

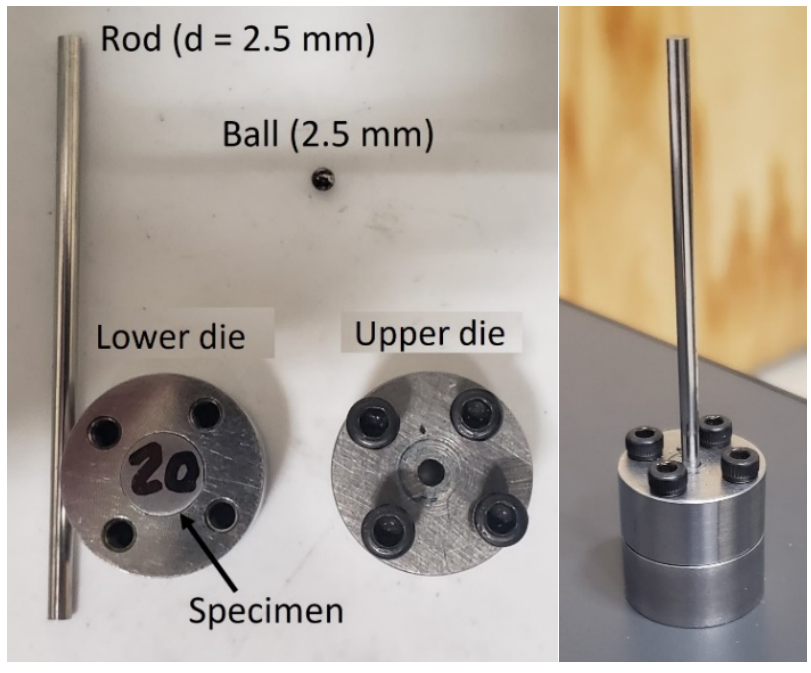

Figure 3 - SP testing fixture used at NIST, shown disassembled (left) and assembled (right).

The fixture was mounted on a universal electro-mechanical test machine, equipped with a $5 \mathrm{kN}$ capacity load cell and an extensometer ${ }^{2}$. The extensometer was attached to one of the columns of the machine in order to measure the relative displacement between the machine actuator and the machine frame, in close proximity to the punch. Fig. 4 shows the fixture mounted on the test machine and the positioning of the extensometer with respect to the machine actuator. Unlike the extensometer signal, actuator displacement includes the compliance of the whole test system.

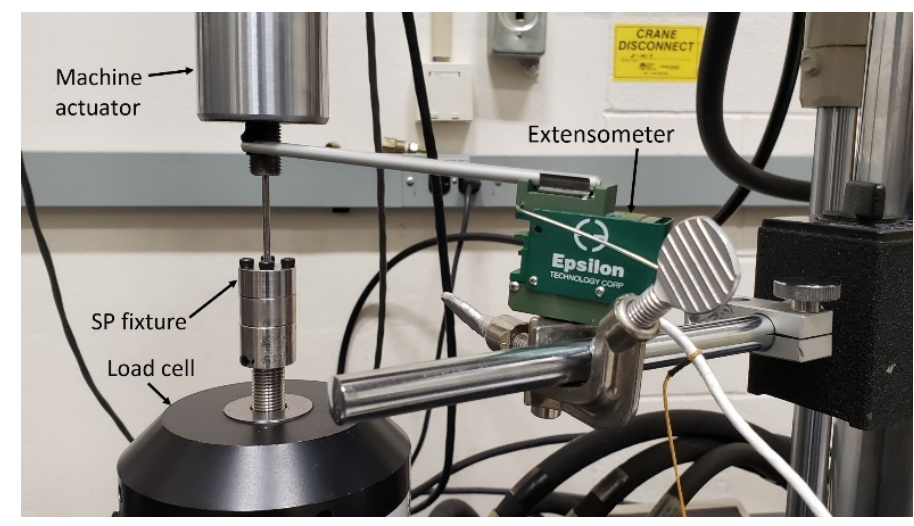

Figure 4 - SP testing fixture mounted on the test machine with the extensometer for punch displacement measurement.

\footnotetext{
${ }^{2}$ Load cell, machine actuator, and extensometer are regularly calibrated in accordance with ASTM E4 and E83. Based on calibrations current at the time of testing, maximum errors were found to be less than $0.7 \%$ for force values, less than $1.5 \%$ for actuator displacements, and less than $2 \%$ for extensometer displacement values.
} 

Annex 1.

The operational procedure for conducting an SP test at NIST in Boulder is detailed in

Many researchers have also reported direct measurements of specimen deflection by the use of a Linear Voltage Displacement Transducer (LVDT) that monitors the displacement of a point at the center of the specimen opposite to the punch (Fig. 5).

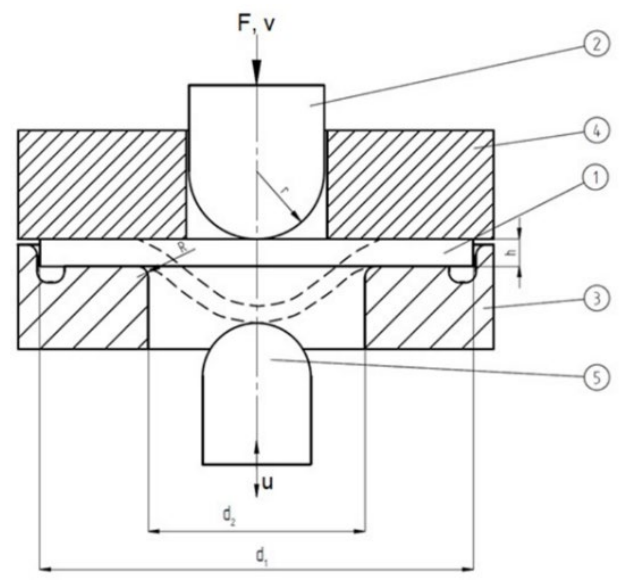

Figure 5 - Cross-sectional view of SP test setup [14]. The LVDT measuring specimen deflection $(u)$ is indicated as item 5. Punch displacement is indicated as $v$.

Currently, the test rig developed at NIST does not accommodate for deflection measurement below the specimen, and therefore all analyses in this study were performed on the basis of punch displacement $(v)$, corrected for test system compliance. It is possible that in the future we will develop a modified fixture that also allows measuring specimen deflection.

\section{Materials and test conditions}

For the validation of the experimental and analytical procedures used at NIST for SP testing, we selected three steels for which conventionally measured tensile properties were available:

- A533B Cl. 1 reactor pressure vessel (RPV) steel, with denomination JRQ. This is a reference RPV steel, widely used in the nuclear community as a radiation/mechanical property correlation monitor material in a number of international and national studies of irradiation embrittlement [12]. This JRQ steel is one of the materials used in an Interlaboratory Study (round-robin) conducted in 2017 to qualify the ASTM Test Method $[11,13]$. This allowed us to directly compare our results with those reported by round-robin participants.

- 4340 steel, used by NIST to produce low-energy certified reference Charpy specimens ${ }^{3}$, heat treated to attain impact energies in the range 15-20 $\mathrm{J}$ at room temperature [14]. We will herein identify this steel as 4340LL.

- 4340 steel, used by NIST to produce high-energy certified reference Charpy specimens ${ }^{2}$, heat treated to attain impact energies in the range 100-120 J at room temperature [14]. We will herein identify this steel as $4340 \mathrm{HH}$.

\footnotetext{
${ }^{3}$ In accordance with ASTM E23 and ISO 148-2.
} 
The chemical composition and the tensile properties of the steels are provided in Table 1 and Table 2. As shown in Table 2, the selected steels cover a wide range of strength and ductility.

Table 1 - Chemical composition of the JRQ and 4340 steels (\%, mass fraction).

\begin{tabular}{|c|c|c|c|c|c|c|c|c|c|c|}
\hline Steel & $\mathbf{C}$ & $\mathbf{S i}$ & $\mathbf{M n}$ & $\mathbf{P}$ & $\mathbf{S}$ & $\mathbf{M o}$ & $\mathbf{N i}$ & $\mathbf{C r}$ & $\mathbf{C u}$ & Ref. \\
\hline JRQ & 0.07 & 0.21 & 1.34 & 0.02 & 0.002 & 0.49 & 0.70 & 0.11 & 0.15 & {$[12]$} \\
\hline $\begin{array}{c}\text { 4340LL } \\
\text { 4340HH }\end{array}$ & 0.40 & 0.28 & 0.66 & 0.004 & 0.001 & 0.28 & 1.77 & 0.83 & N/A & {$[14]$} \\
\hline
\end{tabular}

Table 2 - Tensile properties of the JRQ and 4340 steels.

\begin{tabular}{|c|c|c|c|c|c|}
\hline Steel & $\begin{array}{c}\boldsymbol{R}_{\mathbf{p} 02} \\
(\mathbf{M P a})\end{array}$ & $\begin{array}{c}\boldsymbol{R}_{\mathbf{m}} \\
(\mathbf{M P a})\end{array}$ & $\begin{array}{c}\mathcal{E}_{\mathrm{u}} \\
(\mathbf{\%})\end{array}$ & $\begin{array}{c}\mathcal{E} \\
(\mathbf{\%})\end{array}$ & Ref. \\
\hline JRQ & 477 & 630 & 13.0 & 26.0 & {$[12]$} \\
\hline 4340LL & 1354 & 1513 & 3.4 & 10.9 & \multirow{2}{*}[15]{} \\
\hline $4340 \mathrm{HH}$ & 928 & 1060 & 7.1 & 19.6 & \\
\hline
\end{tabular}

All SP tests were performed at room temperature $\left(21{ }^{\circ} \mathrm{C} \pm 2{ }^{\circ} \mathrm{C}\right)$ in actuator displacement control, with a speed of approximately $0.015 \mathrm{~mm} / \mathrm{s}$. The ASTM Draft Test Method allows displacement rates between $0.0033 \mathrm{~mm} / \mathrm{s}$ and $0.033 \mathrm{~mm} / \mathrm{s}$, with $0.0083 \mathrm{~mm} / \mathrm{s}$ $(0.5 \mathrm{~mm} / \mathrm{min})$ as the most commonly used value. According to [10,11], the following formula provides a reasonable estimate of the maximum punch strain rate, $\dot{\varepsilon}_{S P}^{\max }$, as a function of the punch displacement rate $\mathrm{d} v / \mathrm{d} t$ :

$$
\dot{\varepsilon}_{S P}^{\max } \approx 1000 \mathrm{~m}^{-1} \cdot \frac{d v}{d t}
$$

Force, actuator displacement, and punch displacement (extensometer) data were recorded at a sampling frequency of $1 \mathrm{~Hz}$. The compliance of the test system was measured as detailed in Sec. 4, and subtracted from both actuator and extensometer displacements in order to obtain actual punch displacement values, $v$.

Data analysis was conducted in accordance with [11] by means of a spreadsheet-based software developed in-house. The software and its use are described in detail in Annex 2.

SP specimens were machined out of Charpy specimens (both untested and tested) by means of Electrical Discharge Machining (EDM), in accordance with the dimensions and tolerances shown in Fig. 6 [11].

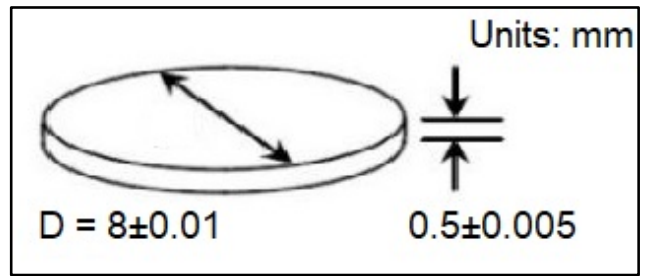

Figure 6 - Dimensions and tolerances of SP specimens [11].

In this investigation, the influence of surface finish was studied by examining two specimen conditions:

- "rough" (as-received) specimens, with surface roughness, $R a$, in the range from $3 \mu \mathrm{m}$ to $4 \mu \mathrm{m}$, resulting from the EDM process; 
- "polished" specimens, with surface roughness, $R a$, in the range from $0.1 \mu \mathrm{m}$ to 0.25 $\mu \mathrm{m}$. This surface condition was obtained by manually grinding slightly oversized asmachined specimens (thickness $\approx 0.55 \mathrm{~mm}$ ) on abrasive paper with a grit size of $\mathrm{P} 400$, followed by fine grinding (P1200) down to the final thickness. Both [10] and [11] require $R a<0.25 \mu \mathrm{m}$. specimen:

Before testing, the following measurements were performed and reported for each

- diameter $D$, measured with a digital comparator;

- thickness $h_{0}$, measured with a caliper;

- surface roughness $R a$, measured with a portable surface roughness tester.

\section{Measurements of test system compliance}

For measuring system compliance, we performed three tests without a specimen in place. The rod + ball system was pressed against the lower plate of the test machine up to the first deviation from linearity (around 1,800 N), to avoid permanent deformation of the rod. Force, actuator displacement, and extensometer signal were recorded with the same sampling frequency of the SP test $(1 \mathrm{~Hz})$.

System compliance was calculated as the inverse of the slope of the linear part of the test record, approximately between $600 \mathrm{~N}$ and 1,400 N (Figs. 7 and 8). The linear regressions were performed by means of the SDAR (Slope Determination by the Analysis of Residuals) algorithm [16]. The regression coefficients for the three tests, and the resulting system compliances in terms of actuator displacements and extensometer displacements, are given in Table 3.

System compliances were quite similar between actuator and extensometer, with the former predictably higher. Force-actuator displacement and force-extensometer signal curves are shown in Fig. 7 and Fig. 8, respectively, with corresponding linear regressions.

The average compliance values used in the SP test analyses and subtracted from the recorded actuator and extensometer displacements, as a function of applied force, were: 1.54 $\times 10^{-4} \mathrm{~mm} / \mathrm{N}$ (actuator) and $1.50 \times 10^{-4}$ (extensometer).

Table 3 - Results of compliance measurements.

\begin{tabular}{|c|c|c|c|c|c|c|}
\hline \multirow{3}{*}{ Test \# } & \multicolumn{3}{|c|}{ Actuator } & \multicolumn{3}{c|}{ Extensometer } \\
\cline { 2 - 7 } & $\begin{array}{c}\text { Slope } \\
(\mathbf{N} / \mathbf{m m})\end{array}$ & $\begin{array}{c}\text { Intercept } \\
\mathbf{( N )}\end{array}$ & $\begin{array}{c}\text { Compliance } \\
(\mathbf{m m} / \mathbf{N})\end{array}$ & $\begin{array}{c}\text { Slope } \\
(\mathbf{N} / \mathbf{m m})\end{array}$ & $\begin{array}{c}\text { Intercept } \\
(\mathbf{N})\end{array}$ & $\begin{array}{c}\text { Compliance } \\
(\mathbf{m m} / \mathbf{N})\end{array}$ \\
\hline 1 & 6453.47 & -437.84 & $1.55 \times 10^{-4}$ & 6699.42 & -445.19 & $1.49 \times 10^{-4}$ \\
\hline 2 & 5331.16 & -103.82 & $1.88 \times 10^{-4}$ & 5378.17 & -86.96 & $1.86 \times 10^{-4}$ \\
\hline 3 & 8370.66 & -151.69 & $1.19 \times 10^{-4}$ & 8614.41 & -273.91 & $1.16 \times 10^{-4}$ \\
\hline Average & 6718.43 & -231.11 & $1.54 \times 10^{-4}$ & 6897.33 & -268.69 & $1.50 \times 10^{-4}$ \\
\hline St. dev. & $23 \%$ & $78 \%$ & $22 \%$ & $24 \%$ & $67 \%$ & $23 \%$ \\
\hline
\end{tabular}



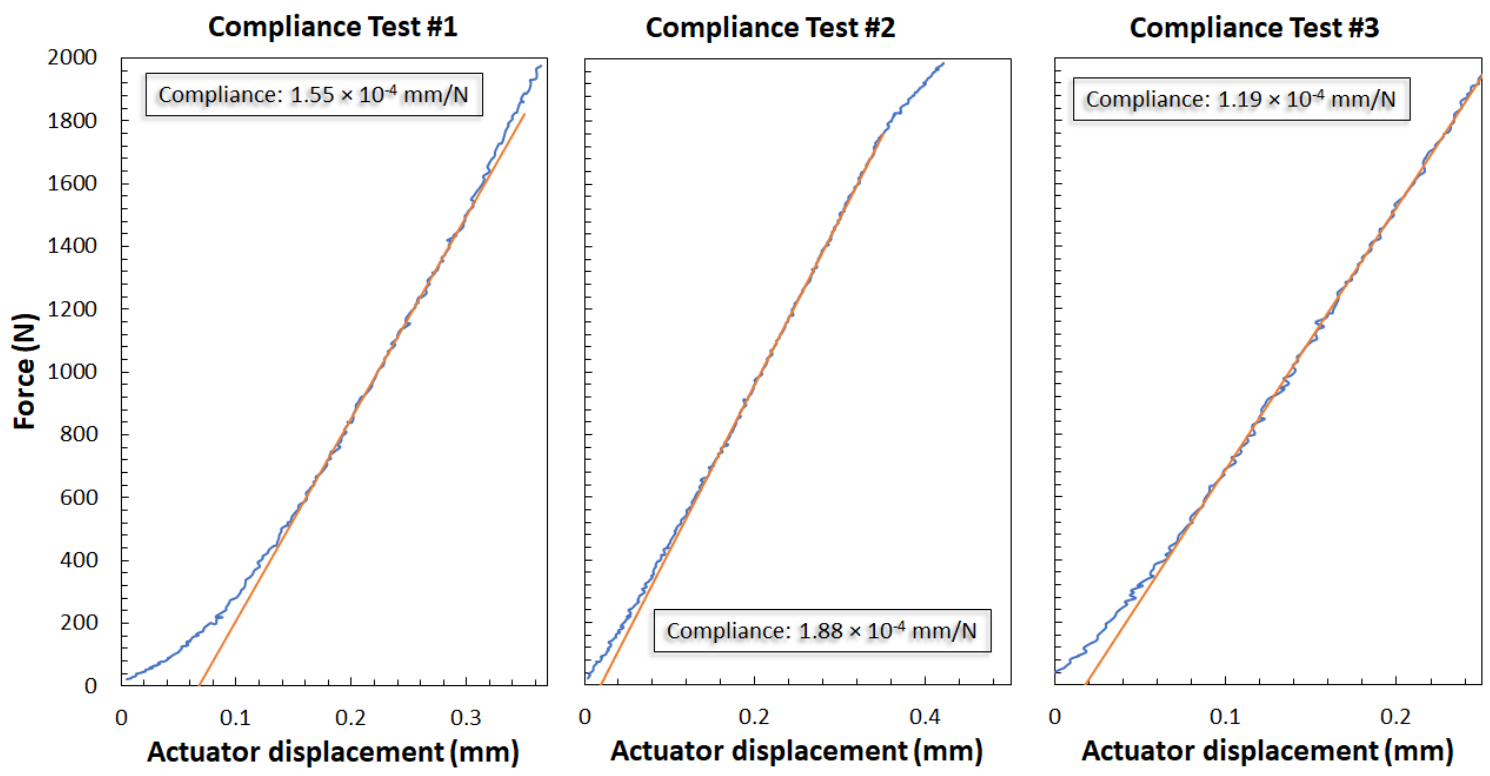

Figure 7 - Compliance measurements as a function of actuator displacement.
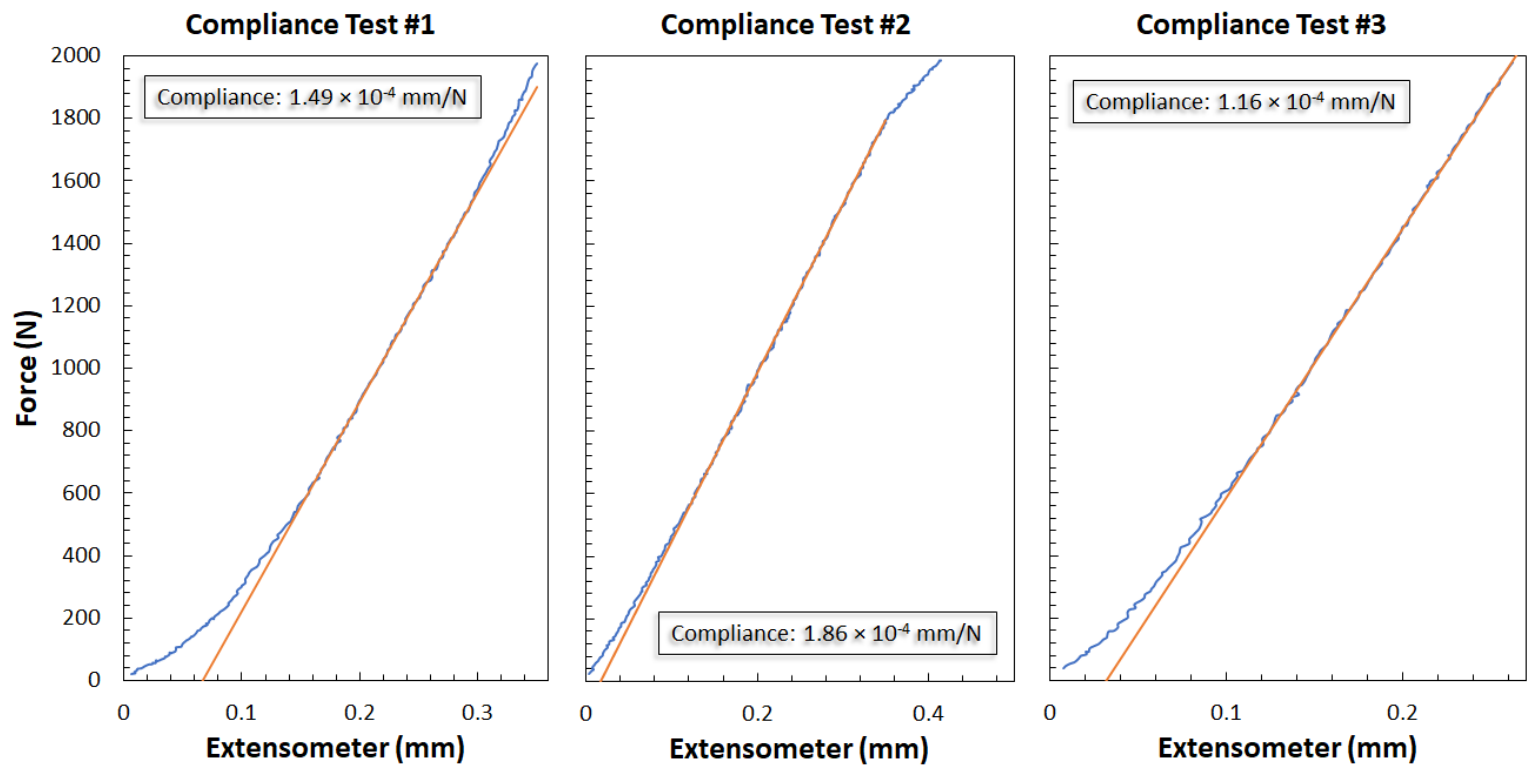

Figure 8 - Compliance measurements as a function of extensometer displacement.

\section{Analysis of an individual SP test}

Three typical test records (JRQ, 4340LL, and 4340HH) are shown in Figs. 9-11, respectively. No qualitative differences were observed between test records from "rough" and "polished" specimens.

The examples in Figs. 9-11 show very good consistency between inferred ${ }^{4}$ actuator displacement and punch displacement measured with the extensometer, with discrepancies becoming apparent just before or after maximum force. However, this wasn't always the case.

${ }^{4}$ After subtracting system compliance. 
For some tests, the two signals started diverging just after the beginning of the test. This was most likely caused by the slightly different positioning of the extensometer arm on the upper machine actuator from test to test. Such tests were included in the overall data analyses.

In this investigation, we used inferred extensometer signal (blue curves in Figs. 9-11) for calculating the results and establishing the correlations with tensile properties.

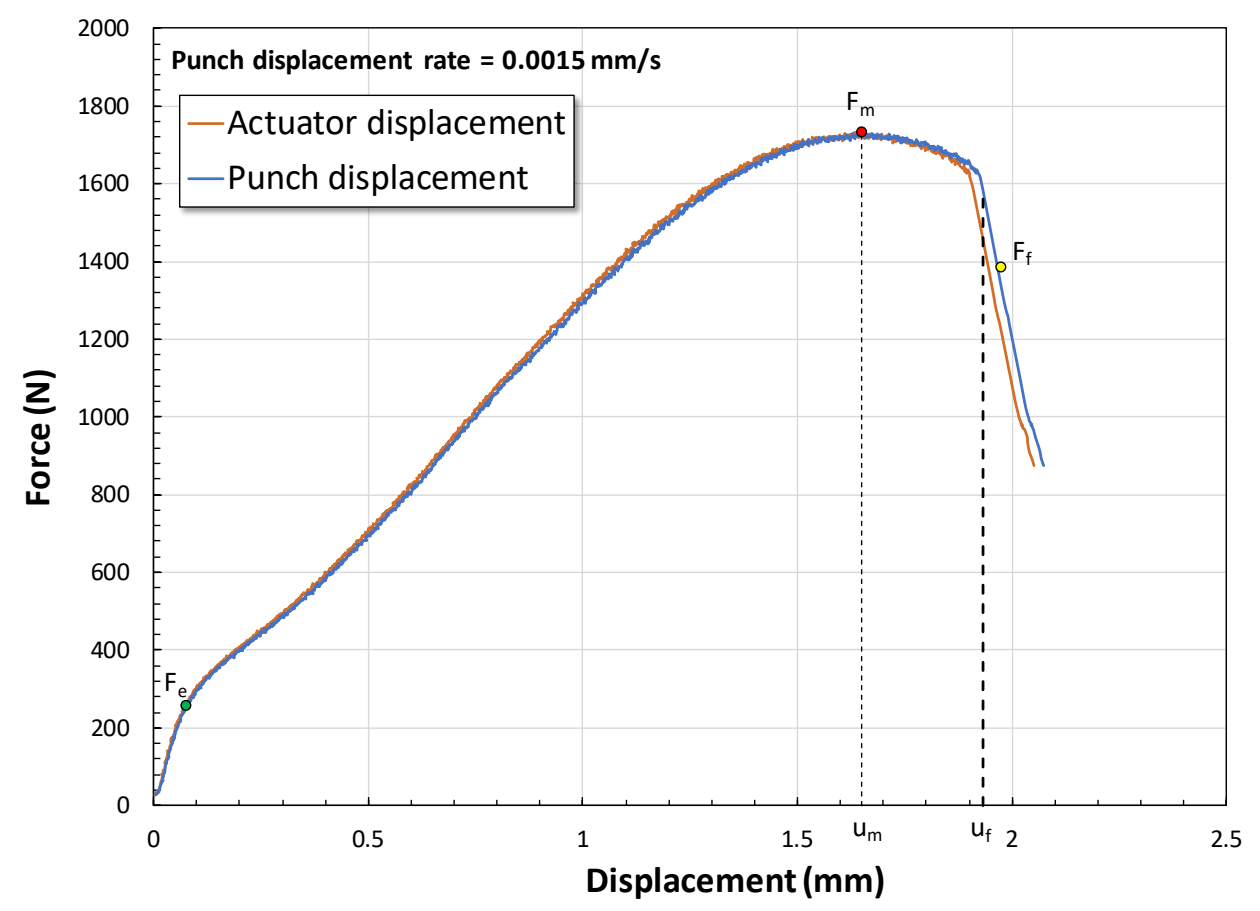

Figure 9 - Force-displacement curves for an SP test on JRQ steel.

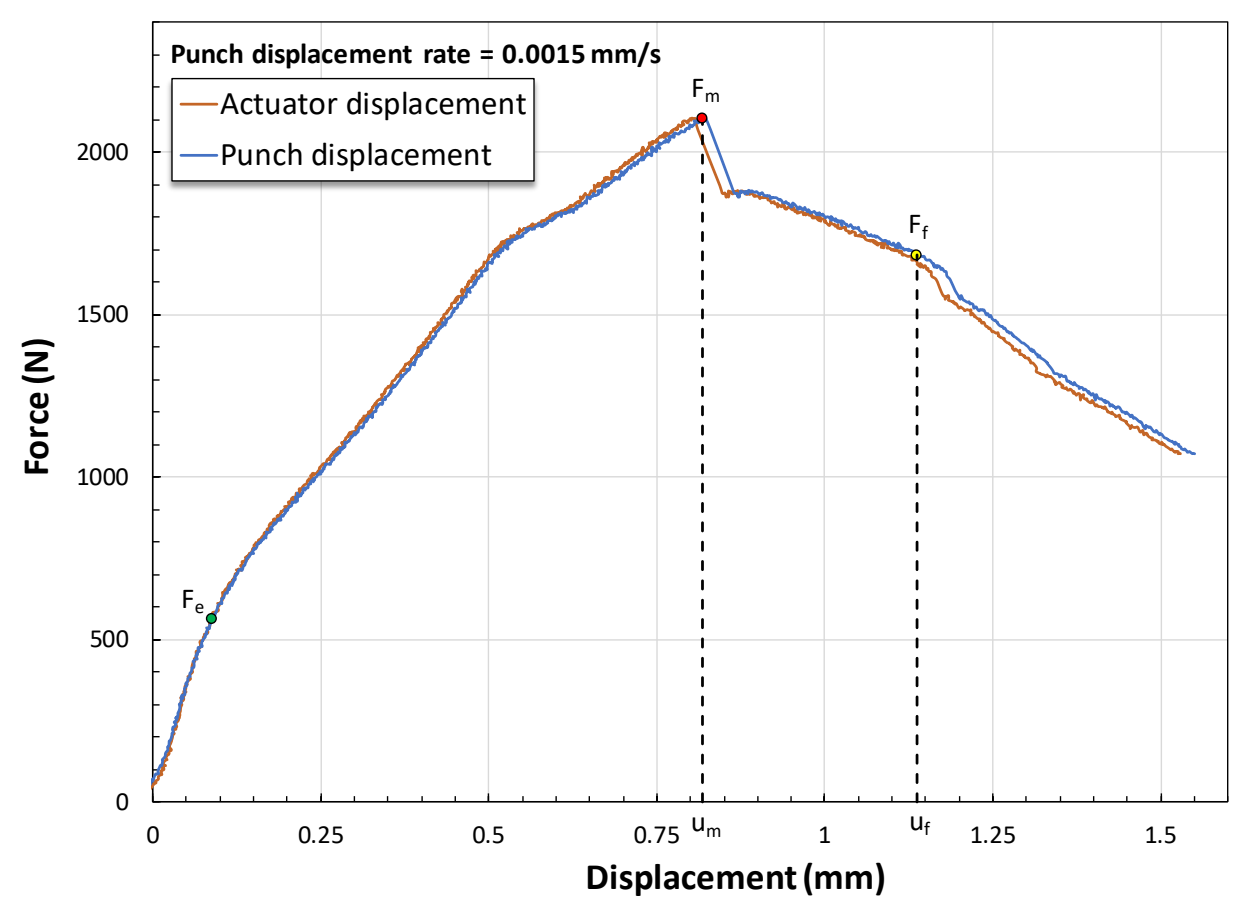

Figure 10 - Force-displacement curves for an SP test on 4340LL steel. 


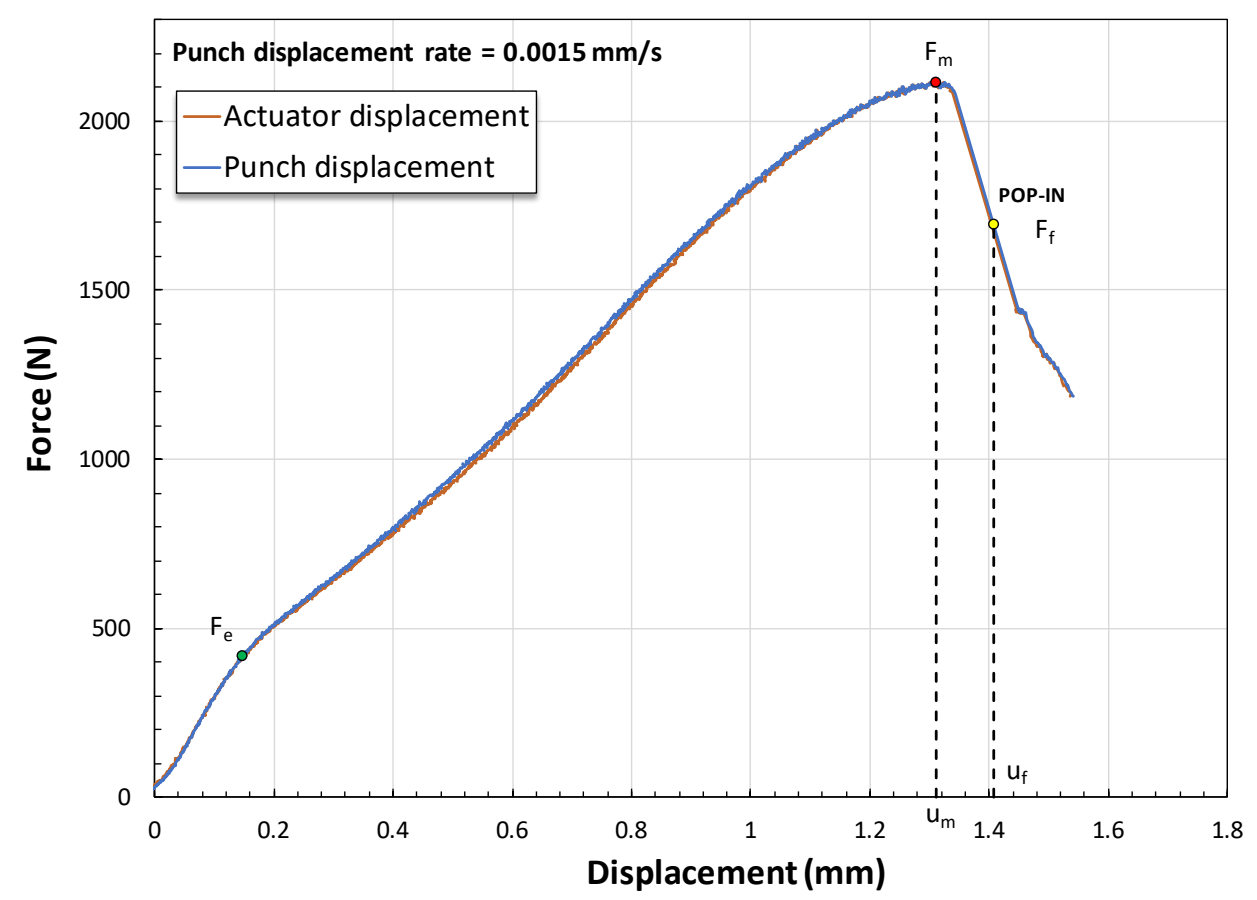

Figure 11 - Force-displacement curves for an SP test on $4340 \mathrm{HH}$ steel.

In according with $[10,11]$, the following characteristic values are determined from $F-u$ or $F$ - $v$ curves.

\subsection{Elastic-plastic transition force, $F_{\mathrm{e}}$}

$F_{\mathrm{e}}$ is defined as the force characterizing the transition from linearity to the stage associated with the spread of the yield zone through the specimen thickness (plastic bending stage) $[10,11]$.

It is determined through the establishment of a bilinear function $f(v)$ from the origin through the points $\mathrm{A}$ and $\mathrm{B}$, defined as (Fig. 12):

$$
f(v)=\left\{\begin{array}{rl}
\frac{f_{A}}{u_{A}} v \text { for } 0 & \leq v<v_{A} \\
\frac{f_{B}-f_{A}}{u_{B}-u_{A}}\left(v-v_{A}\right)+f_{A} & \text { for } v_{A} \leq v \leq v_{B}
\end{array} .\right.
$$

The variables $f_{\mathrm{A}}, f_{\mathrm{B}}$, and $v_{\mathrm{A}}$ are obtained by minimizing the error:

$$
e r r=\int_{0}^{v_{B}}[F(v)-f(v)]^{2} d v
$$

In Eqs. (2) and (3), $v_{\mathrm{B}}$ is taken as the original thickness of the specimen, i.e., $v_{\mathrm{B}}=h_{0}=0.5 \mathrm{~mm}$.

The corresponding yield displacement is $v_{\mathrm{e}}=v_{\mathrm{A}}$, while the experimental transition force $F_{\mathrm{e}}$ is obtained from the experimental test record as $F_{\mathrm{e}}=F\left(v_{\mathrm{A}}\right)$, see Fig. 12. 


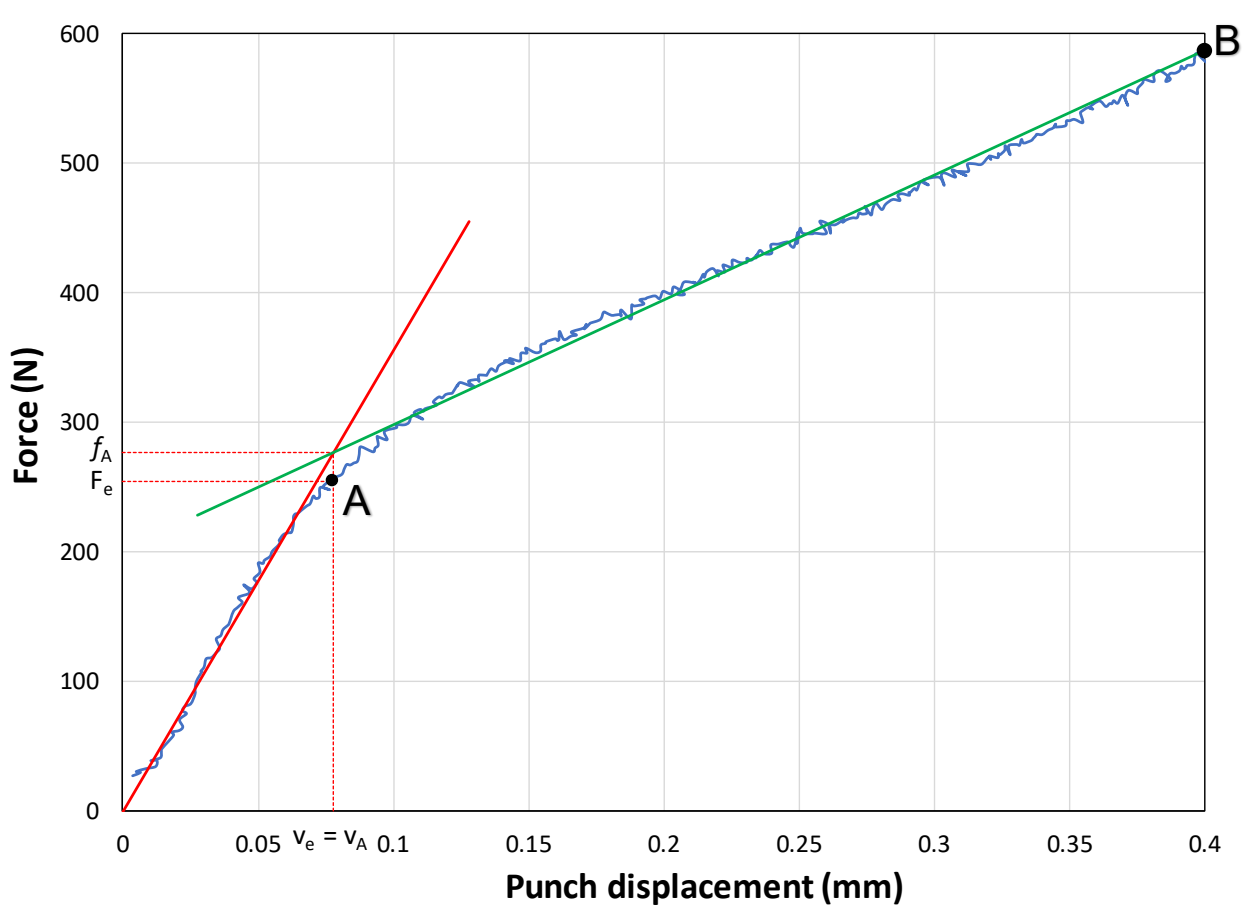

Figure 12 - Determination of the elastic-plastic transition force, $F_{\mathrm{e}}$.

\subsection{Maximum force, $F_{\mathrm{m}}$}

$F_{\mathrm{m}}$ is defined as the maximum force recorded during the SP test $[10,11]$. It is indicated by a red circle in Figs. 9-11. The corresponding value of punch displacement is $v_{\mathrm{m}}$.

\subsection{Displacement at end of test, $v_{f}$}

The end of an SP test is defined by a $20 \%$ force decrease with respect to $F_{\mathrm{m}}[10,11]$. The corresponding punch displacement is $v \mathrm{f}$.

If the specimen exhibits sudden force drops (pop-ins), caused by unstable crack propagation events followed by crack arrests, $v_{\mathrm{f}}$ is replaced by $v_{1 \mathrm{p}}$, the displacement corresponding to the first significant pop-in ${ }^{5}$.

For the SP tests documented in this report, significant pop-ins were observed at maximum force for most 4340LL specimens (example in Fig. 10) and after maximum force for most $4340 \mathrm{HH}$ specimens (example in Fig. 11).

\subsection{SP fracture energy, $E_{\mathrm{SP}}$}

The SP fracture energy is calculated as the area under the force-displacement curve up to $v_{\mathrm{f}}$ or $v_{1 \mathrm{p}}[10,11]$ :

$$
E_{S P}=\int_{0}^{v_{f}} F(v) d v
$$

\footnotetext{
${ }^{5}$ A pop-in is considered significant if it is associated to a force drop of at least $10 \%$.
} 


\subsection{SP total energy, $E_{\mathrm{m}}$}

The SP total energy is calculated as the area under the force-displacement curve up to $v_{\mathrm{m}}[10,11]$ :

$$
E_{m}=\int_{0}^{v_{m}} F(v) d v
$$

\section{6. $\quad$ SP plastic energy, $E_{\mathrm{PL}}$}

The SP plastic energy is calculated as the plastic area under the force-displacement curve up to $v_{\mathrm{m}}[10,11]$ :

$$
E_{P L}=E_{m}-0.5 \frac{F_{m}^{2} \cdot v_{A}}{f_{A}} .
$$

\subsection{Effective fracture strain, $\varepsilon_{\mathrm{f}}$}

The effective fracture strain is calculated as the natural logarithm of the ratio between initial and final specimen thickness $[10,11]$ :

$$
\varepsilon_{f}=\ln \left(\frac{h_{0}}{h_{f}}\right),
$$

where the final thickness $h_{\mathrm{f}}$ is measured adjacent to the area of failure.

Since measurements of specimen final thickness were not performed in this investigation, effective fracture strains were not calculated.

\subsection{Additional parameters}

Other values of force and displacement were correlated with tensile properties in published papers, and are also determined by the software that is described in Annex 2. Details of these parameters and the corresponding correlations will be provided in Sec. 7.

\section{Test results}

\subsection{JRQ steel}

Twenty-eight SP tests were performed (17 on rough specimens and 11 on polished specimens). The characteristic values of force, punch displacement, and energy are provided in Table 4 for rough specimens and Table 5 for polished specimens, with mean values and standard deviations ( $\mathrm{SD}$, absolute and relative). 
Table 4 - Results of SP tests on JRQ steel (rough specimens) ${ }^{6}$.

\begin{tabular}{|c|c|c|c|c|c|c|c|c|c|c|c|}
\hline $\begin{array}{c}\text { Specimen } \\
\text { id }\end{array}$ & $\begin{array}{c}\text { Displacement } \\
\text { rate }(\mathrm{mm} / \mathrm{s})\end{array}$ & $\begin{array}{c}\mathrm{h}_{0} \\
(\mathrm{~mm})\end{array}$ & $\begin{array}{c}\dot{\varepsilon}_{S P}^{\max } \\
\left(\mathrm{s}^{-1}\right)\end{array}$ & $\begin{array}{c}\mathrm{F}_{\mathrm{e}} \\
(\mathrm{N})\end{array}$ & $\begin{array}{c}\mathrm{F}_{\mathrm{m}} \\
(\mathrm{N})\end{array}$ & $\begin{array}{c}\mathrm{v}_{\mathrm{e}} \\
(\mathrm{mm})\end{array}$ & $\begin{array}{c}\mathrm{V}_{\mathrm{m}} \\
(\mathrm{mm})\end{array}$ & $\begin{array}{c}\mathrm{v}_{\mathrm{f}} \\
(\mathrm{mm})\end{array}$ & $\begin{array}{c}\mathrm{E}_{\mathrm{SP}} \\
(\mathrm{J})\end{array}$ & $\begin{array}{c}\mathrm{E}_{\mathrm{m}} \\
(\mathrm{J})\end{array}$ & $\begin{array}{c}\mathrm{E}_{\mathrm{PL}} \\
(\mathrm{J})\end{array}$ \\
\hline JRQ-79-SP1 & 0.0009 & 0.512 & $8.50 \mathrm{E}-04$ & 237.1 & $\mathrm{~N} / \mathrm{A}$ & 0.116 & $\mathrm{~N} / \mathrm{A}$ & $\mathrm{N} / \mathrm{A}$ & $\mathrm{N} / \mathrm{A}$ & $\mathrm{N} / \mathrm{A}$ & $\mathrm{N} / \mathrm{A}$ \\
JRQ-79-SP2 & 0.0018 & 0.511 & $1.81 \mathrm{E}-03$ & 257.1 & 1578.5 & 0.128 & 1.669 & 1.845 & 1.85 & 1.58 & 1.01 \\
JRQ-79-SP3 & 0.0018 & 0.508 & $1.77 \mathrm{E}-03$ & 250.9 & 1578.7 & 0.113 & 1.602 & 1.868 & 1.89 & 1.48 & 0.96 \\
JRQ-79-SP4 & 0.0018 & 0.504 & $1.81 \mathrm{E}-03$ & 279.9 & 1525.0 & 0.118 & 1.587 & 1.845 & 1.83 & 1.45 & 0.99 \\
JRQ-79-SP5 & 0.0013 & 0.511 & $1.35 \mathrm{E}-03$ & 249.1 & 1561.8 & 0.126 & 1.639 & 1.873 & 1.87 & 1.52 & 0.93 \\
JRQ-79-SP6 & 0.0013 & 0.509 & $1.34 \mathrm{E}-03$ & 223.0 & 1538.7 & 0.061 & 1.564 & 1.838 & 1.88 & 1.47 & 1.18 \\
JRQ-79-SP7 & 0.0014 & 0.511 & $1.37 \mathrm{E}-03$ & 232.4 & 1563.0 & 0.078 & 1.592 & 1.729 & 1.69 & 1.49 & 1.13 \\
JRQ-79-SP8 & 0.0014 & 0.511 & $1.35 \mathrm{E}-03$ & 215.5 & 1571.6 & 0.076 & 1.615 & 1.870 & 1.90 & 1.52 & 1.12 \\
JRQ-79-SP9 & 0.0015 & 0.508 & $1.48 \mathrm{E}-03$ & 242.4 & 1547.0 & 0.142 & 1.778 & 2.111 & 2.08 & 1.58 & 0.91 \\
JRQ-80-SP1 & 0.0014 & 0.508 & $1.36 \mathrm{E}-03$ & 252.4 & 1543.9 & 0.115 & 1.646 & 1.845 & 1.83 & 1.53 & 1.01 \\
JRQ-80-SP2 & 0.0014 & 0.509 & $1.37 \mathrm{E}-03$ & 249.7 & 1549.3 & 0.125 & 1.662 & 1.826 & 1.77 & 1.53 & 0.97 \\
JRQ-80-SP4 & 0.0014 & 0.503 & $1.35 \mathrm{E}-03$ & 240.0 & 1561.3 & 0.106 & 1.645 & 1.876 & 1.88 & 1.53 & 1.02 \\
JRQ-80-SP5 & 0.0013 & 0.504 & $1.35 \mathrm{E}-03$ & 237.2 & 1572.7 & 0.109 & 1.616 & 1.883 & 1.89 & 1.48 & 0.94 \\
JRQ-80-SP7 & 0.0014 & 0.508 & $1.36 \mathrm{E}-03$ & 242.3 & 1577.4 & 0.120 & 1.630 & 1.917 & 1.93 & 1.50 & 0.92 \\
JRQ-80-SP8 & 0.0014 & 0.510 & $1.37 \mathrm{E}-03$ & 269.1 & 1584.2 & 0.123 & 1.621 & 1.835 & 1.83 & 1.51 & 0.97 \\
JRQ-80-SP9 & 0.0014 & 0.509 & $1.36 \mathrm{E}-03$ & 264.2 & 1603.0 & 0.126 & 1.660 & 1.877 & 1.90 & 1.57 & 0.99 \\
JRQ-80-SP10 & 0.0014 & 0.503 & $1.36 \mathrm{E}-03$ & 256.1 & 1556.2 & 0.135 & 1.671 & 1.889 & 1.86 & 1.53 & 0.93 \\
\hline
\end{tabular}

Table 5 - Results of SP tests on JRQ steel (polished specimens).

\begin{tabular}{|c|c|c|c|c|c|c|c|c|c|c|c|}
\hline $\begin{array}{c}\text { Specimen } \\
\text { id }\end{array}$ & $\begin{array}{l}\text { Displacement } \\
\text { rate }(\mathrm{mm} / \mathrm{s})\end{array}$ & $\begin{array}{c}\mathrm{h}_{0} \\
(\mathrm{~mm})\end{array}$ & $\begin{array}{c}\dot{\varepsilon}_{S P}^{\max } \\
\left(\mathrm{s}^{-1}\right)\end{array}$ & $\begin{array}{l}\mathrm{F}_{\mathrm{e}} \\
(\mathrm{N})\end{array}$ & $\begin{array}{l}F_{m} \\
(N)\end{array}$ & $\begin{array}{c}v_{e} \\
(\mathrm{~mm})\end{array}$ & $\begin{array}{c}v_{m} \\
(\mathrm{~mm})\end{array}$ & $\begin{array}{c}v_{f} \\
(\mathrm{~mm})\end{array}$ & $\begin{array}{l}E_{S P} \\
(J)\end{array}$ & $\begin{array}{l}E_{m} \\
\text { (J) }\end{array}$ & $\begin{array}{l}E_{P L} \\
(J)\end{array}$ \\
\hline JRQ-SP11 & 0.0008 & 0.50 & 7.91E-04 & 340.1 & 1794.4 & 0.152 & 1.775 & 2.067 & 2.43 & 1.93 & 1.10 \\
\hline JRQ-SP12 & 0.0013 & 0.50 & $1.35 \mathrm{E}-03$ & 249.3 & 1744.8 & 0.074 & 1.580 & 1.955 & 2.27 & 1.63 & 1.21 \\
\hline JRQ-SP13 & 0.0013 & 0.50 & $1.34 \mathrm{E}-03$ & 256.9 & 1778.0 & 0.084 & 1.685 & 2.044 & 2.44 & 1.83 & 1.35 \\
\hline JRQ-SP14 & 0.0013 & 0.50 & $1.33 \mathrm{E}-03$ & 240.8 & 1756.7 & 0.070 & 1.627 & 1.947 & 2.26 & 1.72 & 1.30 \\
\hline JRQ-SP15 & 0.0013 & 0.50 & $1.33 \mathrm{E}-03$ & 254.8 & 1731.9 & 0.078 & 1.650 & 1.975 & 2.27 & 1.73 & 1.31 \\
\hline JRQ-SP16 & 0.0013 & 0.50 & $1.34 \mathrm{E}-03$ & 240.7 & 1713.5 & 0.078 & 1.668 & 2.027 & 2.34 & 1.75 & 1.32 \\
\hline JRQ-SP17 & 0.0013 & 0.50 & $1.34 \mathrm{E}-03$ & 268.9 & 1752.8 & 0.083 & 1.606 & 1.918 & 2.23 & 1.70 & 1.25 \\
\hline JRQ-SP18 & 0.0013 & 0.50 & $1.35 \mathrm{E}-03$ & 241.2 & 1700.8 & 0.082 & 1.663 & 1.938 & 2.17 & 1.72 & 1.27 \\
\hline JRQ-SP19 & 0.0013 & 0.50 & 1.34E-03 & 240.3 & 1745.3 & 0.078 & 1.649 & 1.910 & 2.15 & 1.71 & 1.25 \\
\hline JRQ-SP20 & 0.0013 & 0.50 & $1.34 \mathrm{E}-03$ & 244.5 & 1703.1 & 0.084 & 1.668 & 1.933 & 2.15 & 1.71 & 1.24 \\
\hline JRQ-SP21 & 0.0014 & 0.47 & $1.35 \mathrm{E}-03$ & 219.1 & 1452.2 & 0.104 & 1.660 & 1.967 & 1.86 & 1.43 & 0.97 \\
\hline & & & Mean & 254.2 & 1715.8 & 0.088 & 1.657 & 1.971 & 2.23 & 1.72 & 1.23 \\
\hline & & & SD & $\begin{array}{c}31.121 \\
12.2 \%\end{array}$ & $\begin{array}{c}92.163 \\
5.4 \%\end{array}$ & $\begin{array}{l}0.023 \\
26.1 \%\end{array}$ & $\begin{array}{l}0.050 \\
3.0 \%\end{array}$ & $\begin{array}{l}0.053 \\
2.7 \%\end{array}$ & $\begin{array}{l}0.159 \\
7.1 \%\end{array}$ & $\begin{array}{l}0.122 \\
7.1 \%\end{array}$ & $\begin{array}{l}0.110 \\
8.9 \%\end{array}$ \\
\hline
\end{tabular}

\subsubsection{Comparison with round-robin results}

The JRQ steel is one of seven materials used in an Interlaboratory Study (ILS 1408), conducted in 2017 for establishing the precision of the ASTM Draft Test Method [11,13]. Twelve laboratories participated by testing 463 specimens in total. We compared our average force values and standard deviations for rough (Table 4) and polished (Table 5) specimens with the average force values and standard deviations of the round-robin participants in Table 6 and Fig. 13. Note that displacement and energy values cannot be directly compared, as round-robin participants reported specimen deflection instead of punch displacement.

Table 6 - Comparison between round-robin (R-R) and NIST force results for the JRQ steel.

\begin{tabular}{|c|c|c|c|c|c|c|}
\hline \multirow{2}{*}{ Parameter } & \multicolumn{3}{|c|}{$F_{\mathrm{m}}(\mathrm{N})$} & \multicolumn{3}{c|}{$\mathrm{F}_{\mathrm{e}}$ (N) } \\
& \multicolumn{2}{|c|}{ NIST } & \multicolumn{2}{c|}{ R-R } & \multicolumn{3}{c|}{ NIST } & R-R \\
\hline Condition & Rough & \multicolumn{2}{|c|}{ Polished } & Rough & \multicolumn{2}{c|}{ Polished } \\
\hline Average & 1563.3 & 1715.8 & 1747.7 & 247.0 & 254.2 & 244.4 \\
St. dev. & 19.67 & 92.16 & 29.17 & 16.15 & 31.12 & 17.67 \\
\hline
\end{tabular}

\footnotetext{
${ }^{6}$ Test on specimen JRQ-79-SP1 was accidentally stopped before maximum force was reached.
} 
Our force results on polished specimens are in excellent agreement with the roundrobin results ${ }^{7}$, with $\pm 2 \sigma$ error bands largely overlapping. Results from rough specimens are also statistically not different, except for maximum force values (Fig. 13).

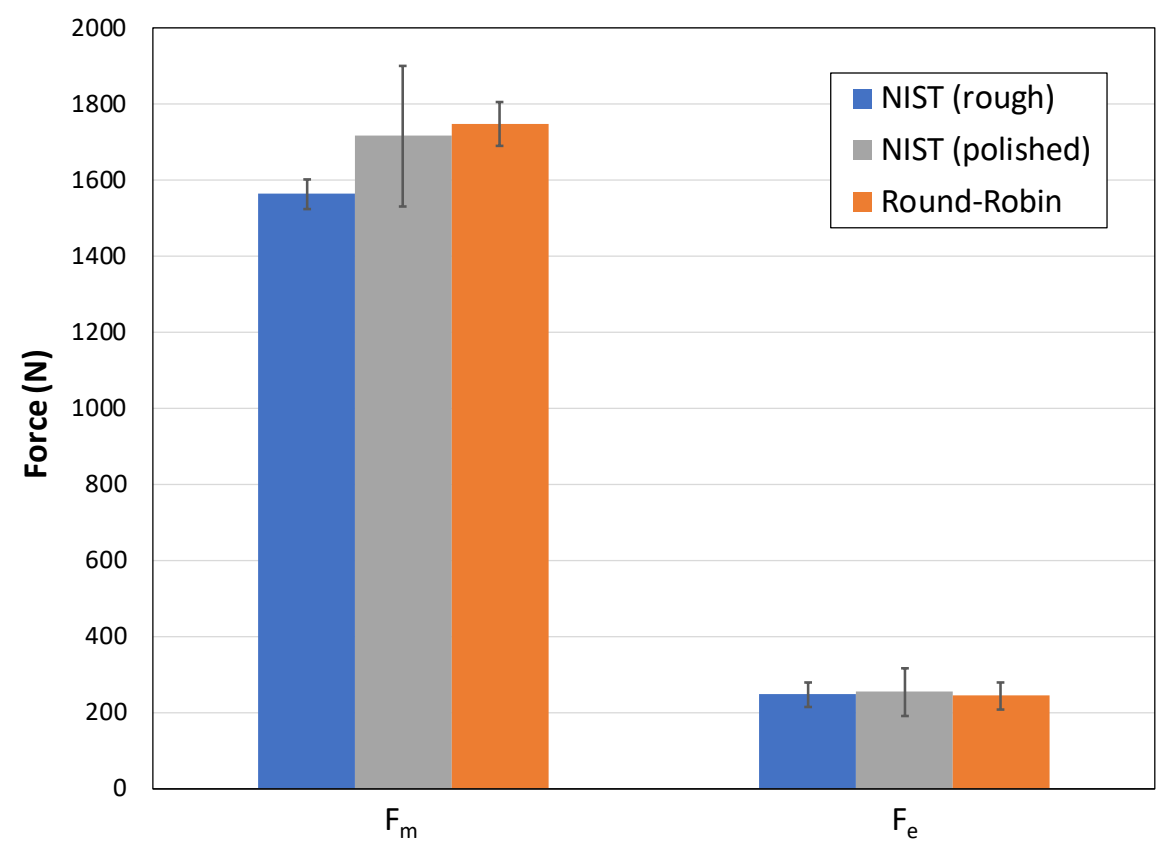

Figure 13 - Comparison between mean force values reported by round-robin participants and NIST on the JRQ steel. Error bands correspond to \pm twice the standard deviation.

\subsection{Low-energy 4340 steel (4340LL)}

Nineteen SP tests were performed (10 on rough specimens and 9 on polished specimens). The characteristic values of force, punch displacement, and energy are provided in Table 7 for rough specimens and Table 8 for polished specimens, with mean values and standard deviations (absolute and relative).

Table 7 - Results of SP tests on 4340LL steel (rough specimens).

\begin{tabular}{|c|c|c|c|c|c|c|c|c|c|c|c|}
\hline $\begin{array}{c}\text { Specimen } \\
\text { id }\end{array}$ & $\begin{array}{c}\text { Displacement } \\
\text { rate }(\mathrm{mm} / \mathrm{s})\end{array}$ & $\begin{array}{c}\mathrm{h}_{0} \\
(\mathrm{~mm})\end{array}$ & $\begin{array}{c}\dot{\varepsilon}_{S P}^{\max } \\
\left(\mathrm{s}^{-1}\right)\end{array}$ & $\begin{array}{c}\mathrm{F}_{\mathrm{e}} \\
(\mathrm{N})\end{array}$ & $\begin{array}{c}\mathrm{F}_{\mathrm{m}} \\
(\mathrm{N})\end{array}$ & $\begin{array}{c}\mathrm{v}_{\mathrm{e}} \\
(\mathrm{mm})\end{array}$ & $\begin{array}{c}\mathrm{v}_{\mathrm{m}} \\
(\mathrm{mm})\end{array}$ & $\begin{array}{c}\mathrm{v}_{\mathrm{f}} \\
(\mathrm{mm})\end{array}$ & $\begin{array}{c}\mathrm{E}_{\mathrm{SP}} \\
(\mathrm{J})\end{array}$ & $\begin{array}{c}\mathrm{E}_{\mathrm{m}} \\
(\mathrm{J})\end{array}$ & $\begin{array}{c}\mathrm{E}_{\mathrm{PL}} \\
(\mathrm{J})\end{array}$ \\
\hline LL-SP1 & 0.0010 & 0.503 & $9.58 \mathrm{E}-04$ & 684.5 & 1893.4 & 0.180 & 0.898 & 1.075 & 1.40 & 1.10 & 0.64 \\
LL-SP2 & 0.0009 & 0.505 & $9.23 \mathrm{E}-04$ & 722.6 & 1886.4 & 0.173 & 0.907 & 1.099 & 1.45 & 1.13 & 0.71 \\
LL-SP3 & 0.0009 & 0.505 & $9.45 \mathrm{E}-04$ & 651.6 & 1840.1 & 0.160 & 0.851 & 1.025 & 1.29 & 1.02 & 0.62 \\
LL-SP4 & 0.0009 & 0.506 & $9.28 \mathrm{E}-04$ & 649.3 & 1897.2 & 0.130 & 0.878 & 1.122 & 1.52 & 1.13 & 0.79 \\
LL-SP5 & 0.0009 & 0.503 & $9.31 \mathrm{E}-04$ & 654.3 & 1880.7 & 0.139 & 0.792 & 0.951 & 1.22 & 0.96 & 0.60 \\
LL-SP6 & 0.0009 & 0.506 & $9.41 \mathrm{E}-04$ & 672.9 & 1860.1 & 0.123 & 0.823 & 1.053 & 1.41 & 1.04 & 0.74 \\
LL-SP7 & 0.0009 & 0.505 & $9.27 \mathrm{E}-04$ & 640.1 & 1958.3 & 0.136 & 0.861 & 1.086 & 1.48 & 1.10 & 0.71 \\
LL-SP8 & 0.0009 & 0.503 & $9.33 \mathrm{E}-04$ & 642.1 & 1899.3 & 0.129 & 0.862 & 1.109 & 1.50 & 1.10 & 0.74 \\
LL-SP9 & 0.0009 & 0.504 & $9.26 \mathrm{E}-04$ & 607.8 & 1931.6 & 0.127 & 0.836 & 1.047 & 1.40 & 1.04 & 0.67 \\
LL-SP10 & 0.0009 & 0.502 & $9.11 \mathrm{E}-04$ & 587.5 & 1913.9 & 0.111 & 0.830 & 1.027 & 1.39 & 1.06 & 0.73 \\
\hline
\end{tabular}

\footnotetext{
${ }^{7}$ Specimens tested in the round-robin were also polished to $R a<0.25 \mathrm{~mm}$, in accordance with the ASTM Draft Test Method [11].
} 
Table 8 - Results of SP tests on 4340LL steel (polished specimens).

\begin{tabular}{|c|c|c|c|c|c|c|c|c|c|c|c|}
\hline $\begin{array}{c}\text { Specimen } \\
\text { id }\end{array}$ & $\begin{array}{c}\text { Displacement } \\
\text { rate (mm/s) }\end{array}$ & $\begin{array}{c}\mathrm{h}_{0} \\
(\mathrm{~mm})\end{array}$ & $\begin{array}{c}\dot{\varepsilon}_{S P}^{\max } \\
\left(\mathrm{s}^{-1}\right)\end{array}$ & $\begin{array}{c}\mathrm{F}_{\mathrm{e}} \\
(\mathrm{N})\end{array}$ & $\begin{array}{c}\mathrm{F}_{\mathrm{m}} \\
(\mathrm{N})\end{array}$ & $\begin{array}{c}\mathrm{v}_{\mathrm{e}} \\
(\mathrm{mm})\end{array}$ & $\begin{array}{c}\mathrm{v}_{\mathrm{m}} \\
(\mathrm{mm})\end{array}$ & $\begin{array}{c}\mathrm{v}_{\mathrm{f}} \\
(\mathrm{mm})\end{array}$ & $\begin{array}{c}\mathrm{E}_{\mathrm{SP}} \\
(\mathrm{J})\end{array}$ & $\begin{array}{c}\mathrm{E}_{\mathrm{m}} \\
(\mathrm{J})\end{array}$ & $\begin{array}{c}\mathrm{E}_{\mathrm{PL}} \\
(\mathrm{J})\end{array}$ \\
\hline LL-SP11 & 0.0013 & 0.50 & $1.35 \mathrm{E}-03$ & 547.8 & 2059.8 & 0.085 & 0.806 & 0.954 & 1.33 & 1.06 & 0.77 \\
LL-SP12 & 0.0013 & 0.47 & $1.35 \mathrm{E}-03$ & 651.6 & 1992.3 & 0.109 & 0.811 & 1.126 & 1.60 & 1.06 & 0.75 \\
LL-SP13 & 0.0013 & 0.50 & $1.27 \mathrm{E}-03$ & 740.0 & 2125.4 & 0.120 & 0.821 & 1.112 & 1.69 & 1.16 & 0.82 \\
LL-SP14 & 0.0013 & 0.50 & $1.32 \mathrm{E}-03$ & 634.8 & 2190.5 & 0.091 & 0.905 & 1.105 & 1.70 & 1.33 & 1.01 \\
LL-SP15 & 0.0014 & 0.50 & $1.36 \mathrm{E}-03$ & 561.3 & 2105.3 & 0.089 & 0.818 & 1.137 & 1.67 & 1.09 & 0.77 \\
LL-SP16 & 0.0013 & 0.50 & $1.31 \mathrm{E}-03$ & 680.0 & 2179.9 & 0.098 & 0.850 & 1.059 & 1.65 & 1.25 & 0.94 \\
LL-SP17 & 0.0013 & 0.50 & $1.32 \mathrm{E}-03$ & 771.4 & 2178.8 & 0.120 & 0.952 & 1.135 & 1.79 & 1.44 & 1.11 \\
LL-SP18 & 0.0014 & 0.50 & $1.36 \mathrm{E}-03$ & 636.9 & 2076.1 & 0.093 & 0.802 & 1.175 & 1.82 & 1.12 & 0.83 \\
LL-SP19 & 0.0013 & 0.50 & $1.31 \mathrm{E}-03$ & 650.5 & 2182.9 & 0.097 & 0.949 & 1.081 & 1.67 & 1.41 & 1.08 \\
\hline
\end{tabular}

\subsection{High-energy 4340 steel $(4340 \mathrm{HH})$}

Twenty SP tests were performed (10 on rough specimens and 10 on polished specimens). The characteristic values of force, punch displacement, and energy are provided in Table 9 for rough specimens and Table 10 for polished specimens, with mean values and standard deviations (absolute and relative).

Table 9 - Results of SP tests on 4340HH steel (rough specimens).

\begin{tabular}{|c|c|c|c|c|c|c|c|c|c|c|c|}
\hline $\begin{array}{c}\text { Specimen } \\
\text { id }\end{array}$ & $\begin{array}{c}\text { Displacement } \\
\text { rate }(\mathrm{mm} / \mathrm{s})\end{array}$ & $\begin{array}{c}\mathrm{h}_{0} \\
(\mathrm{~mm})\end{array}$ & $\begin{array}{c}\dot{\varepsilon}_{S P}^{\max } \\
\left(\mathrm{s}^{-1}\right)\end{array}$ & $\begin{array}{c}\mathrm{F}_{\mathrm{e}} \\
(\mathrm{N})\end{array}$ & $\begin{array}{c}\mathrm{F}_{\mathrm{m}} \\
(\mathrm{N})\end{array}$ & $\begin{array}{c}\mathrm{v}_{\mathrm{e}} \\
(\mathrm{mm})\end{array}$ & $\begin{array}{c}\mathrm{v}_{\mathrm{m}} \\
(\mathrm{mm})\end{array}$ & $\begin{array}{c}\mathrm{v}_{\mathrm{f}} \\
(\mathrm{mm})\end{array}$ & $\begin{array}{c}\mathrm{E}_{\mathrm{SP}} \\
(\mathrm{J})\end{array}$ & $\begin{array}{c}\mathrm{E}_{\mathrm{m}} \\
(\mathrm{J})\end{array}$ & $\begin{array}{c}\mathrm{E}_{\mathrm{PL}} \\
(\mathrm{J})\end{array}$ \\
\hline HH-SP1 & 0.0008 & 0.509 & $8.22 \mathrm{E}-04$ & 460.9 & 2136.5 & 0.121 & 1.195 & 1.318 & 1.60 & 1.49 & 0.93 \\
HH-SP2 & 0.0008 & 0.509 & $8.18 \mathrm{E}-04$ & 418.4 & 2115.6 & 0.148 & 1.311 & 1.408 & 1.65 & 1.59 & 0.82 \\
HH-SP3 & 0.0009 & 0.509 & $8.56 \mathrm{E}-04$ & 472.2 & 2087.5 & 0.139 & 1.213 & 1.304 & 1.55 & 1.48 & 0.87 \\
HH-SP4 & 0.0008 & 0.509 & $8.30 \mathrm{E}-04$ & 427.7 & 2113.9 & 0.115 & 1.236 & 1.334 & 1.72 & 1.53 & 0.96 \\
HH-SP5 & 0.0009 & 0.509 & $8.50 \mathrm{E}-04$ & 499.2 & 2053.2 & 0.116 & 1.150 & 1.258 & 1.50 & 1.40 & 0.94 \\
HH-SP6 & 0.0008 & 0.509 & $8.31 \mathrm{E}-04$ & 476.9 & 2114.1 & 0.125 & 1.255 & 1.350 & 1.68 & 1.60 & 1.06 \\
HH-SP7 & 0.0008 & 0.509 & $8.21 \mathrm{E}-04$ & 440.7 & 2081.8 & 0.106 & 1.162 & 1.247 & 1.49 & 1.44 & 0.96 \\
HH-SP8 & 0.0008 & 0.509 & $8.27 \mathrm{E}-04$ & 433.4 & 2106.2 & 0.120 & 1.225 & 1.331 & 1.63 & 1.53 & 0.95 \\
HH-SP9 & 0.0008 & 0.509 & $8.05 \mathrm{E}-04$ & 436.1 & 2189.0 & 0.128 & 1.365 & 1.398 & 1.85 & 1.78 & 1.10 \\
HH-SP10 & 0.0008 & 0.509 & $8.23 \mathrm{E}-04$ & 420.7 & 2133.8 & 0.126 & 1.278 & 1.364 & 1.63 & 1.59 & 0.94 \\
\hline
\end{tabular}

Table 10 - Results of SP tests on $4340 \mathrm{HH}$ steel (polished specimens).

\begin{tabular}{|c|c|c|c|c|c|c|c|c|c|c|c|}
\hline $\begin{array}{c}\text { Specimen } \\
\text { id }\end{array}$ & $\begin{array}{c}\text { Displacement } \\
\text { rate }(\mathrm{mm} / \mathrm{s})\end{array}$ & $\begin{array}{c}\mathrm{h}_{0} \\
(\mathrm{~mm})\end{array}$ & $\begin{array}{c}\dot{\varepsilon}_{S P}^{\max } \\
\left(\mathrm{s}^{-1}\right)\end{array}$ & $\begin{array}{c}\mathrm{F}_{\mathrm{e}} \\
(\mathrm{N})\end{array}$ & $\begin{array}{c}\mathrm{F}_{\mathrm{m}} \\
(\mathrm{N})\end{array}$ & $\begin{array}{c}\mathrm{v}_{\mathrm{e}} \\
(\mathrm{mm})\end{array}$ & $\begin{array}{c}\mathrm{v}_{\mathrm{m}} \\
(\mathrm{mm})\end{array}$ & $\begin{array}{c}\mathrm{v}_{\mathrm{f}} \\
(\mathrm{mm})\end{array}$ & $\begin{array}{c}\mathrm{E}_{\mathrm{SP}} \\
(\mathrm{J})\end{array}$ & $\begin{array}{c}\mathrm{E}_{\mathrm{m}} \\
(\mathrm{J})\end{array}$ & $\begin{array}{c}\mathrm{E}_{\mathrm{PL}} \\
(\mathrm{J})\end{array}$ \\
\hline HH-SP11 & 0.0012 & 0.50 & $1.21 \mathrm{E}-03$ & 449.1 & 2542.3 & 0.097 & 1.484 & 1.543 & 2.47 & 2.32 & 1.69 \\
HH-SP12 & 0.0013 & 0.50 & $1.27 \mathrm{E}-03$ & 460.1 & 2517.4 & 0.098 & 1.430 & 1.557 & 2.34 & 2.19 & 1.56 \\
HH-SP13 & 0.0012 & 0.50 & $1.23 \mathrm{E}-03$ & 417.1 & 2405.5 & 0.075 & 1.422 & 1.564 & 2.27 & 2.09 & 1.62 \\
HH-SP14 & 0.0012 & 0.50 & $1.24 \mathrm{E}-03$ & 416.2 & 2296.3 & 0.096 & 1.452 & 1.616 & 2.22 & 2.02 & 1.47 \\
HH-SP15 & 0.0012 & 0.48 & $1.24 \mathrm{E}-03$ & 371.7 & 2344.8 & 0.079 & 1.452 & 1.641 & 2.32 & 2.05 & 1.53 \\
HH-SP16 & 0.0012 & 0.50 & $1.22 \mathrm{E}-03$ & 443.1 & 2572.5 & 0.095 & 1.515 & 1.641 & 2.50 & 2.39 & 1.71 \\
HH-SP17 & 0.0012 & 0.50 & $1.20 \mathrm{E}-03$ & 435.4 & 2527.5 & 0.079 & 1.380 & 1.493 & 2.37 & 2.12 & 1.59 \\
HH-SP18 & 0.0012 & 0.50 & $1.22 \mathrm{E}-03$ & 436.6 & 2567.3 & 0.100 & 1.485 & & 2.53 & 2.31 & 1.60 \\
HH-SP19 & 0.0016 & 0.50 & $1.55 \mathrm{E}-03$ & 437.5 & 2489.1 & 0.091 & 1.328 & 1.462 & 2.43 & 2.27 & 1.67 \\
HH-SP20 & 0.0012 & 0.51 & $1.24 \mathrm{E}-03$ & 482.4 & 2648.8 & 0.090 & 1.473 & 1.734 & 2.70 & 2.40 & 1.81 \\
\hline
\end{tabular}




\section{Correlations with tensile properties}

Many empirical correlations between SP characteristic values and tensile properties have been published in the literature [17-33], mostly for steels.

To further qualify the experimental and analytical procedures developed at NIST for SP testing, we derived similar correlations for the three steels investigated (JRQ, 4340LL, and $4340 \mathrm{HH}$ ) and compared them to those proposed by other authors. In most cases, the relationships obtained for rough and polished specimens were clearly different.

Note that characteristic SP forces are typically used for correlations with yield and tensile strengths, while SP deflection or displacement values are correlated to total elongations. SP forces are normalized by specimen thickness, deflection/displacement, or a product of the two; SP deflections/displacements are used directly, or normalized by specimen thickness.

In the literature, SP energy values are only used to construct a transition curve by performing tests at different temperatures. The flexural point of the energy/temperature curve is then empirically correlated to the ductile-to-brittle transition temperature established from Charpy tests [31-32].

A summary of the correlations identified through a bibliographic search, mostly focused on the last 20 years of research, and those obtained by NIST is provided in Annex 3 .

\subsection{Yield strength correlations}

Most authors have linearly correlated yield strength $\left(R_{\mathrm{p} 02}\right)$ with the SP elastic-plastic transition force $\left(F_{\mathrm{e}}\right)$, normalized by the square of the initial specimen thickness $\left(h_{0}^{2}\right)$ [17-23]. Published values of the linear regression coefficients (slope $\alpha_{1}$ and intercept $\alpha_{2}$ ) for steels were found to fall within the following intervals:

- Slope: $\quad \alpha_{1}=0.382$ to 0.884 .

- Intercept $^{8}$ : $\alpha_{2}=-77.136$ to 149 .

For the three steels investigated, we obtained the following correlations:

$$
\begin{array}{ll}
R_{p 02}=0.546 \cdot \frac{F_{e}}{h_{0}^{2}}-35.7 & \text { for rough specimens, and } \\
R_{p 02}=0.538 \cdot \frac{F_{e}}{h_{0}^{2}}-52.2 & \text { for polished specimens. }
\end{array}
$$

The correlation coefficients $(r)^{9}$ are respectively 0.999 (Eq. 8) and 0.997 (Eq. 9).

If we set $\alpha_{2}=0$, we obtain:

$$
\begin{array}{ll}
R_{p 02}=0.528 \cdot \frac{F_{e}}{h_{0}^{2}} & \text { (rough specimens), and } \\
R_{p 02}=0.513 \cdot \frac{F_{e}}{h_{0}^{2}} & \text { (polished specimens), }
\end{array}
$$

with $r=1.000$ and $r=0.999$, respectively.

NIST and literature correlations are compared in Fig. 14.

\footnotetext{
${ }^{8}$ Several authors forced the linear correlation through the origin, i.e., set $\alpha_{2}=0$.

${ }^{9}$ We used Pearson correlation coefficient, $r$, as the quality index of the strength of the correlations.
} 


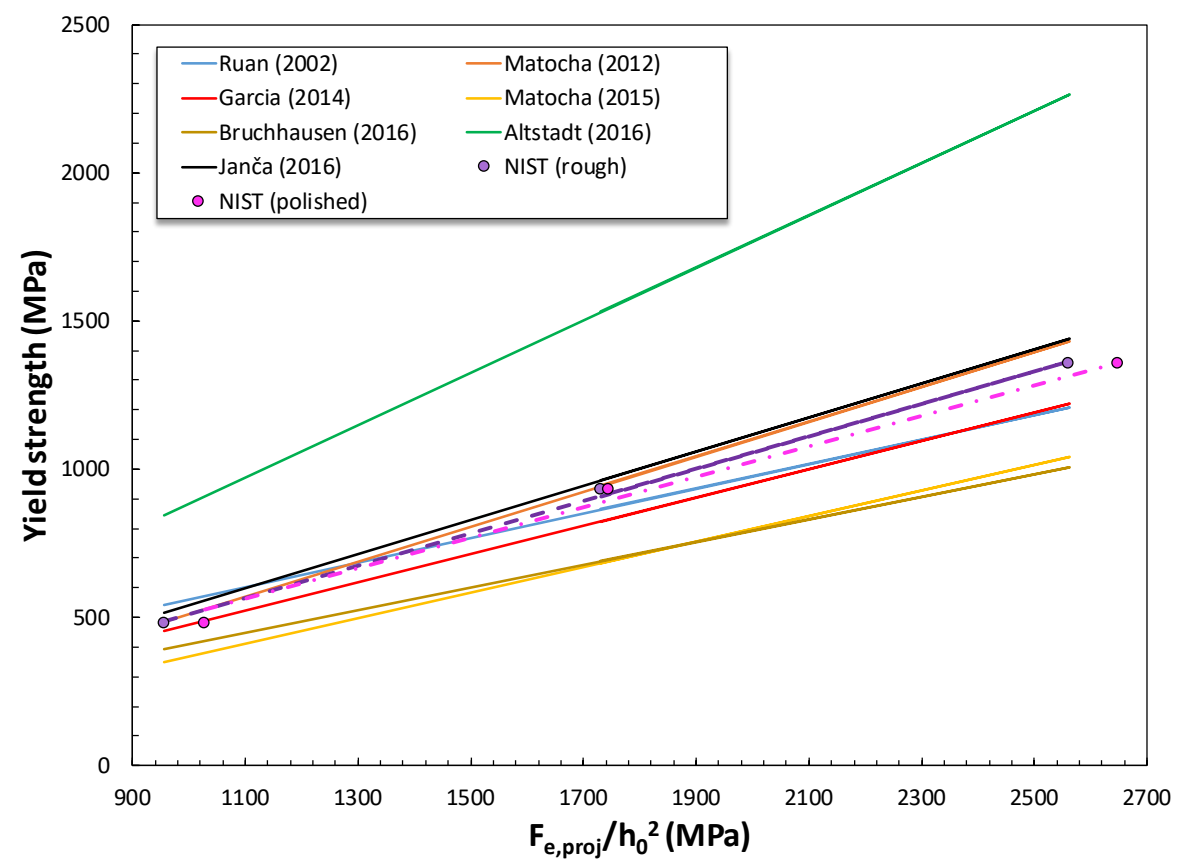

Figure 14 - Correlations between yield strength and SP elastic-plastic transition force. The purple dashed line is the linear fit to the rough specimen data, while the pink dash-dotted line is the linear fit to the polished specimen data.

In this case, results from rough and polished specimens are relatively close, and therefore it's reasonable to establish the following overall linear relationships:

$$
\begin{array}{ll}
R_{p 02}=0.541 \cdot \frac{F_{e}}{h_{0}^{2}}-42.2 & (r=0.997), \text { or } \\
R_{p 02}=0.520 \cdot \frac{F_{e}}{h_{0}^{2}} & (r=0.999) .
\end{array}
$$

Alternative correlations with the following normalized ${ }^{10} \mathrm{SP}$ forces were also proposed in the literature:

- $\quad F_{\mathrm{e}(\mathrm{int})}$ (corresponding to the value $f_{\mathrm{A}}$ in Fig. 12) [19],

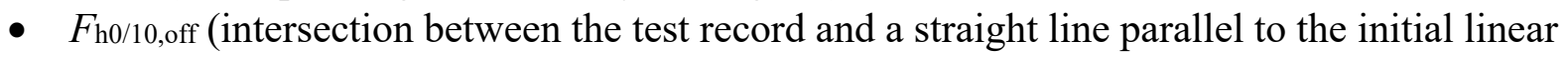
portion, with an offset of $h_{0} / 10 \approx 0.05 \mathrm{~mm}$ ) [19],

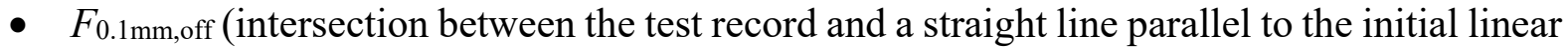
portion, with an offset of $0.1 \mathrm{~mm})[18,20]$,

- $\quad F_{\text {ept }}$ (force corresponding to the maximum curvature in the test record) [23], and

- $F_{\mathrm{e} 1.5}$ (force corresponding to a ratio between area below and above the test record equal to 1.5) [23].

An additional approach [30] is based on calculating a curvature parameter, $K$, for the SP force-displacement curve as:

$$
K=\frac{\left(F_{0.5 \mathrm{~mm}}-F_{0.1 \mathrm{~mm}}\right)-\left(F_{0.9 \mathrm{~mm}}-F_{0.5 \mathrm{~mm}}\right)}{F_{0.9 \mathrm{~mm}}-F_{0.1 \mathrm{~mm}}},
$$

${ }^{10}$ All forces are normalized by $h_{0}^{2}$. 
where $F_{0 . X m m}$ is the force on the SP test record that corresponds to a displacement value of $0 . \mathrm{X}$ $\mathrm{mm}(0 . \mathrm{X}=0.1,0.5$, or 0.9$)$. According to [30], the yield strength is given by:

$$
\begin{array}{ll}
R_{p 02}=(1.28 K-0.062) \frac{F_{0.5 \mathrm{~mm}}}{h_{0}^{2}} & \text { for } K<0.33, \\
R_{p 02}=0.36 \frac{F_{0.5 \mathrm{~mm}}}{h_{0}^{2}} & \text { for } K \geq 0.33 .
\end{array}
$$

Finally, Chica et al. [24] proposed an exponential correlation between $R_{\mathrm{p} 0.2}$ and the slope of the initial linear portion of the SP test record, Slope ini, normalized by $h_{0}$. For our tests on polished specimens (see Annex 3 for rough specimen data), we obtained:

$$
R_{p 02}=0.0059 \cdot e^{1.2913 \frac{\text { slope }_{\text {ini }}}{h_{0}}}
$$

The fitting coefficients in Eq. 17 can be compared with the values 47.41 and $1.736 \times 10^{-4}$ published in [24].

The following correlations were obtained by fitting our results on polished specimens (the results for rough specimens are reported in Annex 3) in accordance with the approaches mentioned above.

$$
\begin{array}{ll}
R_{p 02}=0.474 \cdot \frac{F_{e(i n t)}}{h_{0}^{2}} & (r=1.000) \\
R_{p 02}=0.362 \cdot \frac{F_{h 0 / 10, o f f}}{h_{0}^{2}} & (r=0.999) \\
R_{p 02}=0.296 \cdot \frac{F_{0.1 m m, o f f}}{h_{0}^{2}}+5.35 & (r=0.992) \\
R_{p 02}=0.236 \cdot \frac{F_{e p t}}{h_{0}^{2}}-284.8 & (r=0.699) \\
R_{p 02}=0.310 \cdot \frac{F_{e 1.5}}{h_{0}^{2}}+204.6 & (r=0.970) \\
R_{p 02}=0.206 \cdot \frac{F_{0.5 m m}}{h_{0}^{2}}-60.92 & (r=0.996)
\end{array}
$$

NIST correlations (for both rough and polished specimens) and literature correlations are compared in:

- Fig. 15 (Eq. 17),

- Fig. 16 (Eq. 18),

- Fig. 17 (Eq. 19),

- Fig. 18 (Eq. 20),

- Fig. 19 (Eq. 21),

- Fig. 20 (Eq. 22), and

- Fig. 21 (Eq. 23). 


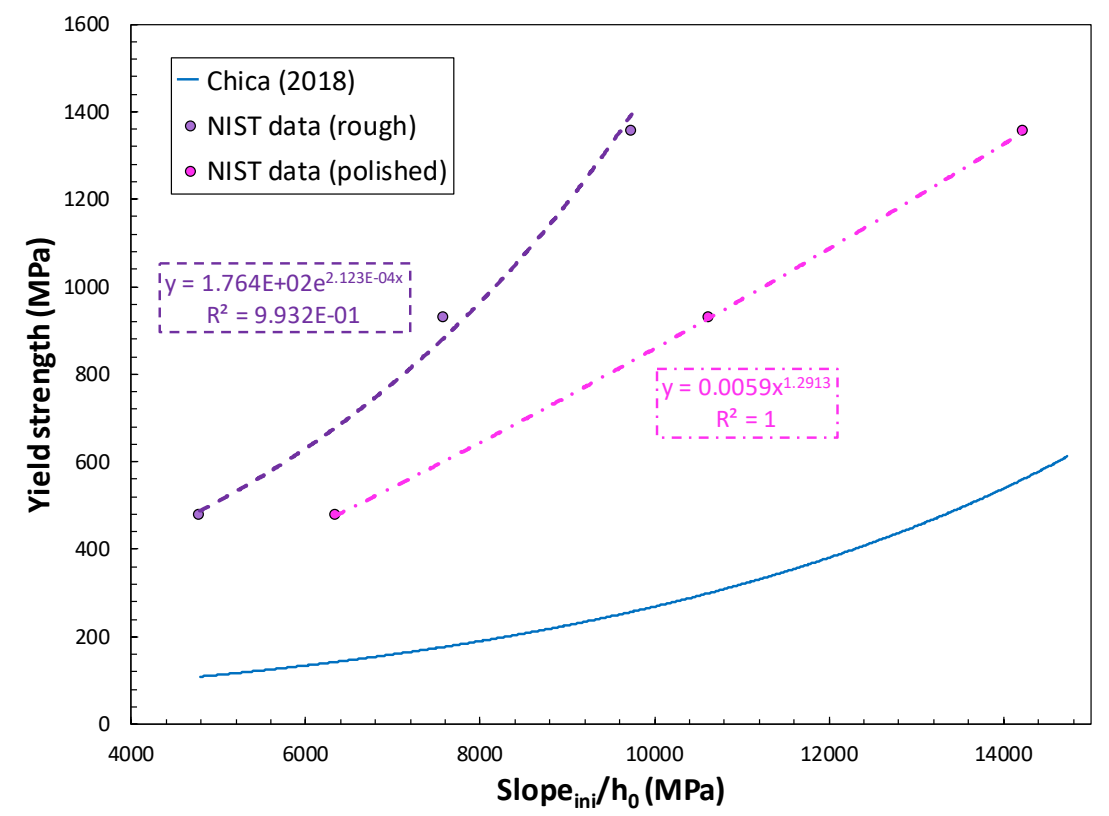

Figure 15 - Comparison between NIST results and the correlation in [24].

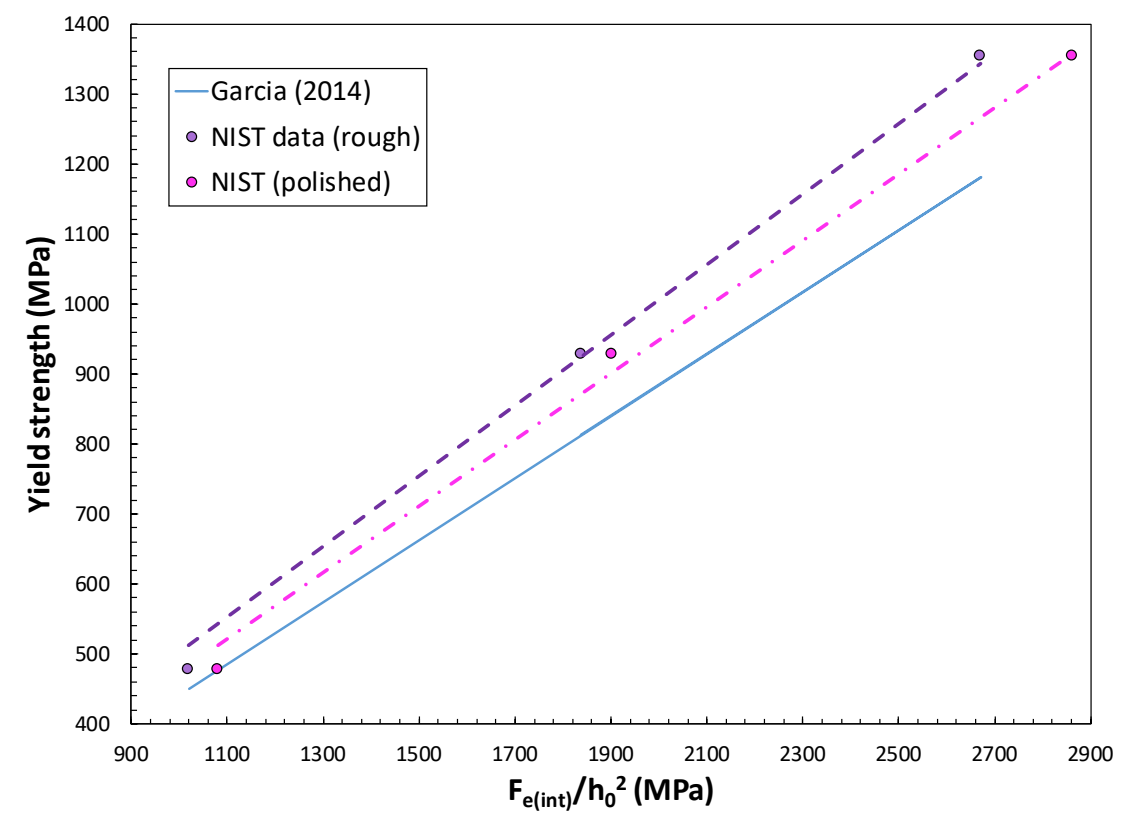

Figure 16 - Comparison between NIST results and the correlation in [19]. 


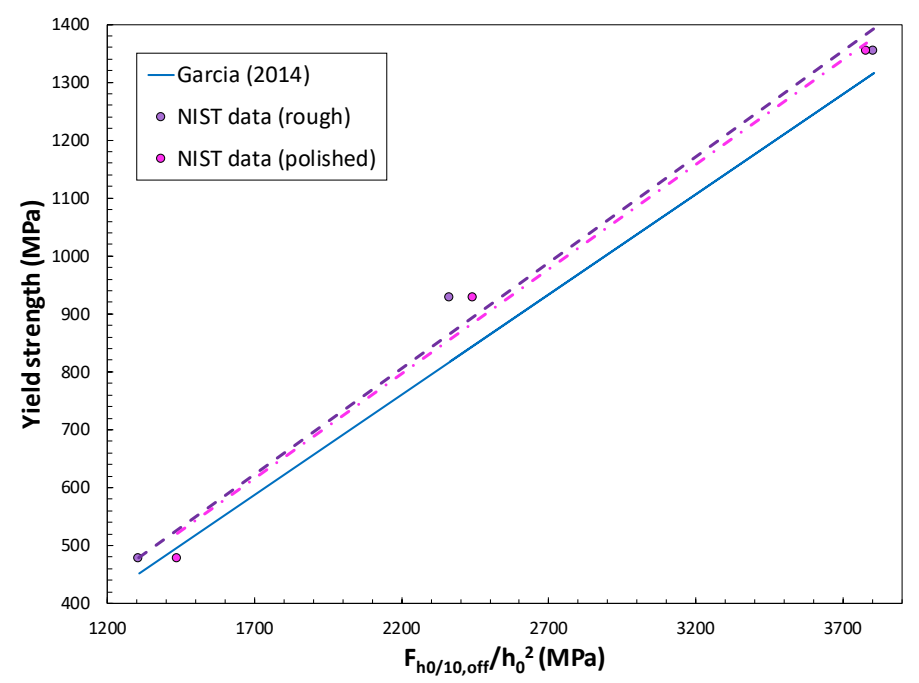

Figure 17 - Comparison between NIST results and the correlation in [19].

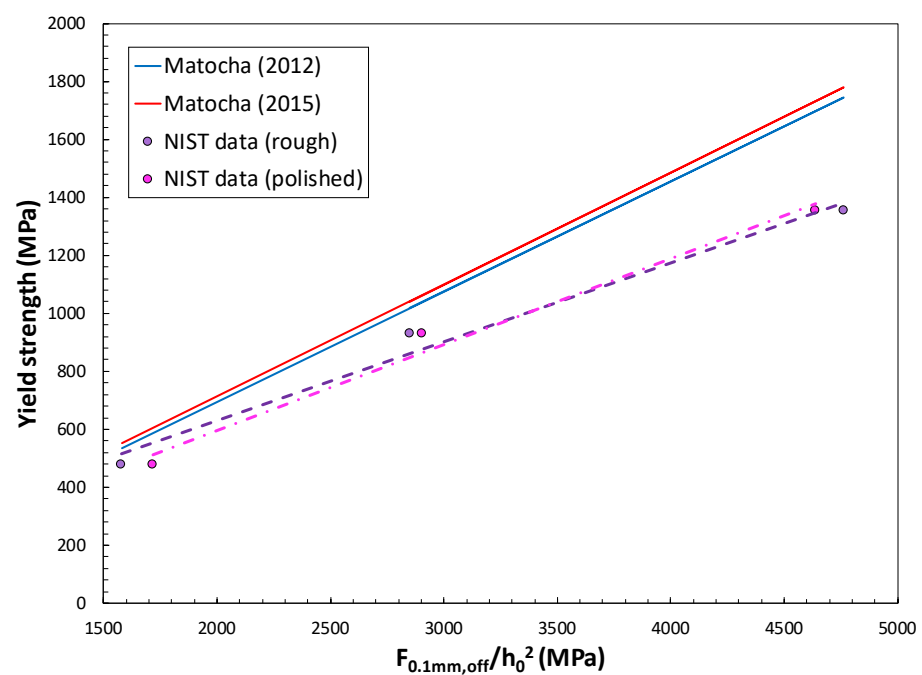

Figure 18 - Comparison between NIST results and the correlation in [18,20].

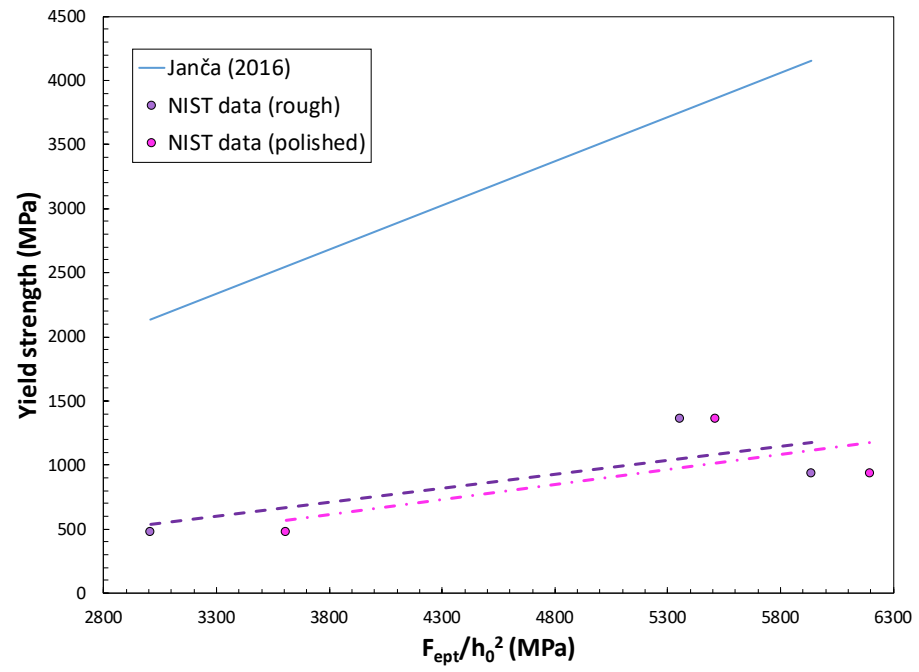

Figure 19 - Comparison between NIST results and the correlation in [23]. 


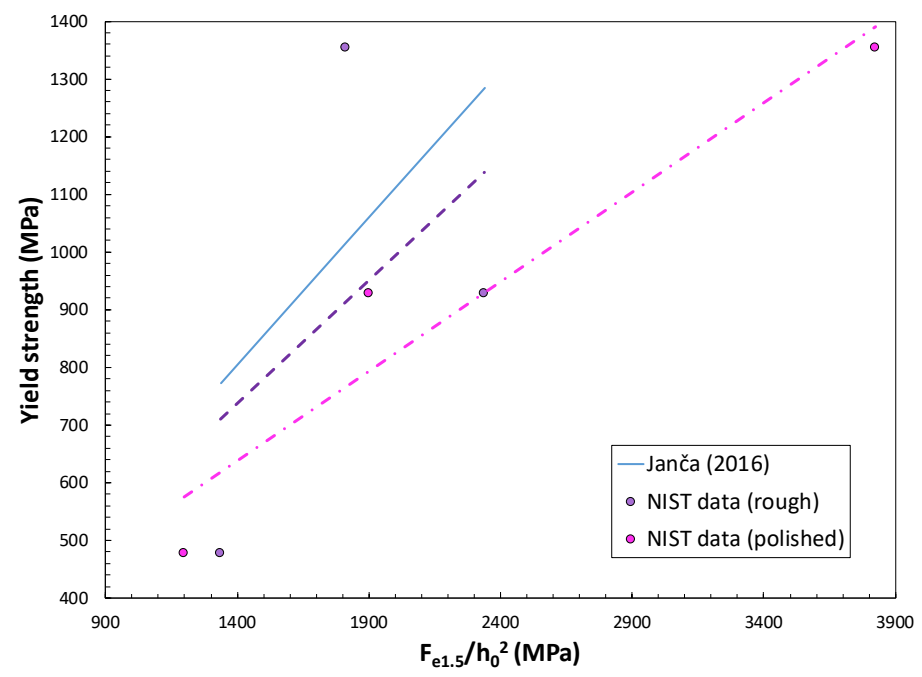

Figure 20 - Comparison between NIST results and the correlation in [23].

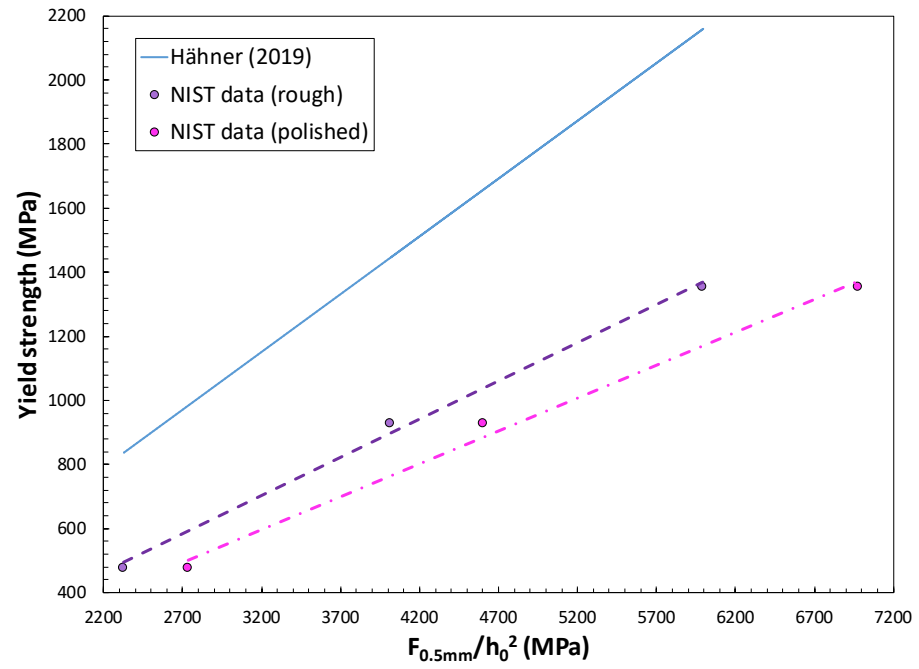

Figure 21 - Comparison between NIST results and the correlation in [30].

Our SP test results are in satisfactory agreement with the published models shown in Figs. 16, 17, and 18. Conversely, differences are significant with respect to the approaches illustrated in Figs. 15, 19, 20, and 21.

As far as the correlations with $F_{\text {ept }}$ (Fig. 19) and $F_{\text {e1.5 }}$ (Fig. 20) are concerned, the force values calculated from our tests showed significant scatter due to experimental noise, and are therefore associated to high uncertainties. The use of Eq. 22 and Eq. 23 is therefore not recommended.

\subsection{Tensile strength correlations}

Published correlations are split between authors who normalized $F_{\mathrm{m}}$ by the square of the initial thickness, $h_{0}^{2}[19,21,23]$, and those (the majority) who used the product between thickness and displacement at maximum force instead, $h_{0} \cdot u_{\mathrm{m}}[17-23,25]$. This latter approach appears justified by the observation that a significant specimen thinning has occurred at maximum force. 
Our results, shown in Fig. 22 and Fig. 24, fully confirm the higher reliability of the normalization by $h_{0} \cdot u_{\mathrm{m}}$. For normalization by $h_{0}^{2}$, the two empirical correlations we obtained:

$$
\begin{array}{ll}
R_{m}=0.266 \cdot \frac{F_{m}}{h_{0}^{2}}-855.61 & \text { for rough specimens, and } \\
R_{m}=0.152 \cdot \frac{F_{m}}{h_{0}^{2}}-228.73 & \text { for polished specimens }
\end{array}
$$

have mediocre correlation coefficients (0.644 and 0.530 , respectively), and are in poor agreement with similar models $[19,21,23]$.

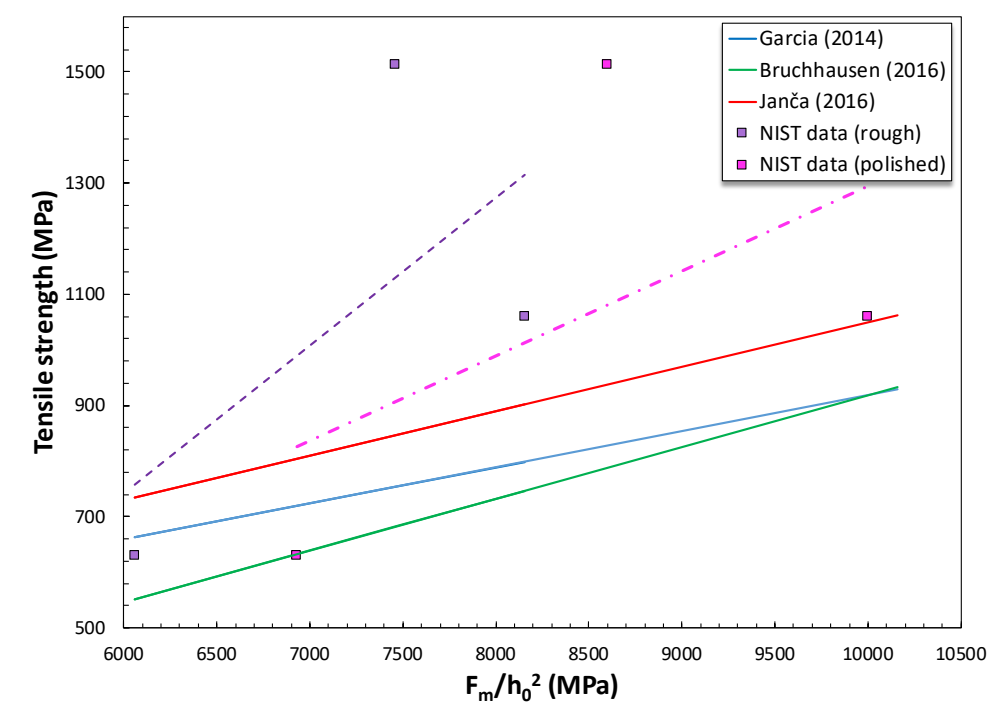

Figure 22 - Correlations between tensile strength and SP maximum force, normalized by $h_{0}^{2}$. The purple dashed line is the linear fit to the rough specimen data, while the pink dash-dotted line is the linear fit to the polished specimen data.

On the other hand, our correlations between tensile strength and $\frac{F_{m}}{h_{0} u_{m}}$ :

$$
\begin{array}{ll}
R_{m}=0.345 \cdot \frac{F_{m}}{h_{0} u_{m}}-42.84 & \text { for rough specimens, and } \\
R_{m}=0.302 \cdot \frac{F_{m}}{h_{0} u_{m}}+4.403 & \text { for polished specimens }
\end{array}
$$

show a very strong degree of correlation $(r=0.944$ and $r=1.000)$ and agree well with most of the published relationships [17-23,25] (Fig. 23). Published values of the coefficients of the linear regression (slope $\beta_{1}$ and intercept $\beta_{2}$ ) for steels were found to fall within the following intervals:

- Slope: $\quad \beta_{1}=0.077$ to 0.451 .

- Intercept $^{11}: \quad \beta_{2}=-195.78$ to 218 .

\footnotetext{
${ }^{11}$ Several authors forced the linear correlation through the origin, i.e., set $\beta_{2}=0$.
} 


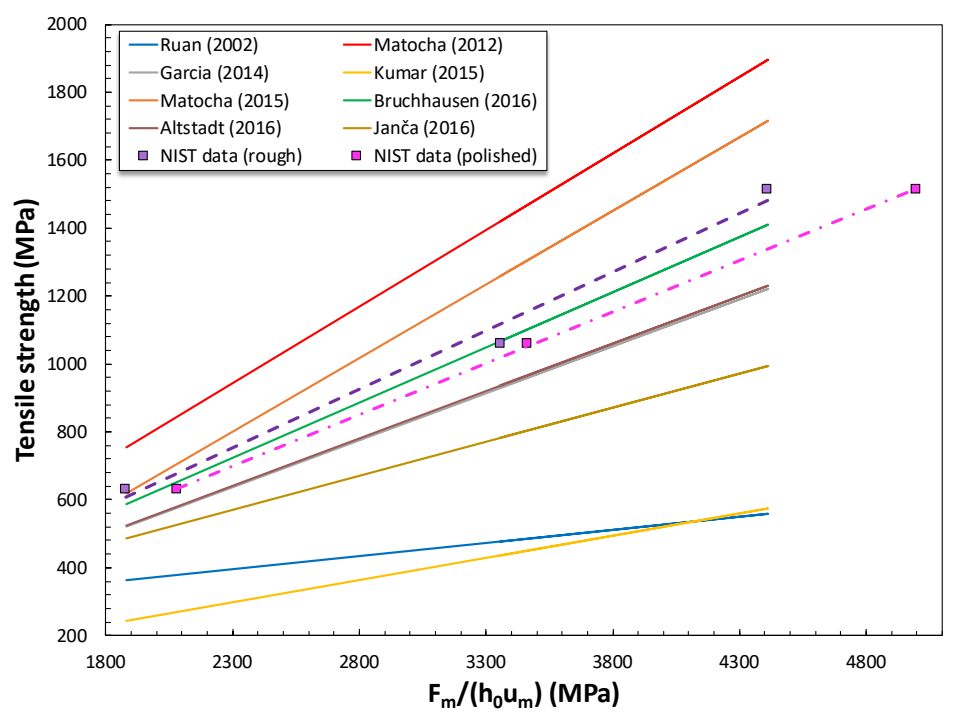

Figure 23 - Correlations between tensile strength and SP maximum force, normalized by $h_{0} u_{m}$.

Based on our literature search, the following additional SP forces were correlated with tensile strength in published papers:

- $F_{\text {infl }}$ (inflection point of the test record, where $\frac{d^{2} F}{d u^{2}}=0$ ), normalized by $h_{0} u_{m}$ [23],

- $F_{0.48 \mathrm{~mm}}$ (force corresponding to a punch displacement value of $0.48 \mathrm{~mm}$ ), normalized by $h_{0}^{2}[25]$, and

- $F_{0.65 \mathrm{~mm}}$ (force corresponding to a punch displacement value of $0.65 \mathrm{~mm}$ ), normalized by $h_{0}^{2}[23,26]$.

The following correlations were obtained by fitting our results on polished specimens (the results for rough specimens are reported in Annex 3) in accordance with the three approaches listed above.

$$
\begin{array}{ll}
R_{m}=0.541 \cdot \frac{F_{\text {infl }}}{h_{0} u_{m}}+142.58 & (r=1.000) \\
R_{m}=0.246 \cdot \frac{F_{0.48 \mathrm{~mm}}}{h_{0}^{2}}+84.83 & (r=0.998) \\
R_{m}=0.230 \cdot \frac{F_{0.65 \mathrm{~mm}}}{h_{0}^{2}}-59.9 & (r=0.998)
\end{array} .
$$

NIST correlations (for both rough and polished specimens) are compared to literature correlations in:

- Fig. 24 (Eq. 28),

- Fig. 25 (Eq. 29), and

- Fig. 26 (Eq. 30). 


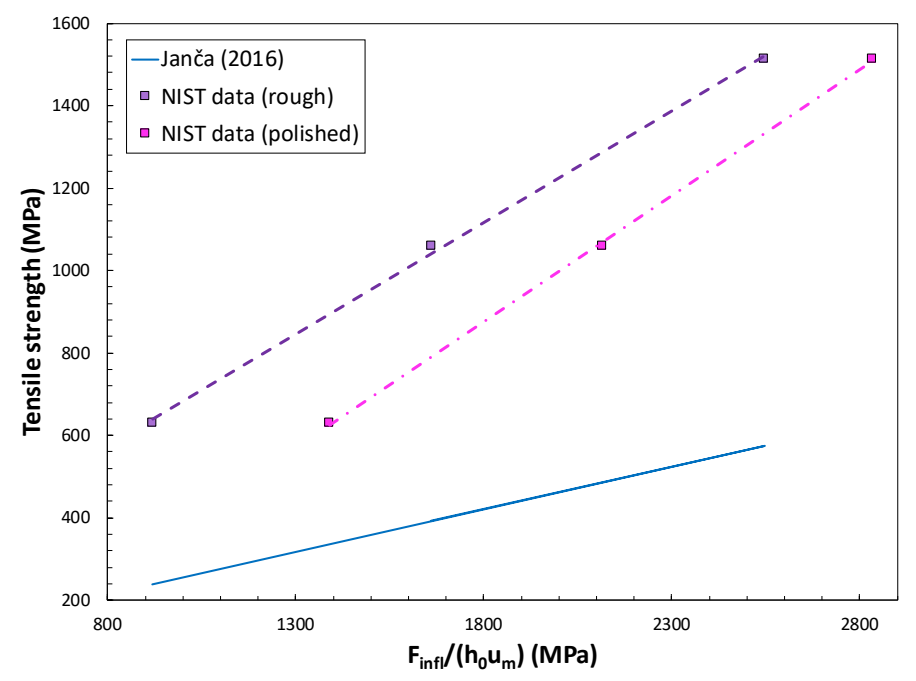

Figure 24 - Comparison between NIST results and the correlation in [23].

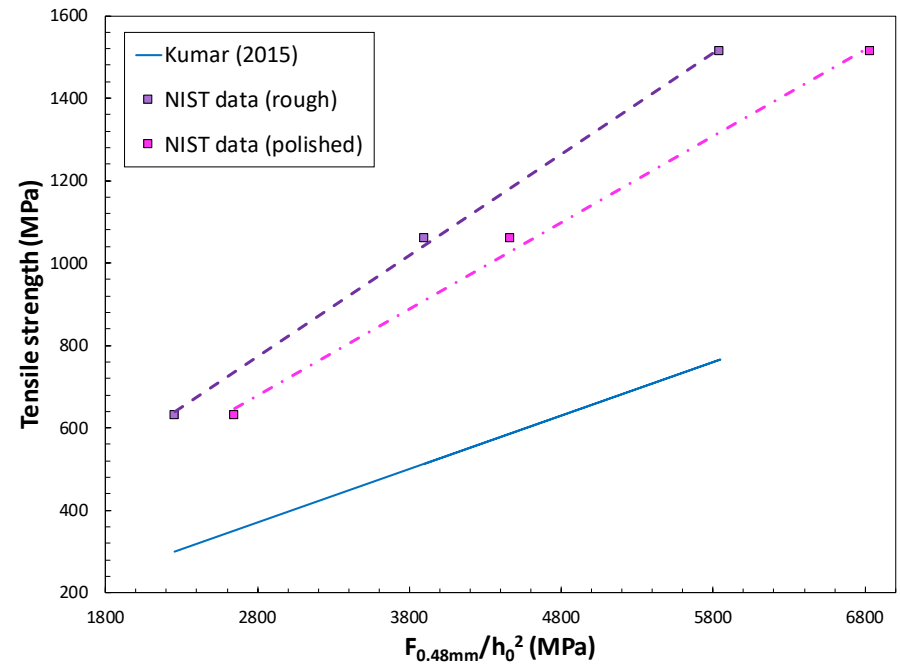

Figure 25 - Comparison between NIST results and the correlation in [25].

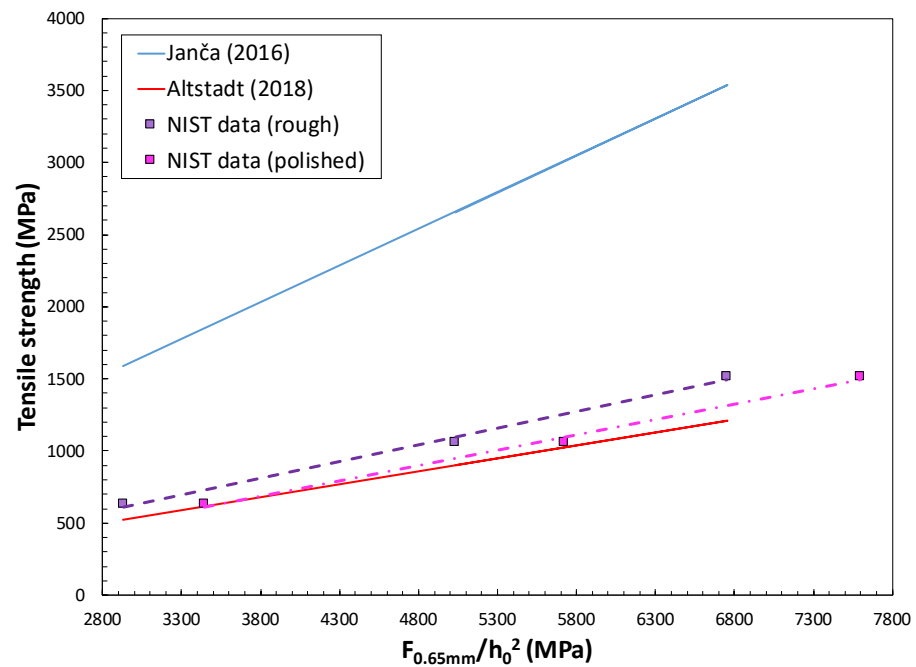

Figure 26 - Comparison between NIST results and the correlations in $[23,26]$. 
Another correlative approach [33] was proposed, based on normalizing $F_{\mathrm{m}}$ by (A + B $u_{\mathrm{m}}$ ), where A and B are least-squares regression coefficients. We obtained (Fig. 27):

$$
R_{m}=\frac{F_{m}}{0.885-815.35 \cdot u_{m}} \quad \text { for polished specimens }(r=0.589) \text {. }
$$

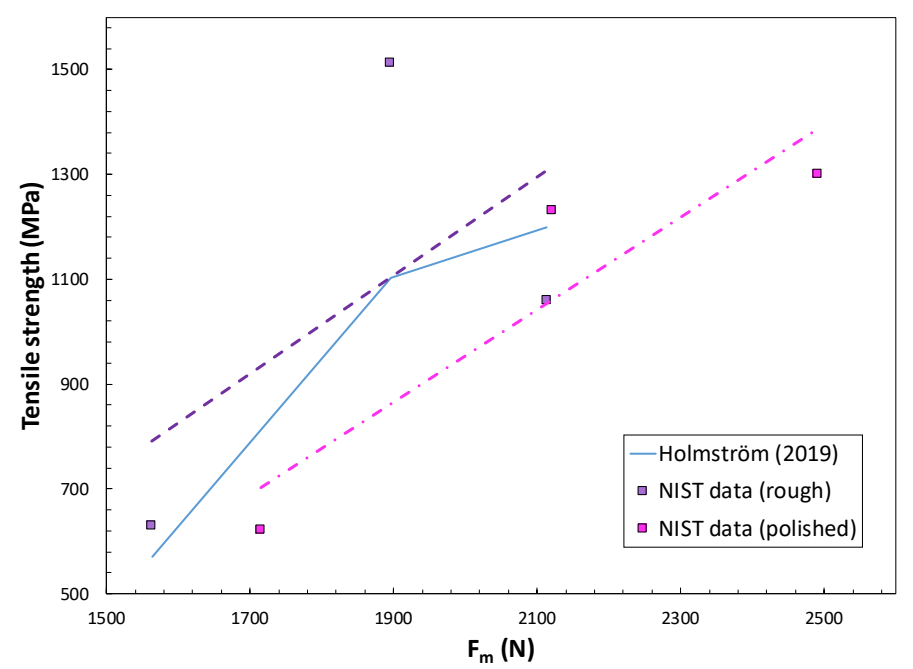

Figure 27 - Comparison between NIST results and the correlation in [33].

For all these alternative approaches, the agreement between our analyses and the literature is not satisfactory, with the exception of Altstadt's model [26] in Fig. 26.

\subsection{Total elongation correlations}

Our literature search identified three distinct empirical correlations for total elongation: the first $[19,27]$ simply converted displacement at maximum force, $u_{\mathrm{m}}$, into $\varepsilon$, the second $[19,28]$ used $u_{\mathrm{m}}$ normalized by the initial thickness $h_{0}$, and the third [29] established a linear regression of the form $\varepsilon_{t}=\omega_{1} \frac{u_{f}-h_{0}}{h_{0}}+\omega_{2}$, using punch displacement at test end, $u_{\mathrm{f}}$.

Our test results yielded the following correlations for polished specimens:

$$
\begin{aligned}
\varepsilon_{t} & =16.045 \cdot u_{m} & & (r=0.839) \\
\varepsilon_{t} & =7.22 \cdot \frac{u_{m}}{h_{0}} & & (r=0.836) \\
\varepsilon_{t} & =8.334 \cdot \frac{u_{f}-h_{0}}{h_{0}}+2.05 & & (r=0.959)
\end{aligned} .
$$

These correlations are compared to published relationships [19, 27-29] in Figs. 28-30. Note that most of the published correlations were established with measurements of specimen deflection, and therefore the comparisons shown in Figs. 28-30 are only qualitative. 


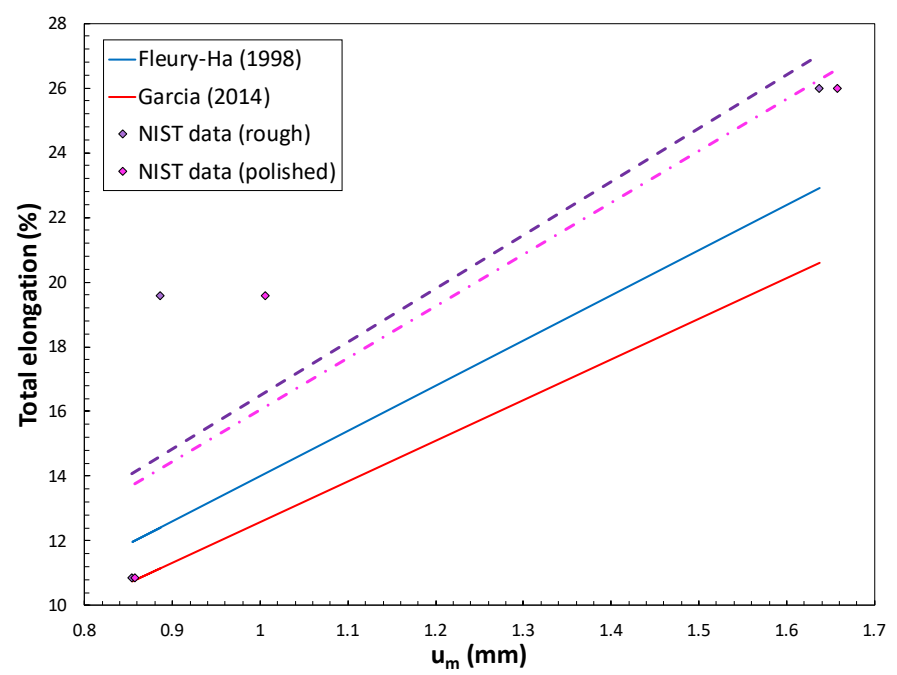

Figure 28 - Comparison between NIST results and the correlations in $[19,27]$ for $\varepsilon$ t.

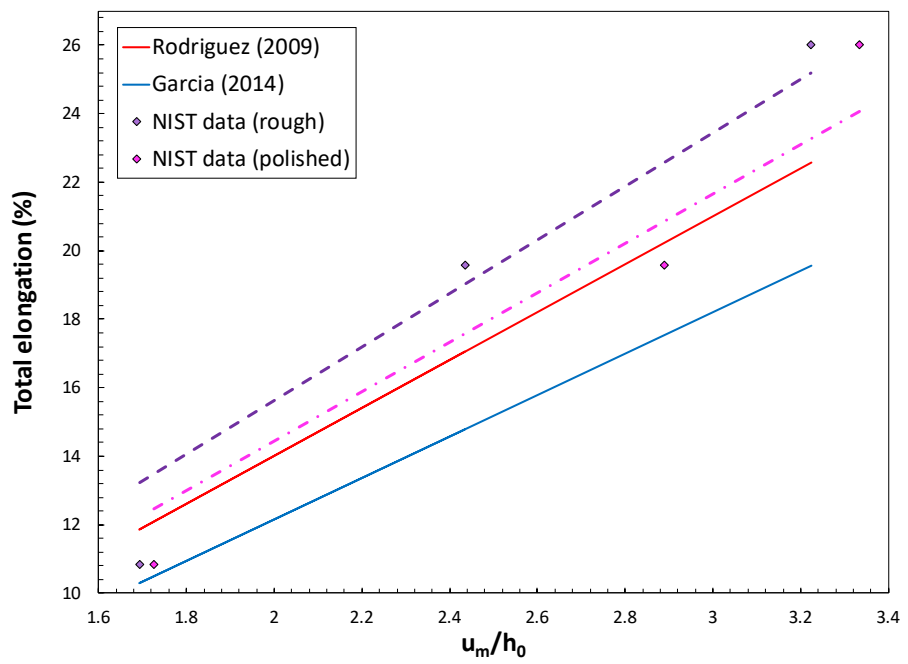

Figure 29 - Comparison between NIST results and the correlations in $[19,28]$ for $\varepsilon$ t.

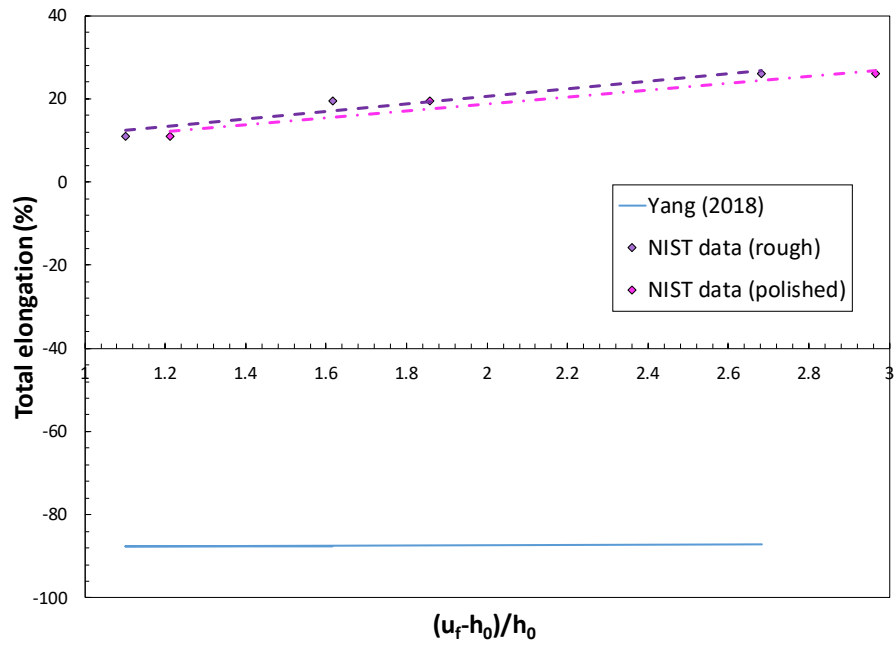

Figure 30 - Comparison between NIST results and the correlation in [29] for $\varepsilon$. 


\section{Additional correlations (not previously published)}

In this study, we also attempted to establish correlations between our SP test results and two other mechanical parameters, for which no relationships exist based on our bibliographic search: uniform elongation, $\varepsilon_{u}$, and Charpy absorbed energy, $K V$.

\subsection{Uniform elongation}

In the case of uniform elongation (which is calculated at maximum force), our correlations were established with $u_{\mathrm{m}}$ normalized by $h_{0}$ (Fig. 31):

$$
\begin{aligned}
\varepsilon_{u} & =6.276 \cdot \frac{u_{m}}{h_{0}}-7.55 & & \text { for rough specimens, and } \\
\varepsilon_{u} & =5.380 \cdot \frac{u_{m}}{h_{0}}-6.43 & & \text { for polished specimens. }
\end{aligned}
$$

The correlation coefficients are 0.976 for Eq. 35 and 0.968 for Eq. 36, showing in both cases a strong degree of linear correlation.

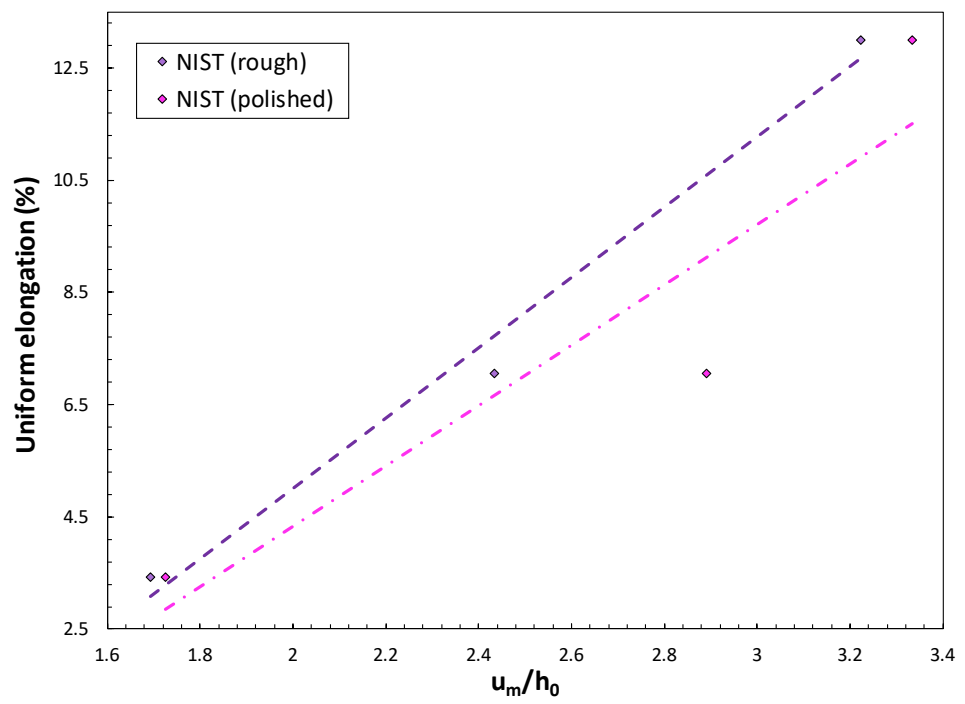

Figure 31 - Correlations between uniform elongation and $\frac{u_{m}}{h_{0}}$ obtained at NIST.

\subsection{Charpy absorbed energy}

For rough specimens, the strongest correlation with $K V$ was obtained with $E_{\mathrm{PL}}$ ( $r=$ 0.924):

$$
K V=522.90 \cdot E_{P L}-354.1,
$$

but the correlations with $E_{\mathrm{SP}}$ and $E_{\mathrm{m}}$ are also fairly strong $(r=0.785$ and $r=0.834$, respectively). More details can be found in Annex 3.

In the case of polished specimens, the strongest linear relationship was found between $K V$ and $E_{\mathrm{SP}}(r=0.956)$ :

$$
K V=289.21 \cdot E_{P L}-438.8,
$$

while the remaining two are poor ( $r=0.484$ for $K V$ vs. $E_{\mathrm{m}}$ and $r=0.436$ for $K V$ vs. $\left.E_{\mathrm{PL}}\right)$.

The two correlations (Eqs. 37 and 38) are illustrated in Fig. 32. 


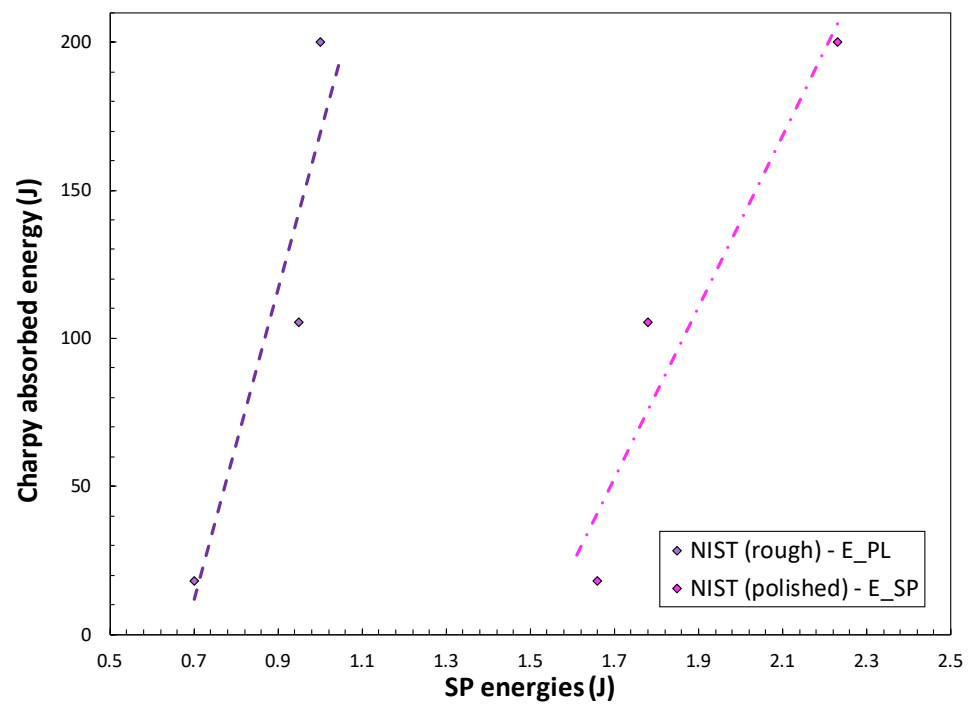

Figure 32 - Correlations between Charpy absorbed energy and SP energies for rough and polished specimens.

\section{Discussion: effect of specimen surface finish}

In order to assess the influence of surface finish on the results of SP tests, we ran twosample t-tests [34] on the mean values of selected SP characteristic values $\left(F_{\mathrm{e}}, F_{\mathrm{m}}, u_{\mathrm{e}}, u_{\mathrm{m}}, u_{\mathrm{f}}\right.$, and $\left.E_{\mathrm{SP}}\right)$ obtained from rough $(R a=3 \mu \mathrm{m}$ to $4 \mu \mathrm{m})$ and polished $(R a=0.05 \mu \mathrm{m}$ to $0.25 \mu \mathrm{m})$ specimens. Specifically, we statistically tested the null hypothesis that the means for rough and polished specimens are equal $\left(t_{\text {calc }}<t_{\text {critical }}\right)$.

The results of the t-tests for the three steels are summarized in Table 11.

Table 11 - Influence of specimen surface finish on SP test results: results of two-sample t-tests on means ${ }^{12}$ of characteristic parameters.

\begin{tabular}{|c|c|c|c|c|c|c|c|}
\hline Steel & $\begin{array}{l}\text { Surface } \\
\text { finish }\end{array}$ & $\begin{array}{c}F_{\mathrm{e}, \text { mean }} \\
(\mathbf{N})\end{array}$ & $\begin{array}{c}F_{\mathrm{m}, \text { mean }} \\
(\mathbf{N})\end{array}$ & $\begin{array}{r}u_{\mathrm{e}, \text { mean }} \\
(\mathbf{m m})\end{array}$ & $\begin{array}{c}u_{\mathrm{m}, \mathrm{mean}} \\
(\mathbf{m m})\end{array}$ & $\begin{array}{l}u_{\mathrm{f}, \text { mean }} \\
(\mathbf{m m})\end{array}$ & $\begin{array}{c}E_{\mathrm{SP}, \text { mean }} \\
(\mathbf{J})\end{array}$ \\
\hline \multirow{5}{*}{ JRQ } & Rough & 247.0 & 1563.3 & 0.113 & 1.637 & 1.870 & 1.87 \\
\hline & Polished & 257.7 & 1742.1 & 0.086 & 1.657 & 1.971 & 2.27 \\
\hline & $t_{\text {calc }}$ & 1.21 & 18.17 & 2.94 & 1.04 & 3.63 & 11.13 \\
\hline & $t_{\text {critical }}$ & 2.06 & 2.06 & 2.06 & 2.06 & 2.06 & 2.06 \\
\hline & Different? & NO & YES & YES & NO & YES & YES \\
\hline \multirow{5}{*}{ 4340LL } & Rough & 651.3 & 1896.1 & 0.141 & 0.854 & 1.059 & 1.41 \\
\hline & Polished & 652.7 & 2121.2 & 0.100 & 0.857 & 1.098 & 1.66 \\
\hline & $\mathrm{t}_{\text {calc }}$ & 0.05 & 9.19 & 4.71 & 0.14 & 1.48 & 4.67 \\
\hline & $t_{\text {critical }}$ & 2.11 & 2.11 & 2.11 & 2.11 & 2.11 & 2.11 \\
\hline & Different? & $\mathrm{NO}$ & YES & YES & $\mathrm{NO}$ & $\mathrm{NO}$ & YES \\
\hline \multirow{5}{*}{$4340 \mathrm{HH}$} & Rough & 448.6 & 2113.2 & 0.124 & 1.239 & 1.331 & 1.63 \\
\hline & Polished & 434.9 & 2491.2 & 0.090 & 1.442 & 1.583 & 2.42 \\
\hline & $t_{\text {calc }}$ & 1.08 & 10.32 & 7.16 & 7.44 & 7.94 & 14.00 \\
\hline & $t_{\text {critical }}$ & 2.10 & 2.10 & 2.10 & 2.10 & 2.11 & 2.10 \\
\hline & Different? & $\mathrm{NO}$ & YES & YES & YES & YES & YES \\
\hline
\end{tabular}

${ }^{12}$ If $t_{\text {calc }}>t_{\text {critical }}$, the means of the two populations are statistically different (at a significance level $\alpha=0.05$ ). 
Based on the results of the t-tests, specimen surface finish does not have a significant influence on elastic-plastic transition forces, but does affect significantly maximum forces, displacements at elastic-plastic transition, and fracture energies for all the steels considered. The effect is particularly strong on $F_{\mathrm{m}}$ and $E_{\mathrm{SP}}\left(\mathrm{t}_{\text {calc }}>>\mathrm{t}_{\text {critical }}\right)$, with lower surface roughness leading to significantly higher values of force and energy. The results are less clear-cut for the remaining parameters ( $u_{\mathrm{e}}$ and $u$ ), where the influence of surface finish seems to depend on the material.

\section{Conclusions}

The Small Punch test technique was developed at NIST to investigate the mechanical properties of metallic materials through the use of a minimal amount of material. This technique was successfully qualified by running tests on three steels (A533B and 4340 with two distinct heat treatments) spanning a large range of tensile and fracture properties (Table 2).

NIST SP test results on the JRQ (A533B) steel were successfully compared to data collected in an international round-robin that was conducted in 2017 in support of the development of an ASTM Test Method.

Empirical correlations were established between SP characteristic parameters (forces and punch displacements) and tensile properties (yield and ultimate tensile strengths, uniform and total elongations) for the three steels investigated. Most of the relationships obtained showed a strong degree of linear correlation and were found to be in satisfactory agreement with published empirical correlations.

Finally, we studied the effect of specimen surface finish on SP results, by testing "rough" $(\mathrm{Ra}=3 \mu \mathrm{m}$ to $4 \mu \mathrm{m})$ and "polished" $(\mathrm{Ra}=0.05 \mu \mathrm{m}$ to $0.25 \mu \mathrm{m})$ samples. A lower surface roughness yielded statistically higher values of most SP characteristic parameters, particularly at maximum force and in terms of energy. Conversely, elastic-plastic transition forces were substantially independent of surface finish for the materials and conditions investigated. Moreover, relationships from polished specimens exhibited generally higher degrees of correlation than those from rough specimens, therefore supporting the requirement $R a<0.25 \mu \mathrm{m}$ in $[10,11]$.

\section{References}

[1] Lucon, E., 2014, “Testing of Small-Sized Specimens," Comprehensive Materials Processing. C. J. Van Tyne, ed., Elsevier Ltd., Vol. 1, pp. 135-163.

[2] Harling, O. K., Lee, M., Sohn, D.-S., Kohse, G., and Lau, C. W., 1986, "The MIT Miniaturised Disc Bend Test," The Use of Small-Scale Specimens for Testing Irradiated Material, ASTM STP 888. W. R. Corwin, and G. E. Lucas, eds., ASTM, Philadelphia, PA, pp. 50-65.

[3] Manahan, M. P., Browning, A. E., Argon, A. S., and Harling, O. K., 1986, "Miniaturised Disc Bend Test Technique Development and Application," The Use of Small-Scale Specimens for Testing Irradiated Material, ASTM STP 888. W. R. Corwin, and G. E. Lucas, eds., ASTM, Philadelphia, PA, pp. 17-49.

[4] Hankin, G. L., Toloczko, M. B., Hamilton, M. L., Garner, F. A., and Faulkner, R. G., 1998, "Validation of the Shear Punch - Tensile Correlation Technique Using Irradiated Materials," Journal of Nuclear Materials, 258-263, pp. 1651-1656. 
[5] Bicego, V., Lucon, E., and Sampietri, C., 1998, "The 'Small Punch' Technique for Evaluating Quasi Non-Destructively the Mechanical Properties of Steels." In Fracture from Defects, ECF 12: Proceedings of the Twelfth European Conference on Fracture. M. W. Brown, E. R. de los Rios, K. J. Miller, eds., EMAS Publishing, London, Vol. 1, pp 1273-1278.

[6] Sainte-Catherine, C., Messier. J., Poussard, C., Rosinski, S., and Foulds, J., 2002, "Small Punch Test: EPRI-CEA Finite Element Simulation Benchmark and Inverse Method for the Estimation of Elastic Plastic Behavior," in Small Specimen Test Techniques: Fourth Volume, ASTM STP 1418, M. A. Sokolov, J. D. Landes, and G. E. Lucas, Eds., ASTM International, West Conshohocken, PA, pp. 350-370.

[7] Abendroth, M. and Kuna, M., "Determination of Deformation and Failure Properties of Ductile Materials by Means of the Small Punch Test and Neural Networks," Computational Materials Science, Vol 28, 2003, pp. 633-644.

[8] Abendroth, M. and Kuna, M., 2004, "Determination of Ductile Material Properties by Means of the Small Punch Test and Neural Networks," Advanced Engineering Materials, Vol 6, No. 7, 2004, pp. 536-540.

[9] Kuna, M. and Abendroth, M., 2012, "Identification and Validation of Ductile Damage Parameters by the Small Punch Test," in Proceedings of the $2^{\text {nd }}$ International Conference SSTT, Determination of Mechanical Properties of Materials by Small Punch and Other Miniature Testing Techniques, Oct 2-4. 2012, Ostrava, Czech Republic, Ocelot Publ., ISBN 978-80-260-0079-2, pp. 4-18.

[10] CEN Workshop Agreement, CWA 15627:2007, "Small Punch Test Method for Metallic Materials," European Committee for Standardization, Brussels, Belgium.

[11] ASTM Subcommittee E10.02, 2019, "Standard Test Method for Small Punch Testing of Metallic Materials," Work Item WK61832, Version 01/29/19.

[12] International Atomic Energy Agency, 2001, "Reference manual on the IAEA JRQ correlation monitor steel for irradiation damage studies," IAEA, Vienna, Austria.

[13] Brumovski, M. and Kopriva, R., 2018, "Interlaboratory Study for Small Punch Testing Preliminary Results," Proceedings of the ASME 2018 Pressure Vessels and Piping Conference, PVP2018, July 15-20, 2018, Prague, Czech Republic.

[14] McCowan, C.N., Siewert, T.A., and Vigliotti, D.P., 2003, "Charpy verification program: reports covering 1989-2002,” NIST Technical Note 1500-9, Materials Reliability Series.

[15] Lucon, E., 2016, "Estimating dynamic ultimate tensile strength from instrumented Charpy data," Materials \& Design, Volume 97, pp. 437-443.

[16] Lucon, E., 2019, "Use and Validation of the Slope Determination by the Analysis of Residuals (SDAR) Algorithm,” NIST Technical Note 2050.

[17] Ruan, Y., Spätig, P., and Victoria, M., 2002, "Assessment of mechanical properties of the martensitic steel EUROFER97 by means of punch tests," Journal of Nuclear Materials, 307-311, pp. 236-239.

[18] Matocha, K., 2012, "Determination of actual tensile and fracture characteristics of critical components of industrial plants under long term operation by SPT," Proceedings of the ASME 2012 Pressure Vessels \& Piping Conference, PVP2012, Toronto, Canada, July 15-19, ASME Paper No. PVP2012-78553.

[19] García, T.E., Rodríguez, C., Belzunce, F.J., and Suárez, C., 2014, "Estimation of the mechanical properties of metallic materials by means of the small punch test," 
Journal of Alloys and Compounds, 582, pp. 708-717.

[20] Matocha, K., 2015, "Small-Punch Testing for Tensile and Fracture Behavior: Experiences and Way Forward," Small Specimen Test Techniques: $6^{\text {th }}$ Volume, ASTM STP 1576. M. A. Sokolov and E. Lucon, eds., West Conshohocken, PA, pp. $145-159$.

[21] Bruchhausen, M., Holmström, S., Simonovski, I., Austin, T., Lapetite, J.-M., Ripplinger, J.-M., and de Haan, F., 2016, "Recent developments in small punch testing: Tensile properties and DBTT," Theoretical and Applied Fracture Mechanics, 86, pp. 2-10.

[22] Altstadt, E., Ge, H.E., Kuksenko, V., Serrano, M., Houska, M., Lasan, M., Bruchhausen, M., Lapetite, and Dai, Y., 2016, "Critical evaluation of the small punch test as a screening procedure for mechanical properties," Journal of Nuclear Materials, 472, pp. 186-195.

[23] Janča, A., Siegl, J., and Haušild, P., 2016, "Small punch test evaluation methods for material characterization," Journal of Nuclear Materials, 481, pp. 201-213.

[24] Chica, J.C., Díez, P.M.B., and Calzada, M.P., 2018, "Development of an improved correlation method for the yield strength of steel alloys in the small punch test." Proceedings of $5^{\text {th }}$ International Small Sample Test Techniques, SSTT2018, Swansea University, UK, July 10-12, 2018, Ubiquity Proceedings.

[25] Kumar, K., Pooleery, A., Madhusoodanan, K., Singh, R.N., Chakravartty, J.K., Shriwastaw, R.S., Dutta, B.K., and Sinha, R.K., 2015, "Evaluation of ultimate tensile strength using Miniature Disk Bend Test," Journal of Nuclear Materials, 461, pp. 100-111.

[26] Altstadt, E., Houska, M., Simonovski, I., Bruchhausen, M., Holmström, S., and Lacalle, R., 2018, "On the estimation of ultimate tensile stress from small punch testing," International Journal of Mechanical Sciences, 136, pp. 85-93.

[27] Fleury, E. and Ha, J.S., 1998, "On the estimation of ultimate tensile stress from small punch testing," International Journal of Pressure Vessels and Piping, 75, pp. 699706.

[28] Rodriguez, C., Garcia Cabezas, J., Cardenas, E., Belzunce, F. J., and Betegon, C., 2009, "Mechanical Properties Characterization of Heat-Affected Zone Using the Small Punch Test," Welding Research, Vol. 88, pp. 188-s-192-s.

[29] Yang, S., Ling, X., and Peng, D., 2018, "Elastic and plastic deformation behavior analysis in small punch test for mechanical properties evaluation," Journal of Central South University, 25(4), pp. 747-753.

[30] Hähner, P., Soyarslan, C., Gülçimen Çakan, B., and Bargmann, S., 2019, "Determining tensile yield stresses from Small Punch tests: A numerical-based scheme," Material and Design, 182, 107974.

[31] Contreras, M.A., Rodríguez, C., Belzunce, F. J., and Betegón, C., 2008, "Use of the small punch test to determine the ductile-to-brittle transition temperature of structural steels," Fatigue \& Fracture of Engineering Materials \& Structures.

[32] Matocha, K. 2015, "Small Punch Testing for Tensile and Fracture Behavior: Experiences and Way Forward," Small Specimen Test Techniques: $6^{\text {th }}$ Volume. STP 1576, Mikhail Sokolov and Enrico Lucon, Eds. ASTM International, West Conshohocken, PA, pp. 145-159. 
[33] Holmström, S., Simonovski, I., Baraldi, D., Bruchhausen, M., Altstadt, E., Delville, R., 2019, "Developments in the estimation of tensile strength by small punch testing," Theoretical and Applied Fracture Mechanics, Volume 101, pp. 25-34.

[34] NIST/SEMATECH e-Handbook of Statistical Methods, http://www.itl.nist.gov/div898/handbook/, update April 2012. 


\section{Annex 1}

\section{Operational Procedure for Performing Small Punch Tests at NIST in Boulder, Colorado}


This Operational Procedure implies the use of the MTS servo-hydraulic 858 Mini Bionix II machine ${ }^{13}$, equipped with a $5 \mathrm{kN}$ calibrated load cell, for Small Punch testing, along with an Epsilon extensometer for measuring punch displacement. Additionally, the MTS TestStar IIs Station Manager, Version 4.0, should be used to operate the machine.

In "Station Manager":

- Select Project: Project 1

- Open Station: Basic (5 kN Load Cell)

- Open Procedure: smallpunch.000.

\section{Pre-Test Operations}

1. Turn on high pressure for the pumps (HPS1, HSM1).

2. In the "Manual Command" window, check that manual command is enabled, then select (actuator) displacement control.

3. Enter $25 \mathrm{~mm}$ as the value of displacement, thus making the actuator rise.

4. Insert snugly the SP specimen into the lower die. If burrs are present that prevent complete introduction of the specimen, remove them by the use of sand paper.

5. Place the upper die onto the lower die, and hand-tighten the four screws.

6. Drop the steel ball into the hole on the top of the upper die.

7. Place the steel rod into the hole, on top of the steel ball.

8. Place the whole fixture in the machine, by inserting the rod into the hole of the upper machine thread, and holding it manually in place.

9. In the "Manual Command" window, enter $5 \mathrm{~mm}$ as displacement, then slowly approach the SP fixture to the lower machine plate by clicking on the left slider bar until the top of the rod is very close to the bottom of the hole in the upper machine thread. At the very end of the process, click on the left arrow to achieve smaller displacements and avoid accidentally overloading the specimen.

10. Tighten the whole setup by turning clockwise the upper machine thread until a force in the range $-15 \mathrm{kN}$ to $-30 \mathrm{kN}$ is attained (check the force in the window "Meters").

11. In the window "Signal Auto Offset", zero Axial Displacement.

12. Approach the extensometer to its working position, and take the safety pin out. Verify that in the window "Meters 1", the last two digits of the extensometer signal keep changing. NOTE: if the digits do not change, the extensometer may be out of range and no signal will be recorded. If that is the case. adjust the extensometer until you see variation in the last two digits of the signal.

${ }^{13}$ Certain commercial equipment, instruments, or materials are identified in this document in order to specify the experimental procedure adequately. Such identification is not intended to imply recommendation or endorsement by the National Institute of Standards and

Technology, nor is it intended to imply that the materials or equipment identified are necessarily the best available for the purpose. 
13. In the window "Signal Auto Offset", zero Extensometer.

14. Input the specimen name/id in Station Manager.

15. Uncheck manual command in the window "Manual Command".

\section{Test Operations}

1. Click the big white arrow in Station Manager.

2. Input all the test information in the "Procedure / User Input" window.

3. After clicking OK, the test starts and the Force-Displacement and Force-Extensometer plots are visualized. NOTE: force, displacement, and extensometer values will be plotted with their actual sign (negative for compression tests).

\section{Post-Test Operations}

1. Once the test is finished (the red square in Station Manager is highlighted), click "New Specimen". The two plots close.

2. In the "Manual Command" window, select manual command and (actuator) displacement control.

3. Move the extensometer away from the actuator and put the safety pin back in place.

4. In the "Manual Command" window, enter $25 \mathrm{~mm}$ as the value of displacement, making the actuator rise.

5. Remove the assembly/fixture from the machine.

6. Extract the rod from the fixture.

7. Disassemble upper and lower die by unscrewing and removing the 4 screws.

8. Take the ball out and store it.

9. Remove the specimen.

\section{End of Testing Operations}

Turn the pumps off (HPS1, HSM1). 


\section{Annex 2}

\section{Spreadsheet-Based Software for the Analysis of a Small Punch Test}


The analyses of Small Punch tests in this study were performed by means of a Microsoft Excel $^{14}$ macro-enabled spreadsheet, which can be distributed free of charge to anyone interested by requesting a copy from enrico.lucon@nist.gov.

\section{Preliminary Operations}

The first worksheet ("Data", Fig. A2-1) contains the raw data of the test (time, actuator displacement, extensometer displacement, force). Before pasting data from a new test, columns A-D can be cleared by clicking the button CLEAR DATA at the top (circled in red in Fig. A2-1). The raw data for the new test should be pasted as values in columns A-D, starting in row 15 (highlighted in yellow). After pasting the data, the user should make sure that the length of columns E-K is the same as columns A-D, by either removing empty rows or copying the information through the last data row.

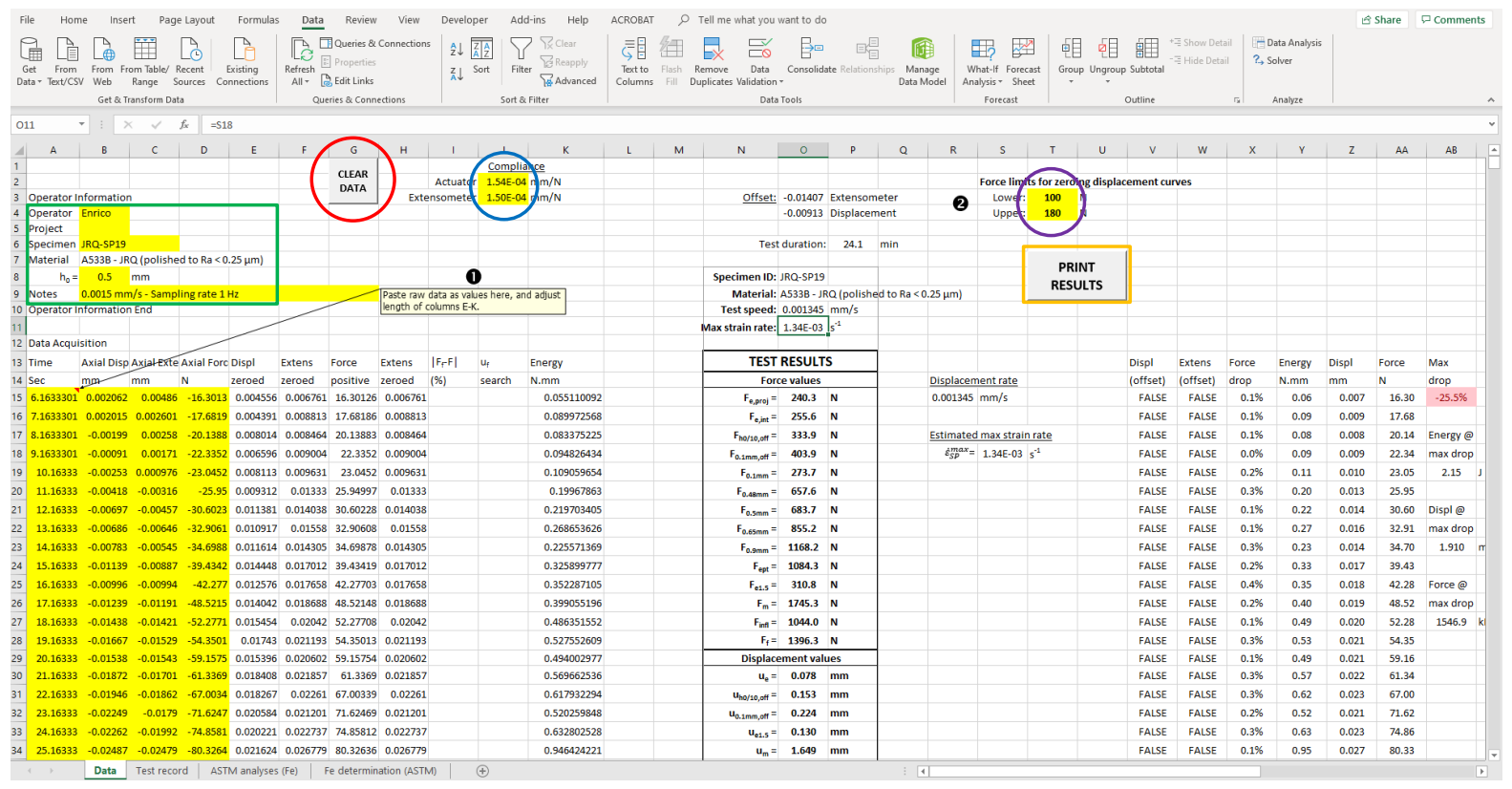

Figure A2-1 - Worksheet "Data".

NOTE: actuator displacement, extensometer displacement, and force data acquired during a SP test at NIST are negative, as the tests are in compression. Columns E-G simply reverse the sign of the values. Should raw data have a positive sign, the formulas in columns E-G ought to be correspondingly modified.

General information for the test (operator, project, specimen id, material information, initial specimen thickness $h_{0}$, optional notes) can be entered in cells B4-B9 (highlighted in yellow and outlined in green in Fig. A2-1). Some of this information is automatically transferred into cells O8-O11, to be printed along with the test results.

Make sure that the system compliance values for the actuator and extensometer signals, in $\mathrm{mm} / \mathrm{N}$, are entered correctly in cells $\mathrm{J} 2-\mathrm{J} 3$ (circled in blue in Fig A2-1).

\footnotetext{
${ }^{14}$ Certain commercial software, equipment, instruments or materials are identified in this report to adequately specify the experimental procedure. Such identification is not intended to imply recommendation or endorsement by the National Institute of Standards and Technology, nor is it intended to imply that the equipment or materials identified are necessarily the best available for the purpose.
} 
Next, define the lower and upper limit of the initial linear portion of the test record, in N, by looking at the curves in the worksheet "Test Record", and input them in cells T3-T4 (highlighted in yellow and circled in purple in Fig. A2-1). The corresponding calculated offset values for the force-displacement and force-actuator curves are displayed in cells O3-O4.

Determination of the Elastic-Plastic Transition Force, $F_{\mathrm{e}}$

Select the worksheet "ASTM analyses (Fe)" (Fig. A2-2). Columns A and B contain raw displacement and force data up to $u=0.5 \mathrm{~mm}$, automatically copied from the "Data" worksheet.

In cell J2 (highlighted in yellow and circled in red in Fig. A2-2), enter " 0.25 ". In cells M2-M3 (highlighted in yellow and circled in green in Fig. A2-2), enter the approximate force values corresponding to $u=0.25 \mathrm{~mm}$ and $u=0.5 \mathrm{~mm}$, respectively. To estimate these forces, look at the diagram in the worksheet "Fe determination (ASTM)".

Enter in cell U2, in N, (highlighted in yellow and circled in blue in Fig. A2-2) the lower force limit, below which data should not be included in the linear fit of the initial portion of the test record. This avoids including any initial non-linearities in the first linear regression.

Click the button PERFORM CALCULATIONS. The bilinear model of the ASTM Draft Test Method [11] is applied by minimizing the error in cell M8 (highlighted in pink) by the use of the SOLVER tool of Microsoft Excel.

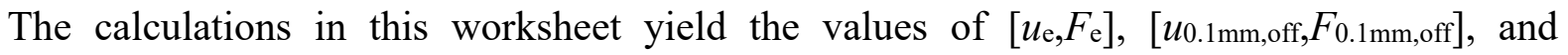

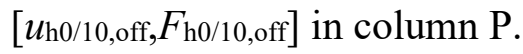

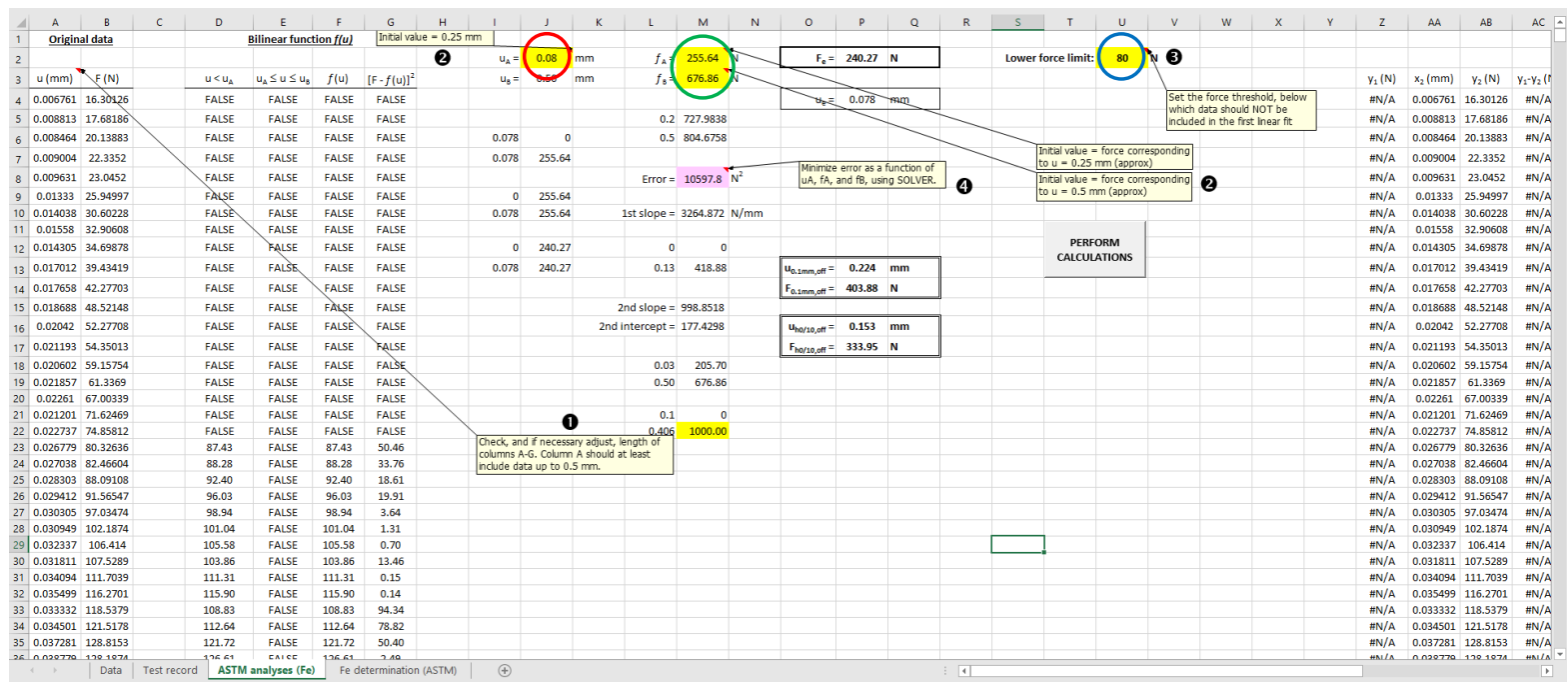

Figure A2-2 - Worksheet "ASTM analyses (Fe)".

Check the plot in the worksheet "Fe determination (ASTM)" (Fig A2-3) and, if necessary, adjust the axis scales and/or the position of the text labels. 


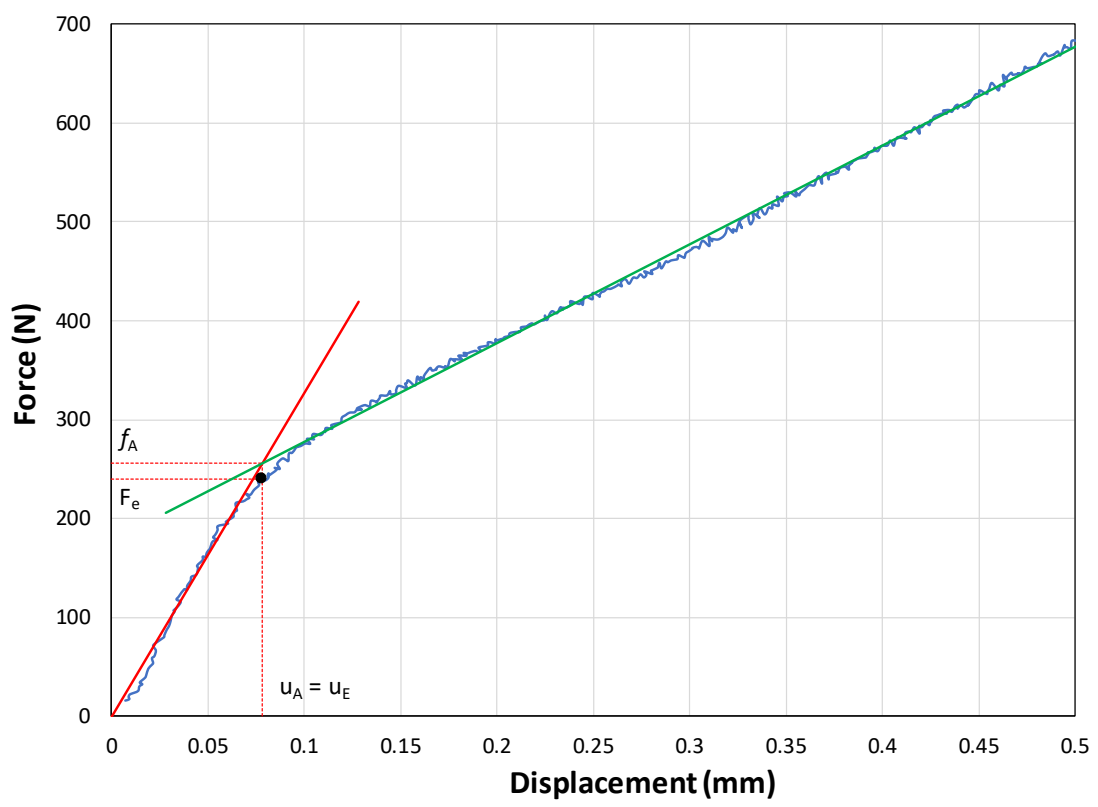

Figure A2-3 - Worksheet "Test record".

\section{Final Operations and Test Results Printing}

Select the worksheet "Test record" and, if necessary, adjust the axis scales and/or the position of the text labels. The data points visualized on this plot are $F_{\mathrm{e}}, F_{\mathrm{m}}$, and $F_{\mathrm{f}}$ (in reference to the blue punch displacement curve, Fig. A2-4).

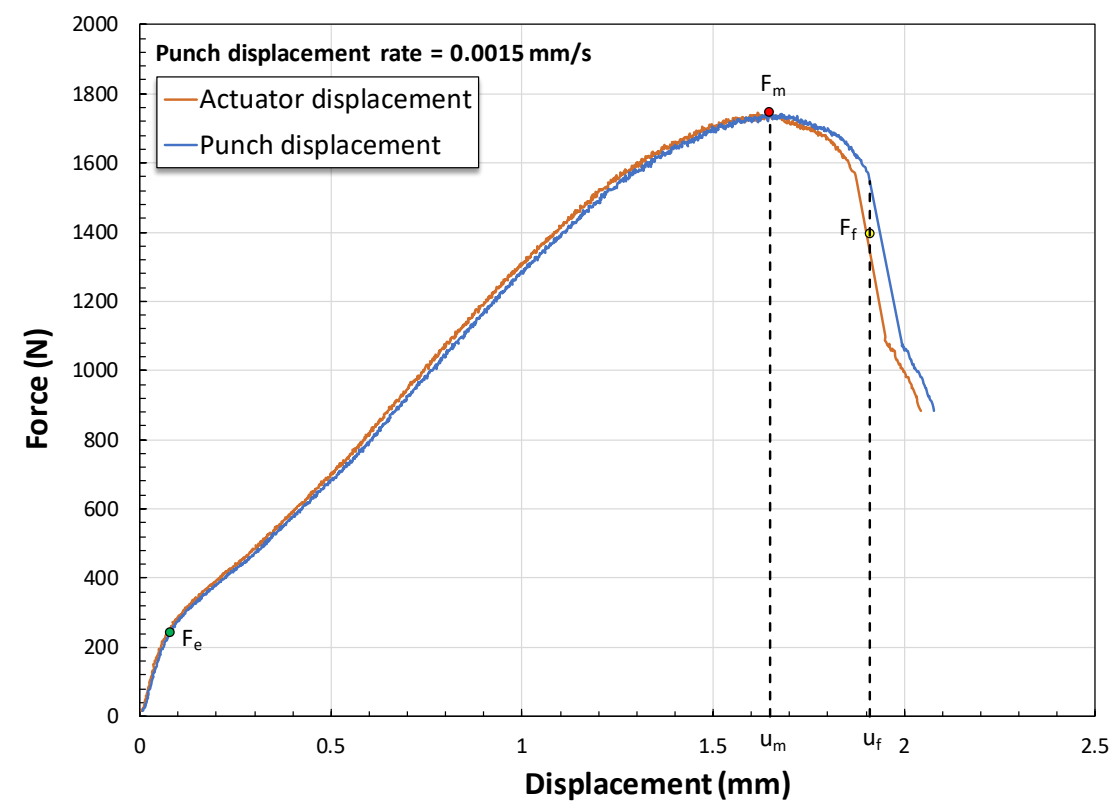

Figure A2-4 - Worksheet "Test record".

To print out the complete test results on the default system printer, click PRINT RESULTS in the "Data" worksheet (outlined in orange in Fig. A2-1). 
Three pages are printed: a summary of the numerical results (test info, forces, displacements, and energies, see Fig. A2-5), the test record (Fig. A2-4), and the graphical results for the determination of $F_{\mathrm{e}}$ (worksheet "Fe determination (ASTM)", Fig. A2-3).

\section{Small Punch Test Results}

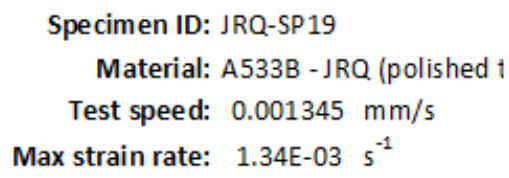

\begin{tabular}{|c|c|c|}
\hline \multicolumn{3}{|c|}{ TEST RESULTS } \\
\hline \multicolumn{3}{|c|}{ Force values } \\
\hline$F_{\text {eproj }}=$ & 240.3 & $\mathrm{~N}$ \\
\hline$F_{e, \text { int }}=$ & 255.6 & $\mathbf{N}$ \\
\hline$F_{h Q / 10, \text { off }}=$ & 333.9 & $\mathrm{~N}$ \\
\hline$F_{0.1 \mathrm{~mm}, \text { off }}=$ & 403.9 & $\mathrm{~N}$ \\
\hline$F_{0.1 \mathrm{~mm}}=$ & 273.7 & $\mathrm{~N}$ \\
\hline $\mathrm{F}_{0.48 \mathrm{~mm}}=$ & 657.6 & $\mathrm{~N}$ \\
\hline$F_{0.5 \mathrm{~mm}}=$ & 683.7 & $\mathrm{~N}$ \\
\hline$F_{0.65 \mathrm{~mm}}=$ & 855.2 & $\mathrm{~N}$ \\
\hline$F_{0.9 \mathrm{~mm}}=$ & 1168.2 & $\mathrm{~N}$ \\
\hline$F_{\text {ept }}=$ & 1084.3 & $\mathrm{~N}$ \\
\hline $\mathrm{F}_{\mathrm{e} 1.5}=$ & 310.8 & $\mathrm{~N}$ \\
\hline$F_{m}=$ & 1745.3 & $\mathrm{~N}$ \\
\hline$F_{\text {infl }}=$ & 1044.0 & $\mathrm{~N}$ \\
\hline$F_{f}=$ & 1396.3 & $\mathrm{~N}$ \\
\hline \multicolumn{3}{|c|}{ Displacement values } \\
\hline$u_{e}=$ & 0.078 & $\mathrm{~mm}$ \\
\hline $\mathbf{u}_{\mathrm{h} Q / 10, \mathrm{off}}=$ & 0.153 & $\mathrm{~mm}$ \\
\hline $\mathbf{u}_{0.1 \mathrm{~mm}, \mathrm{off}}=$ & 0.224 & $\mathrm{~mm}$ \\
\hline $\mathrm{u}_{\mathrm{e} 1.5}=$ & 0.130 & $\mathrm{~mm}$ \\
\hline$u_{m}=$ & 1.649 & $\mathrm{~mm}$ \\
\hline $\mathrm{u}_{\text {infl }}=$ & 2.013 & $\mathrm{~mm}$ \\
\hline$u_{f}=$ & 1.910 & $\mathrm{~mm}$ \\
\hline \multicolumn{3}{|c|}{ Initial linear slope } \\
\hline Slope $_{\text {ini }}=$ & 3264.87 & $\mathrm{~N} / \mathrm{mm}$ \\
\hline \multicolumn{3}{|c|}{ Energy values } \\
\hline$E_{S P}=$ & 2.15 & J \\
\hline $\mathrm{E}_{\mathrm{m}}=$ & 1.71 & J \\
\hline $\mathrm{E}_{\mathrm{PL}}=$ & 1.25 & J \\
\hline
\end{tabular}

Figure A2-5 - Test results printout. 


\section{Annex 3}

\section{Summary of Correlations between SP Parameters and Tensile Properties \\ (from the Literature, 1998-2019, and Obtained at NIST)}




\section{Small Punch-Tensile Property Correlations}

\section{Yield Strength correlations}

Characteristic SP force: $\boldsymbol{F}_{\boldsymbol{e}, \boldsymbol{p} r \boldsymbol{j}}$ (two tangents, projection - CWA 15267 \& ASTM Draft) $R_{p 02}=\alpha_{1} \frac{F_{e, p r o j}}{h_{0}^{2}}+\alpha_{2}$

\begin{tabular}{|c|c|c|c|}
\hline$\alpha_{1}$ & $\alpha_{2}$ & Reference & Notes \\
\hline 0.413 & 149 & [17] & EUROFER97 \\
\hline 0.5892 & -77.136 & {$[18]$} & 14MoV6-3 steel \\
\hline 0.476 & 0 & [19] & \\
\hline 0.4334 & -67.041 & {$[20]$} & \\
\hline 0.382 & 28.8 & [21] & \\
\hline 0.884 & 0 & {$[22]$} & T91 steel \\
\hline 0.575 & -34 & {$[23]$} & \\
\hline 0.5460 & -35.7 & \multirow{2}{*}{ NIST [rough] } & \multirow{4}{*}{$\begin{array}{c}\text { A533B (JRQ) \& } \\
4340 \text { steels }\end{array}$} \\
\hline 0.5282 & 0 & & \\
\hline 0.5379 & -52.2 & \multirow{2}{*}{ NIST [polished] } & \\
\hline 0.5125 & 0 & & \\
\hline \multicolumn{3}{|c|}{ Characteristic SP force: $\boldsymbol{F}_{\boldsymbol{e}, \boldsymbol{i n t}}$ (two tangents, intersection) } & $R_{p 02}=\alpha_{1} \frac{F_{e, i n t}}{h_{0}^{2}}+\alpha_{2}$ \\
\hline$\alpha_{1}$ & $\alpha_{2}$ & Reference & Notes \\
\hline 0.442 & 0 & [19] & \\
\hline 0.503 & 0 & NIST [rough] & A533B (JRQ) \& \\
\hline 0.474 & 0 & NIST [polished] & 4340 steels \\
\hline \multicolumn{3}{|c|}{ Characteristic SP force: $\boldsymbol{F}_{\boldsymbol{h} 0 / 10, \text { off }}$ (offset, punch displacement $t / 10 \approx 0.05 \mathrm{~mm}$ ) } & $R_{p 02}=\alpha_{1} \frac{F_{h_{0} / 1,0,0 f f}}{h_{0}^{2}}+\alpha_{2}$ \\
\hline$\alpha_{1}$ & $\alpha_{2}$ & Reference & Notes \\
\hline 0.346 & 0 & [19] & \\
\hline 0.366 & 0 & NIST [rough] & A533B (JRQ) \& \\
\hline 0.362 & 0 & NIST [polished] & 4340 steels \\
\hline
\end{tabular}




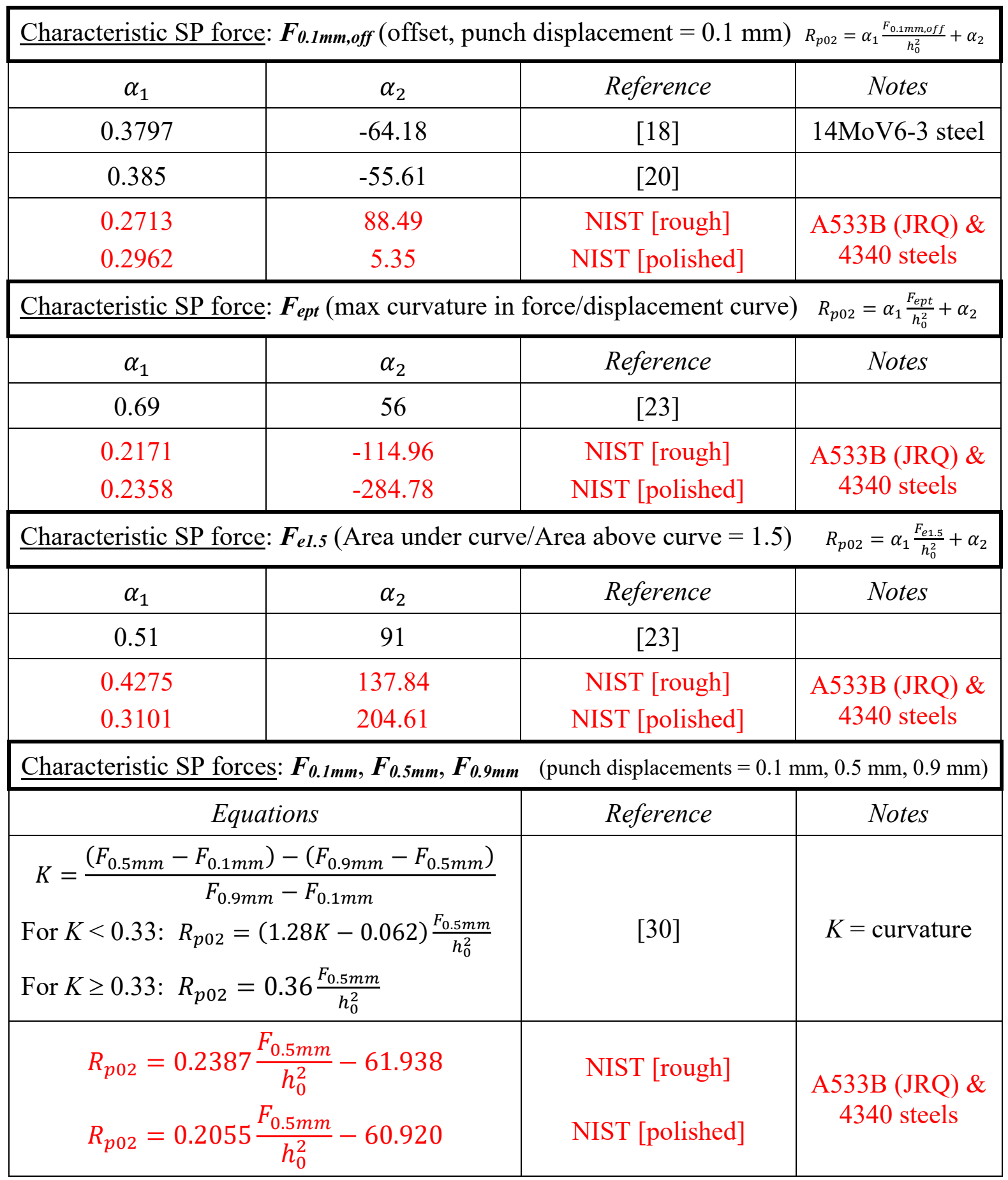




\begin{tabular}{|c|c|c|c|}
\hline \multicolumn{2}{|c|}{ Characteristic SP values: Slope $_{\boldsymbol{i n i}}$} & e initial region $\mathrm{SP}$ & $\mathrm{ve}-$ Zone I) $R_{p 02}=\gamma_{1} e^{\gamma_{2} \cdot \frac{\text { slope }}{h_{0}}}$ \\
\hline$\gamma_{1}$ & $\gamma_{2}$ & Reference & Notes \\
\hline 47.41 & $1.736 \cdot 10^{-4}$ & [24] & \\
\hline $\begin{array}{l}176.42 \\
0.0059\end{array}$ & $\begin{array}{c}2.123 \cdot 10^{-4} \\
1.2913\end{array}$ & $\begin{array}{l}\text { NIST [rough] } \\
\text { NIST [polished] }\end{array}$ & A533B (JRQ) \& 4340 steels \\
\hline
\end{tabular}




\section{Tensile Strength correlations}

Characteristic SP force: $\boldsymbol{F}_{\boldsymbol{m}} \quad R_{m}=\beta_{1} \frac{F_{m}}{h_{0}^{2}}+\beta_{2}$

\begin{tabular}{|c|c|c|c|}
\hline$\beta_{1}$ & $\beta_{2}$ & Reference & Notes \\
\hline 0.065 & 268.81 & {$[19]$} & \\
\hline 0.093 & -11.86 & {$[21]$} & \\
\hline 0.08 & 250 & {$[23]$} & \\
\hline 0.2662 & -855.61 & NIST [rough] & A533B (JRQ) \& 4340 steels \\
0.1523 & -228.73 & NIST [polished] & \\
\hline
\end{tabular}

Characteristic SP force: $\boldsymbol{F}_{\boldsymbol{m}} \quad R_{m}=\beta_{1} \frac{F_{m}}{h_{0} u_{m}}+\beta_{2}$

\begin{tabular}{|c|c|c|c|}
\hline$\beta_{1}$ & $\beta_{2}$ & Reference & Notes \\
\hline 0.077 & 218 & [17] & EUROFER97 \\
\hline 0.451 & -93.46 & [18] & 14MoV6-3 steel \\
\hline 0.277 & 0 & [19] & \\
\hline 0.130 & 0 & {$[25]$} & \\
\hline 0.4335 & -195.78 & [20] & \\
\hline 0.326 & -27.04 & [21] & \\
\hline 0.279 & 0 & [22] & \\
\hline 0.201 & 108 & [23] & \\
\hline $\begin{array}{l}0.3453 \\
0.3024\end{array}$ & $\begin{array}{l}-42.84 \\
4.403\end{array}$ & $\begin{array}{l}\text { NIST [rough] } \\
\text { NIST [polished] }\end{array}$ & A533B (JRQ) \& 4340 steels \\
\hline \multicolumn{4}{|c|}{ Characteristic SP force: $\boldsymbol{F}_{\boldsymbol{m}} \quad R_{m}=\frac{F_{m}}{A+B u_{m}}$} \\
\hline$A$ & $B$ & Reference & Notes \\
\hline 0.6143 & 1.2954 & [33] & $\mathrm{MCH}$ model \\
\hline $\begin{array}{l}0.9386 \\
0.8845\end{array}$ & $\begin{array}{l}-675.83 \\
-815.35\end{array}$ & $\begin{array}{l}\text { NIST [rough] } \\
\text { NIST [polished] }\end{array}$ & A533B (JRQ) \& 4340 steels \\
\hline
\end{tabular}


Characteristic SP force: $\boldsymbol{F}_{\text {inf }}$ (inflection point, $\left.\frac{d^{2} F}{d u^{2}}=0\right) \quad R_{m}=\beta_{1} \frac{F_{\text {infl }}}{h_{0} u_{m}}+\beta_{2}$

\begin{tabular}{|c|c|c|c|}
\hline$\beta_{1}$ & $\beta_{2}$ & Reference & Notes \\
\hline 0.207 & 48 & {$[33]$} & \\
\hline 0.5413 & 142.58 & NIST [rough] & A533B (JRQ) \& 4340 steels \\
0.6122 & -226.39 & NIST [polished] & \\
\hline
\end{tabular}

Characteristic SP force: $\boldsymbol{F}_{0.48 m \boldsymbol{m}}$ (punch displacement $\left.=0.48 \mathrm{~mm}\right) \quad R_{m}=\beta_{1} \frac{F_{0.48 m m}}{h_{0}^{2}}+\beta_{2}$

\begin{tabular}{|c|c|c|c|}
\hline$\beta_{1}$ & $\beta_{2}$ & Reference & Notes \\
\hline 0.13 & 6 & {$[25]$} & \\
\hline 0.2456 & 84.829 & NIST [rough] & A533B (JRQ) \& 4340 steels \\
0.2098 & 92.13 & NIST [polished] & \\
\hline
\end{tabular}

Characteristic SP force: $\boldsymbol{F}_{0.645 \mathrm{~mm}}($ punch displacement $=0.645 \mathrm{~mm}) R_{m}=\beta_{1} \frac{F_{0.645 \mathrm{~mm}}}{h_{0}^{2}}+\beta_{2}$

\begin{tabular}{|c|c|c|c|}
\hline$\beta_{1}$ & $\beta_{2}$ & Reference & Notes \\
\hline 0.51 & 91 & {$[23]$} & \\
\hline 0.2298 & -59.9 & NIST [rough] & A533B (JRQ) \& 4340 steels \\
0.2115 & -113.94 & NIST [polished] & \\
\hline
\end{tabular}

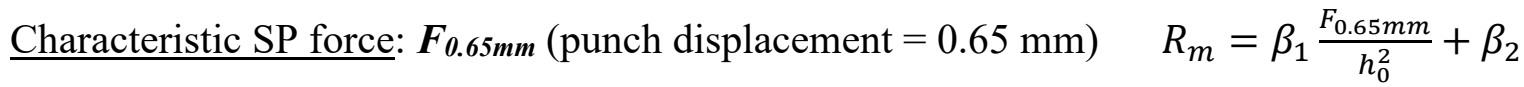

\begin{tabular}{|c|c|c|c|}
\hline$\beta_{1}$ & $\beta_{2}$ & Reference & Notes \\
\hline 0.179 & 0 & {$[26]$} & ALT model \\
\hline 0.2298 & -59.9 & NIST [rough] & A533B (JRQ) \& 4340 steels \\
0.2115 & -113.94 & NIST [polished] & \\
\hline
\end{tabular}




\begin{tabular}{|c|c|c|c|}
\hline \multicolumn{4}{|c|}{ Total Elongation correlations } \\
\hline Characteristic SP parameter: $\boldsymbol{u}_{\boldsymbol{m}}$ & Reference [\%] $=\omega_{1} u_{m}$ \\
\hline$\omega_{1}$ & {$[27]$} & Notes \\
\hline 14 & {$[19]$} & A533B (JRQ) \& 4340 steels \\
\hline 12.57 & NIST [rough] & NIST [polished]
\end{tabular}

